\title{
AVALIAÇÃO DA INGESTÃO DE FLÚOR DE CRIANCAS BRASILEIRAS DE 2 A 6 ANOS DE IDADE
}

Tese apresentada à Faculdade de Odontologia de Bauru, da Universidade de São Paulo, como parte dos requisitos para obtenção do título de Doutor em Odontologia.

Área de concentração: Biologia Oral

Orientadora: Profa. Dra. Marília Afonso Rabelo Buzalaf 
Levy, Flávia Mauad

L579a Avaliação da ingestão de flúor de crianças brasileiras de 2 a 6 anos de idade / Flavia Mauad Levy. -- Bauru, 2008.

169 p. : il. ; $30 \mathrm{~cm}$.

Tese (Doutorado) -- Faculdade de Odontologia de Bauru . Universidade de São Paulo.

Orientadora: Profa. Dra. Maria Afonso Rabelo Buzalaf

Autorizo, exclusivamente pra fins acadêmicos e científicos, a reprodução total ou parcial desta tese, por processo fotocopiadores e/ou meios eletrônicos.

Assinatura da autora:

Data:

Comitê de Ética da FOB-USP

Processo n..:: 68/2004

Data: 23 de junho de 2004 




\section{FLÁVIA MAUAD LEVY}

23 de Dezembro de 1974

\section{Guaraci - SP}

Filiação

$1993-1997$

1998

$1999-2000$

2001-2003

Associações
Nascimento

Marilene Carvalho Mauad Levy

José Carlos Levy

Curso de Graduação em Odontologia

- Universidade do Sagrado Coração

- Bauru - SP.

Curso de Aperfeiçoamento em Odontologia Preventiva pela PREV Assessoria Odontológica

Curso de Especialização em Odontologia em Saúde Coletiva pela Faculdade de Odontologia de Bauru, USP.

Curso de Pós-Graduação em Ortodontia, opção Odontologia em Saúde Coletiva, na Faculdade de Odontologia de Bauru, USP.

Conselho Regional de Odontologia do Estado de São Paulo- CRO- SP Associação Paulista de CirurgiõesDentistas - APCD

Sociedade Brasileira de Pesquisa Odontológica - SBPqO 



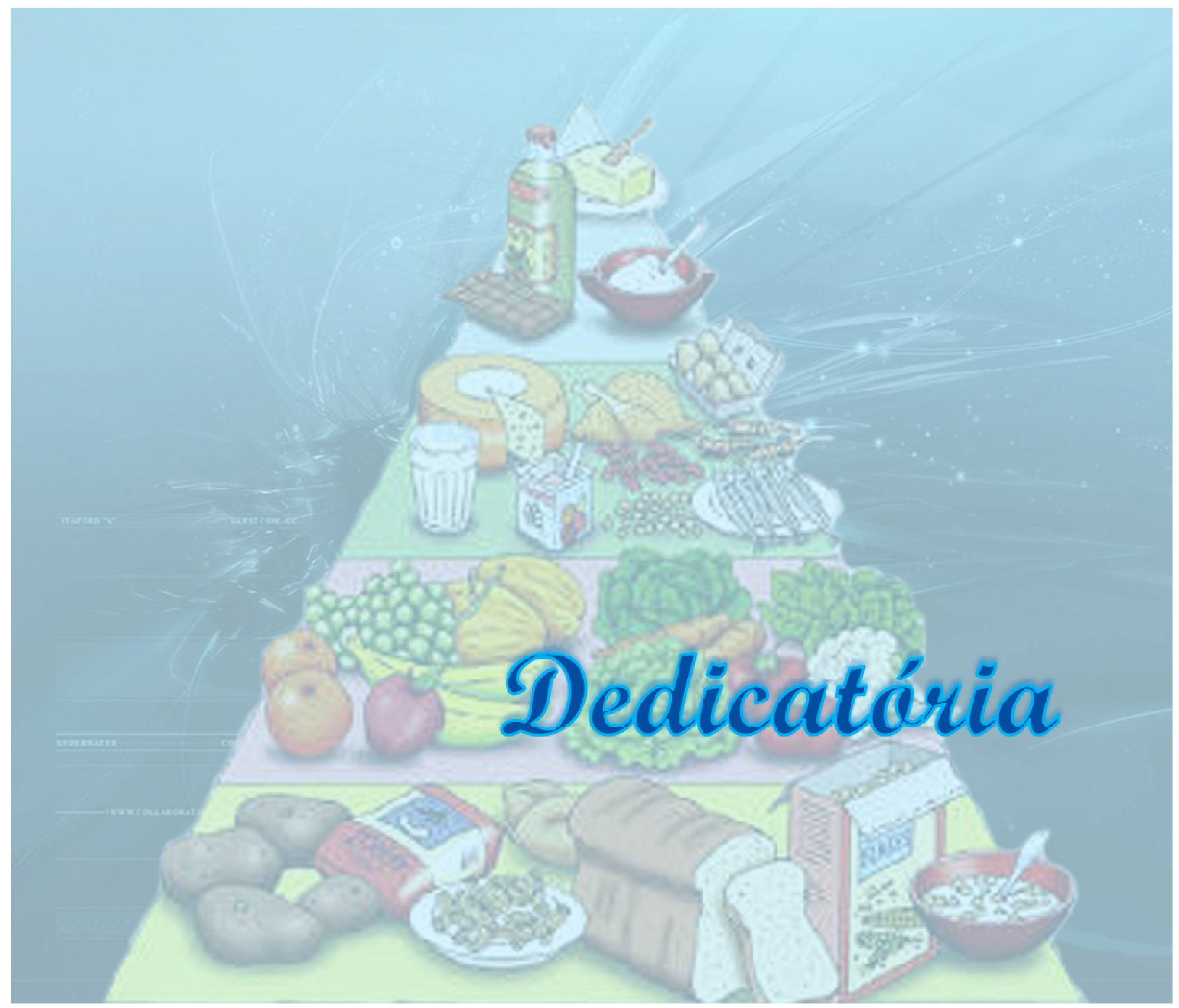



Deus nos concede, a cada dia, uma página de vida nova no livro do tempo. Aquilo que colocarmos nela,corre por nossa conta. "Chico Xavier"

\section{Dedico este trabalho:}

\section{À Deus,}

Pois sem Ele nada seria possível.

Proporcionando força e saúde para mais uma conquista, nesta passagem, que é a vida.

\section{Aos meus pais, Nico e Mila,}

Que possibilitaram uma trajetória suave, apoiada na verdade e pelo incentivo constante na minha vida.

\section{Ao meu namorado Rodrigo,}

Verdadeiro aliado em todos os momentos,

meu eterno agradecimento pelo companheirismo, compreensão e carinho. 



\section{AGRADECIMENTO ESPECIAL}

\section{À Profa. Dra Marília Afonso Rabelo Buzalaf,}

a minha eterna gratidão e respeito.

Obrigada pela paciência, carinho e palavras de coragem com que sempre me orientou. E principalmente pela oportunidade de compartilhar de seus conhecimentos e ter o privilégio de sua convivência e amizade. Sempre lembrarei da sua determinação, dedicação , atenção e competência.

Afeto e reciprocidade são particularidades que vivem no coração de cada um. Mais importante que a forma de expressar os sentimentos bons, é a grandeza que existe num ato de amor. E neste ato, seja ele qual for, certamente sempre existirão os três quesitos básicos: respeito, confiança e admiração.

\section{Muito obrigada!}



AGRADECIMENTOS

\section{A Profa. Dra Sonia Tucunduva Philippi, pelos}

seus ensinamentos e contribuição na implantação deste estudo, e também por sua alegria contagiante, meu muito abrigada.

\section{A Ana Paula Borges Miziara, muito obrigada pela} dedicação e contribuição.

\section{A Profa Dra Suely Prieto de Barros Almeida Peres, que contribuiu com a fase de implantação deste estudo.}

\section{À amiga, Maria Heloisa Correa Rodrigues Pedro,}

pela amizade que nos une e por poder compartilhar com você tantas alegrias e aflições.

À amiga, Irene Ramires, pela amizade, companherismo e alegria.

À Aline Lima Leite, obrigada pelo apoio, dedicação e disposição, que permitiram a realização deste trabalho.

\section{Aos amigos de turma: Maria Heloisa, Silvia, Ariadne, Ester, Ana Elisa, Tânia, Cláudia, e Renato,} por participarem desta etapa da minha vida. 



\section{Aos amigos do laboratório de Bioquímica}

"Nenhum caminho é longo demais quando um amigo nos acompanha"

Aos funcionários Thelma, Ovídio, do Departamento de Ciência Biológicas, Laboratório de Bioquímica pela boa vontade e simpatia.

À funcionária Vera do Departamento de Ciências Biológicas, Fisiologia, que sempre que precisei me ajudou com muito carinho.

Aos amigos do Centro de Saúde e do Programa de Saúde da Família da Prefeitura Municipal de Boracéia-SP. "Nenhum caminho é longo demais quando um amigo nos acompanha"

Aos voluntários participantes deste estudo, pela fundamental e efetiva colaboração.

\section{À Faculdade de Odontologia de Bauru, na pessoa de seu Excelentíssimo Diretor, Prof. Dr. Luiz Fernando Pegoraro.}

\section{À Prefeitura do Campus Administrativo de Bauru, da Universidade de São Paulo, através de seu Prefeito, Prof. Dr. José Roberto de Magalhães Bastos, mestre} que me incentivou a estar sempre me aperfeiçoando. 



\section{À Comissão de Pós-Graduação da Faculdade de Odontologia de Bauru, Universidade de São Paulo, através de sua presidente, Profa. Dra. Maria Aparecida de Andrade Moreira Machado}

\section{À Instituição de Fomento CAPES pelo auxílio}

financeiro durante o curso

À todos que direta ou indiretamente colaboraram para o desenvolvimento e conclusão deste trabalho.

Muito Obrigada! 



\section{SUMÁRIO}

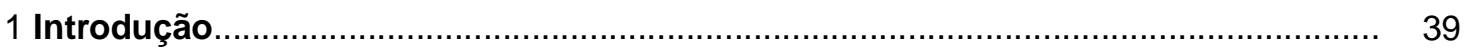

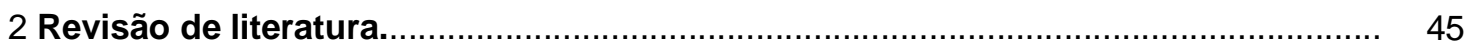

2.1 Fontes de ingestão de flúor e fluorose dentária....................................................... 45

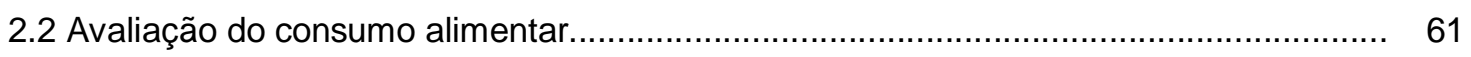

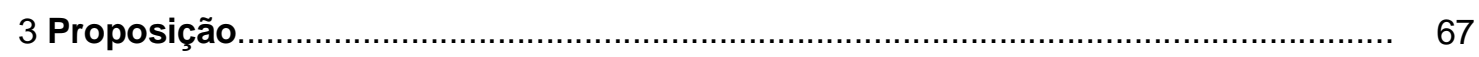

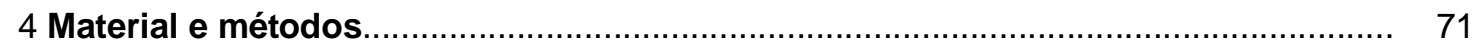

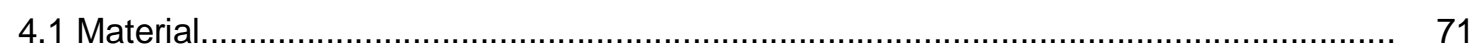

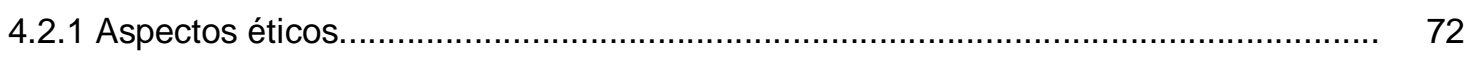

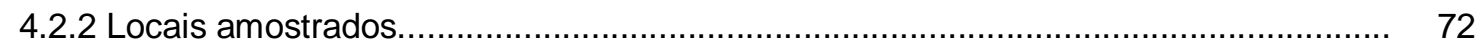

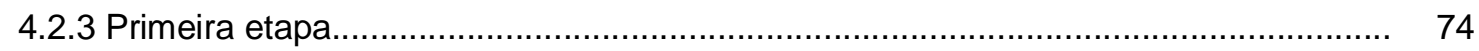

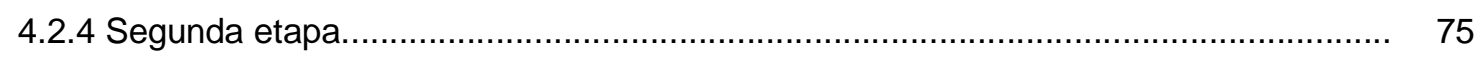

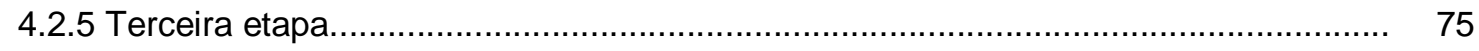

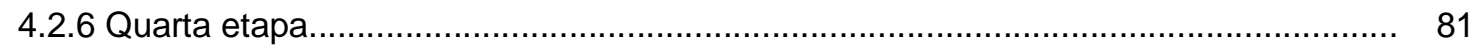

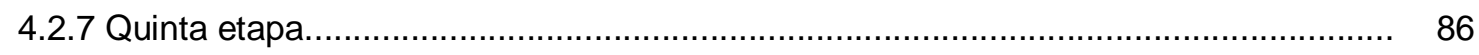

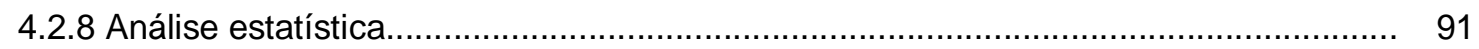

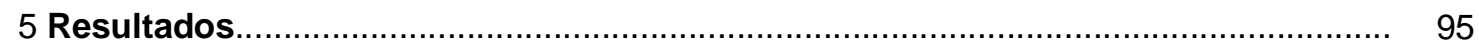

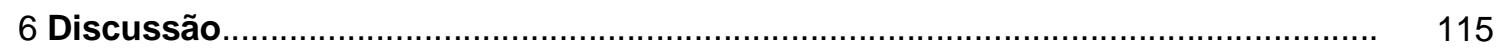

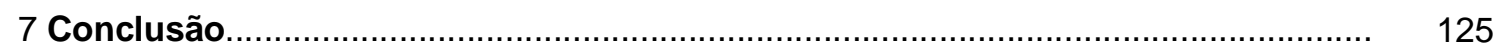

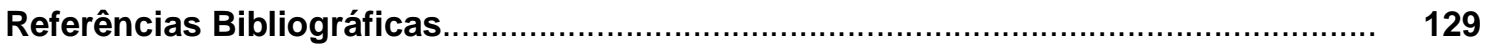

Anexos 



\section{LISTA DE FIGURAS}

FIGURA 1 - Localização geográfica de Bauru, São Paulo 74

FIGURA 2 - Localização geográfica de Pirajuí, São Paulo 74

FIGURA 3 - Pirâmide alimentar adaptada por PHILIPPI et al., (2003) 77

FIGURA 4 - Placa de Petri vaselinada. Adição das amostras de dieta. 84

FIGURA 5 - Adição de $2 \mathrm{~mL}$ de água deionizada e $50 \mu \mathrm{L}$ de $\mathrm{NaOH}$ 0,05 85 M na tampa da placa de Petri.

FIGURA 6 - Fechamento das placas e adição de 2 mL de HMDS 85

FIGURA 7 - Eletrodo Orion 9409 e um micro eletrodo calomelano de 85 referência para leitura de $\mathrm{F}$

FIGURA 8 - Método da dieta duplicada 87

FIGURA 9 Seqüência da técnica da estimativa de ingestão de F através do dentifrício 



\section{LISTA DE TABELAS}

TABELA 1 - Concentração de íon F recomendada na água de beber em relação à temperatura média da cidade

TABELA 2 - Dosagem de suplemento fluoretado recomendada por dia em $\mathrm{mg}$.

TABELA 3 - Municípios selecionados, de acordo com a presença de $F$ na água de abastecimento público e IDH-M (Fonte: Átlas do 73 Desenvolvimento Humano do Brasil, 2000).

TABELA 4 - Gênero (M-masculino, F-feminino), idade média (anos), peso médio $(\mathrm{Kg})$ e altura média $(\mathrm{cm})$ das crianças residentes em 95 Pirajuí-SP ( $n=398)$, às quais o QFAsq foi aplicado.

TABELA 5 - Média, desvio-padrão, mínimo, máximo e intervalo de confiança $95 \%$ da estimativa de ingestão total de $\mathrm{F}(\mathrm{mg})$ estimada pela aplicação do QFAsq a crianças de 2-6 anos de idade, residentes em Bauru-SP e Pirajuí-SP.

TABELA 6 - Freqüência de consumo dos itens alimentares do grupo sólidos obtida através da aplicação do QFA sq a 398 crianças de 2-6 anos 96 de idade, residentes em Pirajuí-SP

TABELA 7 - Freqüência de consumo dos itens alimentares do grupo sólidos obtida através da aplicação do QFA sq a 398 crianças de 2-6 anos 98 de idade, residentes em Pirajuí-SP

TABELA 8 - Freqüência de consumo dos itens alimentares do grupo água, obtida através da aplicação do QFA sq a 398 crianças de 2-6 anos 99 de idade, residentes em Pirajuí-SP. 

TABELA 9 - Concentração de $\mathrm{F}(\mathrm{em} \mu \mathrm{g} / 100 \mathrm{~g}$ para alimentos ou $\mu \mathrm{g} / 100 \mathrm{~mL}$ para bebidas) dos alimentos e bebidas presentes no QFA das 100 cidades de Pirajuí-SP e Bauru-SP.

TABELA 10 - Gênero (M-masculino, F-feminino), idade média, peso médio $(\mathrm{Kg})$, altura média $(\mathrm{cm})$, e número de voluntários que participaram da estimativa de ingestão de F obtida 102 através do QFAsq e da dieta duplicada, em Bauru-SP e Pirajuí-SP.

TABELA 11 - Médias e desvios-padrão (amplitude) das concentrações de $\mathrm{F}(\mathrm{mg} / \mathrm{L})$ na água de abastecimento público coletada nas residências dos voluntários residentes em Bauru e 102 Pirajuí, durante os dois dias de coletas.

TABELA 12 - Estimativa da ingestão de F (mg) das crianças de Bauru (água artificialmente fluoretada), Brasil, através da água, sólidos e outros líquidos, obtida a partir do método da 103 dieta duplicada, nos dois dias de coletas.

TABELA 13 - Estimativa da ingestão de F (mg) das crianças de Pirajuí (não-fluoretada), através da água, sólidos e outros líquidos, obtida a partir do método da dieta duplicada, 104 nos dois dias de coletas.

TABELA 14 - Estimativa de ingestão de $F(\mathrm{mg})$ das crianças de Bauru (água artificialmente fluoretada). Brasil, através da água, sólidos e outros líquidos, obtida a partir do método da 105 dieta duplicada, e a contribuição dos diferentes constituintes da dieta para a ingestão de $\mathrm{F}$.

TABELA 15 - Estimativa de ingestão de F (mg) das crianças de Pirajuí (não fluoretada), através da água, sólidos e outros líquidos, obtida a partir do método da dieta duplicada, e a contribuição dos diferentes constituintes da dieta para a ingestão total de F através da dieta. 

TABELA 16 - Estimativa de ingestão de $F(\mathrm{mg})$ das crianças de Bauru ( água artificialmente fluoretada), através da água, sólidos e outros líquidos, e a contribuição dos diferentes constituintes da dieta para a ingestão total de $\mathrm{F}$, estimada através do QFAsq.

TABELA 17 - Estimativa de ingestão de $F(\mathrm{mg})$ das crianças de Pirajuí 108 (não fluoretada), através da água, sólidos e outros líquidos e a contribuição dos diferentes constituintes da dieta para a ingestão total de $\mathrm{F}$ através do QFA.

TABELA 18 - Média $( \pm D P)$ da ingestão de $F$ estimada a partir do 109 QFAsq e da dieta duplicada, para Bauru e Pirajuí, considerando-se a dieta total e os diferentes componentes avaliados.

TABELA 19 - Correlação entre os dados de ingestão de $F$ a partir da 109 dieta obtidos através do QFAsq e da dieta duplicada.

TABELA 20 - Estimativa de ingestão de F a partir do dentifrício (mg) 110 obtida pela aplicação do questionário e da escovação simulada.

TABELA 21 - Valores individuais, médias e desvios-padrão (amplitude) 112 da ingestão total diária de $\mathrm{F}$ ( $\mathrm{mg} / \mathrm{Kg}$ de peso corporal), estimados através do QFAsq associado ao questionário para ingestão de dentifrício e da dieta duplicada associada à escovação simulada. 



\section{LISTA DE ABREVIATURAS E SÍMBOLOS}

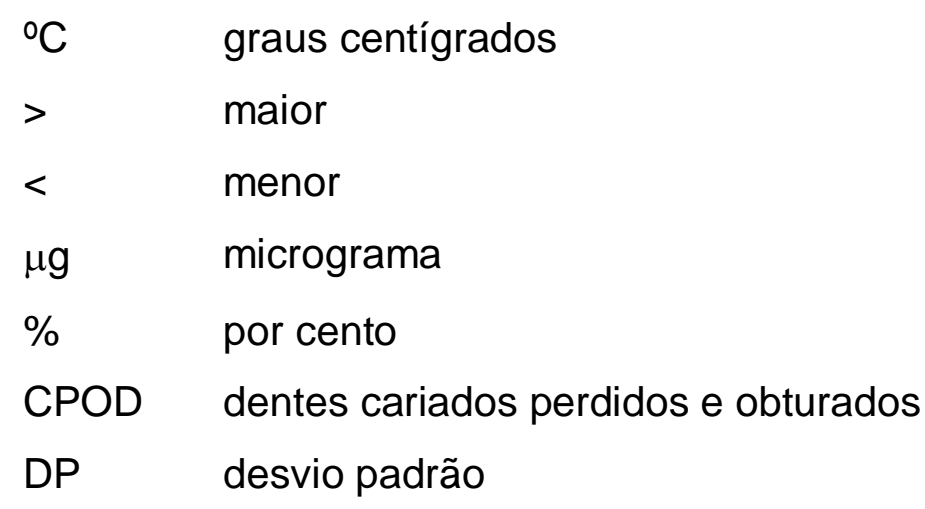

FSESP Fundação Serviços de Saúde Pública

g grama

h horas

$\mathrm{HCl}$ ácido clorídrico

HF ácido fluorídrico

HMDS hexametil-disilazano ou hexametil-disiloxano

IBGE Instituto Brasileiro de Geografia e Estatística

L $\quad$ litro

M $\quad \operatorname{molar}(\mathrm{mol} / \mathrm{L})$

mg miligrama

$\mathrm{mL} \quad$ mililitro

$\mathrm{mm} \quad$ milímetros

$\mathrm{mV} \quad$ milivoltagem

$\mathrm{NaF} \quad$ fluoreto de sódio

$\mathrm{NaOH}$ hidróxido de sódio

$\mathrm{OH}^{-} \quad$ ĺon hidroxila

OMS Organização Mundial de Saúde

p nível de significância

ppm partes por milhão

QFA Questionário de Freqüência Alimentar

QFAsq Questionário de Freqüência Alimentar semi quantitativo 

TF índice de fluorose dentária Thysltrup e Ferjerskow

TISAB Total lonic Exchange Adjustment Buffer

TSIF índice de fluorose dentária Horowitz 



\section{RESUMO}

Este estudo comparou a ingestão de flúor $(F)$ de crianças de 2 a 6 anos residentes em área fluoretada (Bauru-SP, 0,6-0,8 ppm F) e não fluoretada (Pirajuí-SP), avaliada através do método da dieta duplicada associado à escovação simulada e do Questionário de Freqüência Alimentar semi-quantitativo (QFAsq) associado a questionário para estimativa de ingestão de $\mathrm{F}$ a partir do dentifrício. Inicialmente, $\mathrm{O}$ QFAsq foi aplicado em 398 crianças residentes no município de Pirajuí-SP. Posteriormente, foram avaliadas subamostras de 25 crianças residentes em Bauru e 24 residentes em Pirajuí. Nestas subamostras, a quantidade de F ingerida através da dieta foi determinada pelo QFAsq e também pela "dieta duplicada", considerando seus diferentes constituintes (água, outros líquidos e sólidos). A ingestão de F através do dentifrício foi determinada pelo questionário para estimativa da ingestão de dentifrício e pela escovação simulada. $O \mathrm{~F}$ foi analisado por eletrodo, depois de difusão facilitada por hexametildiloxano ou após tamponameno com TISAB. A análise estatística foi feita utilizando o software GraphPad InStat, aplicando os testes $t$ pareado, $t$ não pareado, Wilcoxon pareado, Mann-Whitney e estatística de correlação $(p<0.05)$. O QFAsq aplicado à amostra de 398 crianças de Pirajuí encontrou valores de ingestão total de $\mathrm{F}$ significativamente menores que os relatados previamente para crianças residentes em Bauru (Miziara, 2006). Na subamostra de crianças avaliadas, a média $( \pm D P, m g)$ da ingestão de $F$ estimada a partir do QFAsq e da dieta duplicada, considerando-se a dieta total foi de 0,420 $\pm 0,087$ e 0,805 $\pm 0,190$ (Bauru) e 0,227 $\pm 0,072$ e 0,144 $\pm 0,050$ (Pirajuí), sendo a diferença entre os métodos significativa em ambos os municípios. Somente foi obtida uma correlação significativa entre os dois métodos no caso dos sólidos, para ambos os municípios. Considerando a estimativa da ingestão de $\mathrm{F}$ a partir do dentifrício obtida pela aplicação do questionário e pela escovação simulada, as médias ( $\pm \mathrm{DP}, \mathrm{mg}$ ) compiladas (Bauru mais Pirajuí) foram 0,611 00,452 e $0,784 \pm 0,737$, respectivamente, não havendo diferença e nem correlação significativas entre os métodos. Através da utilização dos questionários, foi possível detectar diferença significativa na ingestão total de $F$ entre Bauru e Pirajuí. Entretanto, o mesmo não ocorreu quando se utilizou o método da dieta duplicada associado à escovação simulada. Face aos resultados obtidos, o QFAsq associado a um questionário para estimativa da ingestão de $\mathrm{F}$ a partir do dentifrício parece ter um bom potencial para utilização a nível epidemiológico, para se avaliar o risco de grupos de crianças à fluorose dentária. Alguns parâmetros do QFAsq podem ser melhor trabalhados para uma análise mais fidedigna, principalmente com relação à freqüência de ingestão de água e outros líquidos. Em adição, a aplicabilidade desses questionários a nível individual para detecção de risco à fluorose dentária ainda precisa ser melhor estudada.

Palavras-Chaves: Questionário de Freqüência Alimentar; Fluorose Dentária; Flúor; Ingestão. 



\begin{abstract}
This study compared the fluoride $(F)$ intake of 2-6-year-old children, living in fluoridated (Bauru-SP, 0,6-0,8 ppm F) and non-fluoridated (Pirajuí-SP) areas. The methods used were the duplicate diet associated to simulated toothbrushing and the semi-quantitative food frequency questionnaire (sqFFQ) associated to a questionnaire for estimation of $F$ intake from dentifrice. Initially, the sqFFQ was applied to 398 children living in Pirajuí. In another phase, subsamples of 25 children living in Bauru and 24 living in Pirajuí were evaluated. In these subsamples the $F$ intake from diet was determined using the sqFFQ as well as the duplicate diet method, considering the different constituents of the diet (water, other liquids and solids). The $F$ intake from the dentifrice was determined using the questionnaire for estimation of $F$ intake, as well as simulated toothbrushing. $\mathrm{F}$ was analyzed with the electrode, following hexamethyldisiloxanefacilitated diffusion or after buffering with TISAB. For statistical analysis, the GraphPad InStat software was used. The applies tests were paired and unpaired $t$ tests, paired Wilcoxon test, Mann-Whitney test and correlation analysis $(p<0.05)$. The sqFFQ, when applied to the sample constituted by 398 children living in Pirajuí, found values of total $\mathrm{F}$ intake significantly lower when compared to previous data reported by Miziara (2006) for children living in Bauru. In the subsample of evaluated children, the mean $( \pm S D$, $\mathrm{mg}) \mathrm{F}$ intakes estimated by the sqFFQ and duplicate diet (total diet) were $0.420 \pm 0.087$ and $0.805 \pm 0.190$ (Bauru) and $0.227 \pm 0.072$ and $0.144 \pm 0.050$ (Pirajuí), respectively. The difference between the methods was significant for both municipalities. For both municipalities, a significant correlation between the methods was obtained in the case of solids only. Considering the estimation of $F$ intake from dentifrice obtained by the application of the questionnaire and simulated toothbrushing, the compiled (Bauru plus Pirajuí) means ( $\pm S D, m g$ ) were $0.611 \pm 0.452$ and $0.784 \pm 0.737$, respectively. The difference as well as the correlation between the methods were not significant. By using the questionnaires, it was possible to detect a significant difference in the total $F$ intake between Bauru and Pirajuí. However, the same did not occur when using the method of duplicate diet associated with simulated toothbrushing. Due to the results obtained, it seems that the sqFFQ associated to a questionnaire for estimation of $F$ intake from dentifrice has a good potential for use at epidemiological level in order to evaluate the risk of groups of children to dental fluorosis. Some parameters of the sqFFQ need to be better addressed for a more precise analysis, mainly with respect to the frequency of water and other liquids intake. In addition, the applicability of these questionnaires at the individual level for the detection of risk to dental fluorosis requires further studies.
\end{abstract}

Keywords: Food Frequency Questionnaire; Dental Fluorosis; Fluoride; Intake. 



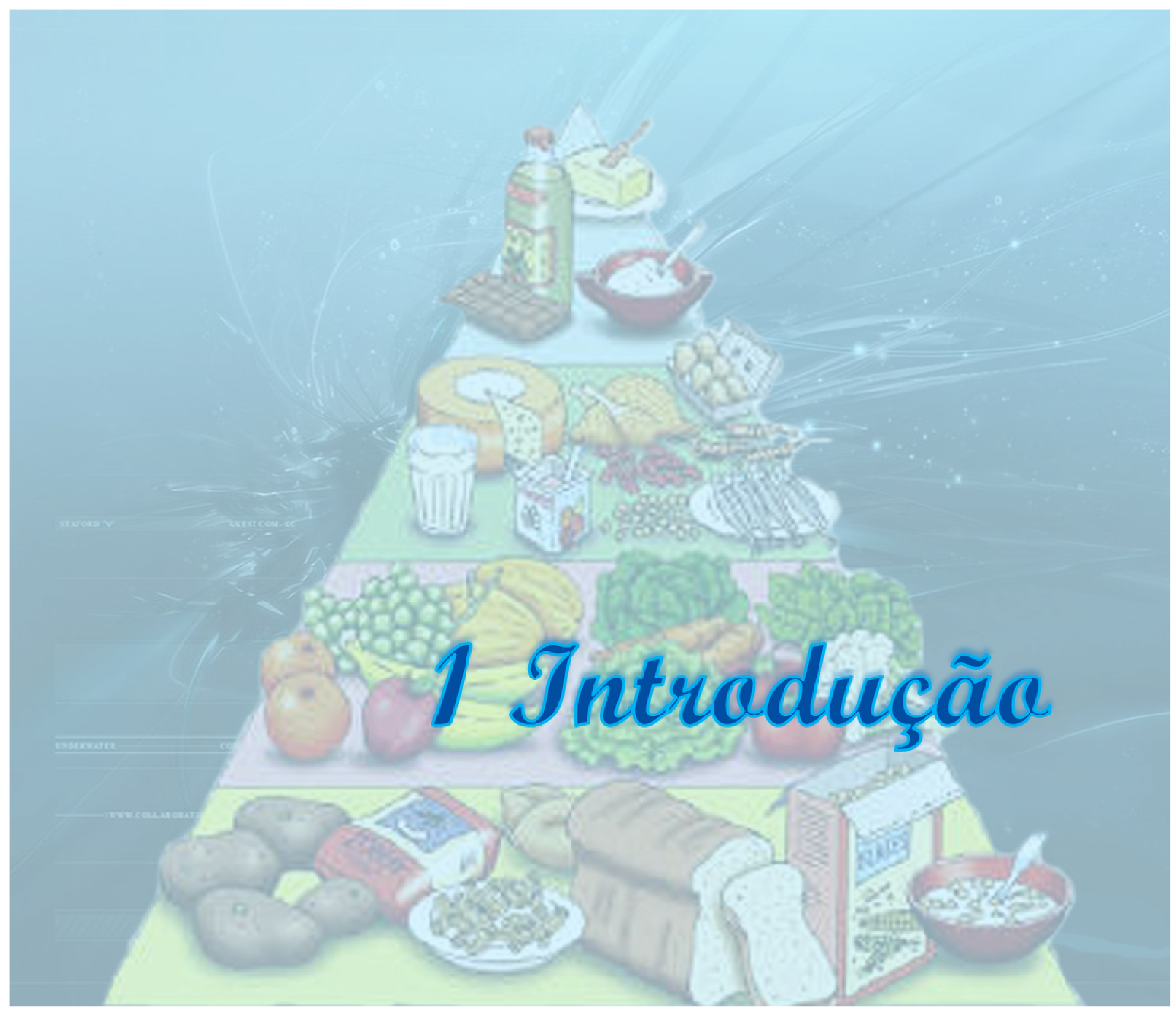





\section{INTRODUÇÃO}

O uso do flúor $(F)$ tem um papel fundamental na prevenção e controle da cárie dentária. Desde os excelentes trabalhos de Dean e seus colaboradores (DEAN, 1934; DEAN et al, 1942), nos quais a associação entre a presença de $\mathrm{F}$ na água de beber e a ocorrência de distúrbios de formação dentária (manchamento do esmalte ou fluorose dentária), bem como a concomitante redução na experiência de cáries, foi demonstrada, a fluorose dentária tem sido a principal preocupação de todos os programas que usam as propriedades únicas do $F$ para o controle $\mathrm{e}$ prevenção da cárie.

Em meados do século passado, o paradigma era que, para exercer o seu máximo efeito cariostático, o $\mathrm{F}$ deveria ser incorporado à estrutura do esmalte dentário durante o seu desenvolvimento. Desse modo, parecia inevitável ter uma certa prevalência e severidade de fluorose numa população, a fim de minimizar a prevalência e severidade da cárie dentária entre as crianças. A fluorose dentária era então considerada como um efeito colateral indesejado dos benefícios "cárieprotetores" do F. As possibilidades de se tentar "atenuar" os possíveis efeitos tóxicos do $\mathrm{F}$ no esmalte dentário em desenvolvimento, não raro, levavam os profissionais de Odontologia a apresentarem a fluorose como um problema meramente cosmético.

Em 1981, foi proposta uma mudança no paradigma relacionado aos mecanismos cariostáticos do F (FEJERSKOV et al., 1981), segundo a qual seu efeito predominante para o controle da lesão cariosa seria tópico, através de uma atuação nos processos de des e remineralização que acontecem na interface, superfície dentária e fluidos orais. Esse conceito ganhou ampla aceitação (TEN CATE, DUIJSTERS, 1983; TEN CATE, FEATHERSTONE, 1991) e trouxe a possibilidade de se obter a máxima proteção no controle da cárie dentária, sem que houvesse a necessidade de uma grande ingestão de $F$.

Uma vez que a prevalência de fluorose dentária tem aumentado tanto em regiões fluoretadas quanto em regiões não fluoretadas (JACKSON, 1999; LEVERETT, 1986; TABARI, 2000; TSUTSUI et al., 2000) em muitos países, assim como no Brasil (PEREIRA et al., 2000), muitos pesquisadores têm estudado as razões para esse aumento e os principais fatores de risco para a fluorose dentária (OSUJl et al., 1988; PENDRYS et al., 1994; PENDRYS, KATZ, 1989; PENDRYS et 
al., 1996; WANG et al., 1997; PENDRYS, 1995; SKOTOWISKI et al., 1995; GRIMALDO et al., 1995; LALUMANDIER, ROZIER, 1995; BUZALAF et al., 2002; JACKSON et al., 2002; BUZALAF et al., 2003; KHAN; MOOLA; CLEATON-JONES, 2005).

O fator de risco mais importante para fluorose dentária é a quantidade de $\mathrm{F}$ ingerida a partir de todas as fontes, durante o período crítico de formação do dente (DEAN et al., 1942; DENBESTEN, 1999; EVANS, 1991; MASCARENHAS, 2000).

O aumento da prevalência de fluorose dentária está associado ao fato de que o F está amplamente distribuído para a população, principalmente através de água fluoretada, dentifrícios fluoretados, suplementos e alimentos manufaturados, fazendo com que sua ingestão venha aumentando consideravelmente, desde a década de 1930 (FOMON et al., 2000). Em vista disso, vários estudos vêm sendo conduzidos, avaliando a ingestão de $F$ através dos fatores já citados, principalmente com crianças (OPHAUG et al., 1985; LEVY et al., 1995a; LEVY et al., 1993; CLOVIS, HARGREAVES, 1988; LEVY et al., 2001; CHITTAISONG et al., 1995; LEVY et al., 1995b; GUHA-CHOWDHURY et al., 1996; CHOWDHURY et al., 1990; KIMURA et al., 2001; LIMA, CURY, 2001; PESSAN et al., 2003; ALMEIDA et al., 2007). Esses estudos têm relatado quatro fatores de risco como: água fluoretada, suplementos, dentifrícios fluoretados e fórmulas infantis (MASCARENHAS, 2000). Alguns alimentos e bebidas infantis manufaturados também podem contribuir significativamente para a ingestão total diária de $\mathrm{F}$ (BUZALAF et al., 2001a; BUZALAF et al., 2002b; BUZALAF et al., 2003). No Brasil, a prevalência de fluorose dentária constatado no levantamento epidemiológico nacional SB Brasil é de $9 \%$ aos 12 anos e de 5\% em adolescentes de 15 a 19 anos. Para a idade de 12 anos, as Regiões Sudeste e Sul estão acima da média nacional (12\%), enquanto que as Regiões Centro-Oeste e Nordeste, abaixo da média nacional com 4\% (BRASIL, 2004). Vale salientar que neste levantamento nacional, o índice de fluorose aplicado é de baixa sensibilidade, devido ao fato de não ter sido feita profilaxia dentária e secagem prévias. Levantamentos epidemiológicos realizados no Brasil e no exterior, indicam que a prevalência de fluorose dentária é em realidade 2 a 3 vezes maior quando se utiliza outro índice, como o de Thysltrup e Fejerskov (THYLSTRUP e FEJERSKOV,1978). Entretanto, os estudos brasileiros têm mostrado que a prevalência de fluorose dentária pode variar nas diferentes comunidades, variando de 0,37 a 97,6\%. (CAPELLA et al.; 1989). Um estudo recente revelou uma 
prevalência de fluorose dentária em adolescentes de 12 a 15 anos, residentes em Bauru, SP, de 36\% (RAMIRES et al., 2006), sendo 28\% referente ao escore TF1.

Os hábitos alimentares das crianças mudaram substancialmente nas ultimas décadas. Fomon, Ekstrand e Ziegler (2000) relataram que na década de 80, 28\% das crianças americanas, entre 4 e 5 anos, consumiam refrigerantes e, na década de 90, essa porcentagem subiu para 48,2\%. Pang et al (1992) observaram que refrigerantes, sucos, chá, café e Gatorade $^{\circledR}$ representavam $60 \%$ das bebidas consumidas por crianças de 2 a 10 anos de idade.

Ao se avaliar o consumo alimentar de um grupo populacional não basta mensurar quantitativamente o consumo de energia e nutrientes, mas também é sobretudo estudar as relações entre o consumo de determinados alimentos e a ocorrência de doenças; avaliar a influência de fatores socioeconômicos, culturais e fisiológicos, como condicionantes do consumo alimentar, e assim desenvolver e aprimorar instrumentos para avaliação desse consumo (WILLETT, 1998).

A avaliação das dietas das crianças apresenta algumas dificuldades, como a grande variação diária da alimentação, a rápida mudança dos hábitos alimentares e a limitada capacidade cognitiva deste grupo (PERSSON e CARLGREN, 1984, BARANOWSKI e DOMEL, 1994, THOMPSON e BYERS 1994, ROCKETT e COLDITZ, 1997). A medida que as crianças crescem, a contribuição das refeições realizadas fora do domicílio tende a aumentar em relação ao consumo alimentar total, dificultando ainda mais a avaliação (ROCKETT e COLDITZ, 1997). A idade da criança também é outra dificuldade apontada. A capacidade de fornecer informações confiáveis sobre a alimentação e de raciocinar de forma semelhante a um indivíduo adulto, só é adquirida pela criança a partir de 10 anos de idade (EMMONS e HAYES, 1973, NUZZO, 1998, SLATER e col., 2000).

A metodologia mais utilizada atualmente (2008) para avaliação da ingestão de F por crianças, através da dieta, é a realização da dieta duplicada (GUHACHOWDHURRY ET AL., 1996). No entanto, a sua realização envolve a coleta de todos os alimentos e bebidas que a criança ingere num intervalo de $24 \mathrm{~h}$. Portanto, trata-se de um procedimento que requer uma grande colaboração por parte das crianças e dos pais e/ou responsáveis, no sentido de monitorá-las o tempo todo, durante as $24 \mathrm{~h}$ em que as coletas são feitas. Em adição, um dilema ético surge freqüentemente, em estudos desse tipo, já que uma porção igual de alimentos e bebidas que a criança ingere em $24 \mathrm{~h}$ tem que ser desprezada. Num país como o 
Brasil, onde a grande maioria da população tem um baixo nível sócio-econômico, este "desperdício" de alimentos e bebidas, nem sempre é visto com bons olhos. Há ainda, a necessidade de se ressarcir os pais das crianças pelos alimentos coletados no período, o que encarece a pesquisa.

Sendo assim, o Questionário de Freqüência Alimentar (QFA) tornou-se o método dominante nos estudos epidemiológicos para avaliação do consumo dietético, em especial, para avaliar a relação da dieta com a ocorrência de doenças crônicas não transmissíveis. É um instrumento que tem como objetivo a avaliação da dieta habitual de grupos populacionais e apresenta como vantagens a rapidez na aplicação e a eficiência na prática epidemiológica para identificar o consumo habitual de alimentos, através de um questionário, além do baixo custo. Constitui ferramenta útil nos estudos sempre que seu desenvolvimento tenha sido precedido de procedimentos metodológicos cuidadosamente planejados que garantirão confiabilidade e precisão dos dados obtidos (SLATER et al, 2003).

Sendo assim, seria de grande interesse o desenvolvimento de um instrumento de medida da ingestão de $F$, simplificado, que possa ser utilizado em levantamentos epidemiológicos de grande porte, uma vez que é inviável a realização da dieta duplicada nesses casos. 


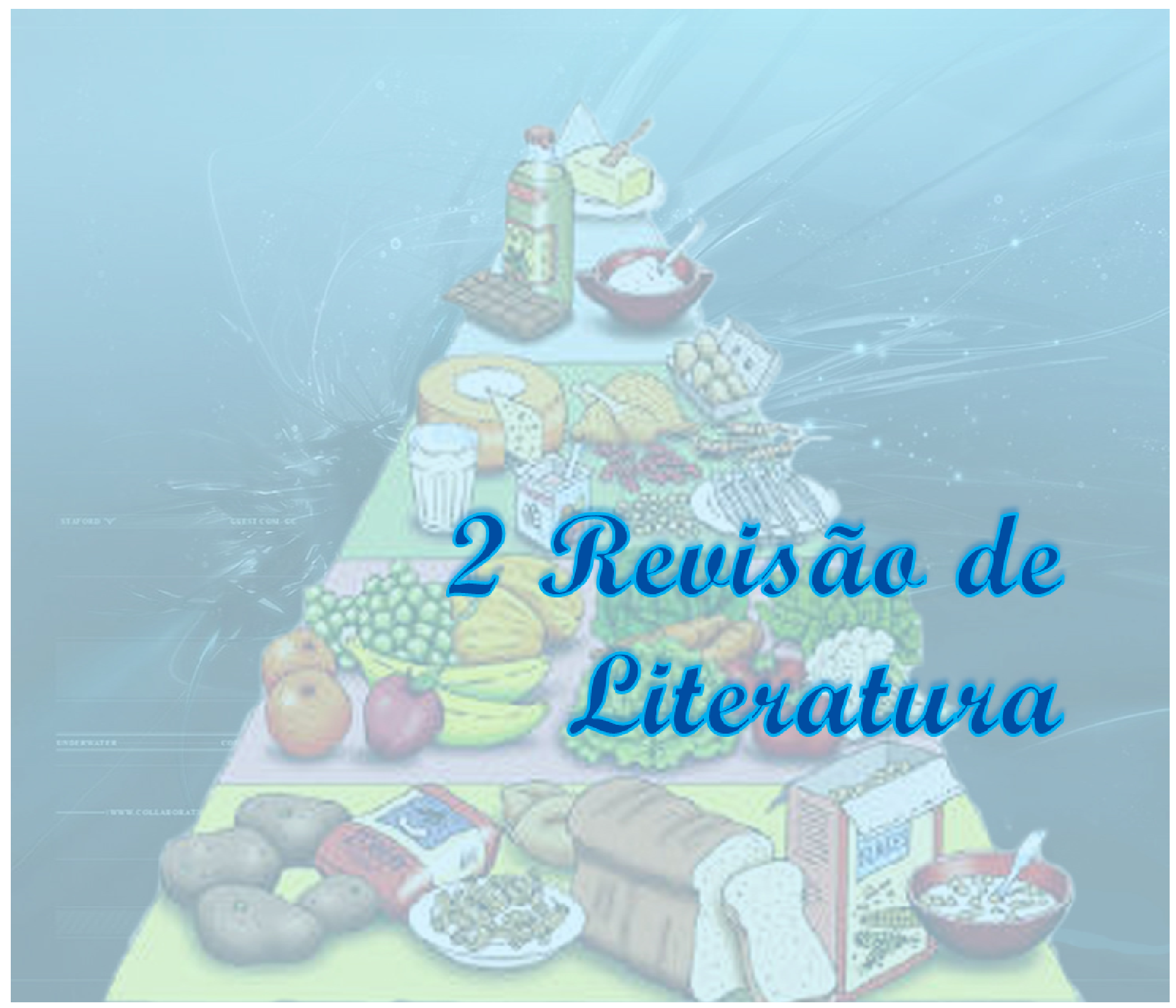




\section{REVISÃO DE LITERATURA}

Nesta revisão de literatura, serão abordados dois tópicos principais, abaixo relacionados:

2.1 Fontes de ingestão de $\mathrm{F}$ e fluorose dentária

2.2 Avaliação do consumo alimentar de crianças em relação ao $F$

\subsection{Fontes de ingestão de $\mathrm{F}$ e fluorose dentária}

\subsection{1 Água fluoretada}

Em 1901, Jonh Macauley Eager escreveu um relato que foi depois conhecido como a primeira documentação científica no que diz respeito à fluorose dentária (EAGER, 1901). Ele escreveu detalhadamente sobre uma descoloração marrom nos dentes, chamada "denti di chiaie", baseado em observações de emigrantes italianos no porto de Nápoles. A causa de tais descolorações foi atribuída provavelmente à água de beber.

Em 1911, Mckay (1933) descreveu a presença de dentes com o esmalte mosqueado em crianças residentes na zona urbana de Colorado Springs, nos Estados Unidos, fato que não ocorria nas crianças que habitavam a zona rural. Mais tarde, em 1916, Mckay, juntamente com Black, observaram que as pessoas que residiam na área urbana, provida pela água de abastecimento de Colorado Springs e que estavam naquele momento no período de formação dentária, apresentavam o manchamento, caracterizando assim, uma distrofia endêmica do esmalte dentário. Porém, os indivíduos da área rural, desprovida de abastecimento de água, não apresentavam os sinais do mosqueamento, sugerindo existir uma relação direta entre a defeito estrutural no esmalte e a presença de alguma substância na água. Também naquele momento, os autores verificaram que as crianças moradoras em áreas que apresentavam o esmalte mosqueado, tinham uma prevalência menor de cárie dentária, quando comparadas com aquelas residentes em locais desprovidos pelo abastecimento e que não tinham os mesmos sinais de mosqueamento do esmalte. 
Em 1942, Dean realizou um relevante estudo conhecido como o "Estudo das 21 cidades", que procurou responder em outras especulações qual concentração de $\mathrm{F}$ na água provocava o mosqueamento dentário, ao mesmo tempo em que buscou descobrir concentrações capazes de uma ação preventiva e eficaz na redução da cárie dentária. Os resultados deste estudo mostraram uma redução de 50\% na experiência de cárie dentária em concentrações de 0,6 ppm quando comparada com a concentração de 0,2 ppm, e uma redução de mais de $60 \%$ em concentrações de 1,2 ppm, salientando a possibilidade de controle da cárie por meio da fluoretação controlada e de níveis adequados da água de abastecimento. Nesse estudo foi determinado que o $\mathrm{F}$ presente na água em concentrações em torno de $1 \mathrm{ppm}$ promovia a máxima redução no índice CPOD sem, no entanto, provocar o aparecimento de manchas antiestéticas e que, quando o nível de $\mathrm{F}$ na água excedia a 1,5 ppm, não ocorria queda significativa no índice CPOD, porém havia um aumento na ocorrência e na severidade da fluorose (DEAN,1950).

No entanto, os primeiros estudos controlados da fluoretação artificial datam de 1945. O "momento da verdade na história da fluoretação das águas", conforme descrito por Frank McClure (McCLURE, 1970), teve início em 25 de janeiro de 1945, quando Grand Rapids, Michigan, Estados Unidos da América, tornou-se a primeira cidade do mundo a ajustar sua concentração de $F$ na água visando à promoção da saúde dentária. Logo depois, a fluoretação foi implantada em outras cidades dos EUA e mais tarde em outros países.

No Brasil, após oito anos de iniciados os estudos em Grand Rapids, a Fundação Serviços de Saúde Pública (FSESP), do Ministério da Saúde, implantou em 31 de outubro de 1953, o primeiro sistema de fluoretação de águas. O primeiro município brasileiro a adicionar $\mathrm{F}$ nas águas de abastecimento público foi Baixo Guandu, no Espírito Santo. O teor de $\mathrm{F}$ natural da água era de $0,15 \mathrm{mg} / \mathrm{L}$ e o teor ótimo foi estabelecido em 0,8 ppm (MENEGHIM et al., 2003).

Após 21 anos em 24 de maio de 1974, a lei federal no 6050, dispôs a respeito da fluoretação da água em sistemas públicos de abastecimento(BRASIL, 1974), sendo devidamente regulamentada pelo Decreto federal oㅜ 76.872, de 22 de dezembro de 1975. A Portaria do Ministério da Saúde de no 635/Bsb, de 26 de dezembro de 1975, aprovou e determinou normas e padrões a serem seguidos para a correta fluoretação das águas dos sistemas de abastecimento, desde a concentração de íon $\mathrm{F}$ a ser utilizada de acordo com a média das temperaturas 
máximas anuais de cada região (Tabela 1), até os compostos fluoretados recomendados. Ainda constituem a legislação pertinente, as portarias do Ministério da Saúde oㅜ 3.313, de janeiro de 1998, e oㅜ 1.469, de dezembro de 2000, que estabelecem os procedimentos e as responsabilidades relativas ao controle e à vigilância da qualidade da água para o consumo humano, e a portaria $n^{\circ} 518$, de 25 de março de 2004, que estabelece os procedimentos e responsabilidades relativos ao controle e vigilância da qualidade da água para consumo humano e seu padrão de potabilidade.

Viegas, em 1987, ressalta que a fluoretação das águas de abastecimento público é um método adequado, eficiente, seguro e prático, sendo uma medida ideal de saúde pública para a prevenção da cárie dentária em países onde existam serviços de abastecimento de água.

Tabela 1 - Concentração de íon $\mathrm{F}$ recomendada na água de beber em relação à temperatura média da cidade

\begin{tabular}{cccc}
\hline $\begin{array}{c}\text { Médias das temperaturas } \\
\text { máximas diárias }\left({ }^{\circ} \mathrm{C}\right)\end{array}$ & \multicolumn{3}{c}{$\begin{array}{c}\text { Limites recomendados para a } \\
\text { concentração de íon F em mg/L }\end{array}$} \\
\hline & Mínimo & Máximo & Ótimo \\
$\mathbf{1 0 - 1 2 , 1}$ & 0,9 & 1,7 & 1,2 \\
$\mathbf{1 2 , 2 - 1 4 , 6}$ & 0,8 & 1,5 & 1,1 \\
$\mathbf{1 4 , 7 - 1 7 , 7}$ & 0,8 & 1,3 & 1,0 \\
$\mathbf{1 7 , 8 - 2 1 , 4}$ & 0,7 & 1,2 & 0,9 \\
$\mathbf{2 1 , 5 - 2 6 , 3}$ & 0,7 & 1,0 & 0,8 \\
$\mathbf{2 6 , 8 - 3 2 , 5}$ & 0,6 & 0,8 & 0,7 \\
\hline
\end{tabular}

Muitos trabalhos têm sido realizados relacionando a água fluoretada com a ocorrência da fluorose dentária. Em 1995, Carmo et al., realizaram um estudo que relacionou a prevalência de fluorose dentária em áreas com diferentes concentrações de $\mathrm{F}$ na água de consumo. Escolares $(\mathrm{n}=610)$ na idade de 10-14 anos, residentes em três cidades brasileiras, Piracicaba $(0,7$ ppm F), Iracemápolis 
(0,2 ppm F) e Pereiras (6,4 ppm F), foram avaliados para a fluorose dentária pelos índices de Dean e TF. Foram encontradas prevalências de 2,0\%, 20,4\% e 58,8\%, utilizando-se o índice TF, e de 4,5\%, 20,8\% e 58,8\%, com o índice de Dean, nas cidades de Iracemápolis, Piracicaba e Pereiras, respectivamente.

Por outro lado, Maltz e Farias (1998) também avaliaram a prevalência de fluorose dentária em escolares de cidades brasileiras com e sem água de consumo artificialmente fluoretada, no ano de 1987, isto é, anteriormente ao uso disseminado de dentifrício fluoretado. Nas cidades sem água de abastecimento fluoretada, a prevalência de fluorose dentária foi praticamente inexistente. Nas duas cidades com água de consumo fluoretada, a prevalência e severidade da fluorose foram bastante baixas, sugerindo que somente o consumo de água artificialmente fluoretada, nas concentrações utilizadas $(0,45-0,96$ ppm $F$ e 0,32-0,72 ppm $F)$, não causa alta prevalência de fluorose dentária.

Numa revisão sistemática acerca da fluoretação da água, McDonagh et al. (2000), após análise de 214 estudos, observaram que a fluoretação da água estava associada com um aumento na proporção de crianças livres de cáries e uma redução no número de dentes afetados por cárie. Os autores encontraram ainda um aumento dose-dependente na fluorose dentária, sendo que com um nível de $\mathrm{F}$ de 1 ppm, estimou-se que $12,5 \%$ das pessoas expostas teriam fluorose dentária considerada preocupante do ponto de vista estético. Não foram encontradas evidências claras de outros possíveis efeitos colaterais. Os autores reforçaram a idéia de que qualquer decisão acerca da fluoretação das águas deve considerar não apenas a relação risco (fluorose dentária) - benefício (redução da cárie dentária), mas também aspectos éticos, ambientais, ecológicos, financeiros e legais.

Em Toronto, Canadá, no outono de 1999 a concentração de $F$ na água de abastecimento foi reduzida em 2 estágios (de 1,2 ppm para 1,0 ppm e então para 0,8 ppm). Num levantamento realizado durante o ano escolar de 1999-2000, encontrou-se uma prevalência de fluorose moderada (TSIF $\geq 2$ ) em $14 \%$ das crianças de 7 anos de idade e de 12,3\% em crianças de 13 anos. Os autores acreditam que esta prevalência deva diminuir conforme a redução na concentração de $\mathrm{F}$ na água de abastecimento começar a fazer efeito (LEAKE et al., 2002).

Com os objetivos de avaliarem a concentração de $F$ na água de abastecimento público e a prevalência de fluorose dentária Ramires et al. (2006), realizaram um estudo com 52 escolares de 7 a 15 anos de idade, residentes em um 
bairro da periferia de Bauru. A concentração de $F$ na água variou entre 0,62 e 1,15 $\mathrm{mg} / \mathrm{L}$, mantendo a média de 0,9 mg/L. A prevalência de fluorose dentária foi avaliada através do índice TF, e foi encontrada uma prevalência de $33 \%$. Os graus de severidade variaram de TF1 a TF4: 11\% TF1, 8\% TF2, 12\% TF3 e $2 \%$ TF4. Para os autores as amostras de água indicaram uma concentração média de $F$ acima do recomendado para Bauru e o índice de fluorose dentária foi maior que o esperado para um bairro de periferia, onde a água é uma, em alguns casos a única fonte de ingestão de F disponível para aquela população.

Catani et al. (2007), avaliaram a relação entre os níveis de fluoreto na água de abastecimento público e a prevalência de fluorose dentária em 386 escolares de sete anos de idade, moradores em dois municípios do estado de São Paulo, que realizaram heterocontrole da fluoretação das suas águas. Um deles apresentando concentração homogênea $(0,6-0,8 \mathrm{ppm})$ de $\mathrm{F}$ e outro oscilante $(0,3-1,2 \mathrm{ppm})$. fluorose dentária foi determinada examinando os incisivos superiores permanentes pelo índice de Dean. Em ambos os municípios, verificaram-se grau leve de fluorose. A prevalência de fluorose no município com teores oscilantes de $F$ na água foi de $31,4 \%$, e no município com teores homogêneos de 79,9\%. Os autores sugeriram a existência de associação entre a regularidade da manutenção da concentração ótima de $\mathrm{F}$ na água com o aumento da prevalência de fluorose.

Um aspecto importante quando se fala em fluoretação da água de abastecimento público diz respeito ao controle de qualidade da fluoretação. Em Bauru-SP, Buzalaf et al. (2002) monitoraram a qualidade da fluoretação da água de abastecimento público em diversos pontos de distribuição, no ano de 1999. A concentração de $\mathrm{F}$ variou de 0,01 a 9,35 ppm, havendo uma grande variação nas concentrações encontradas entre as diferentes áreas de abastecimento de água da cidade, bem como entre os diferentes dias de coleta de amostras. Diante dos resultados, foi implantado o heterocontrole da fluoretação da água na cidade. Através do heterocontrole, todos os meses e em dias aleatórios, estabelecidos por sorteio, são coletadas amostras de 60 pontos de abastecimento de água, distribuídos em toda a cidade. Os resultados obtidos após um ano do início do heterocontrole apontam para uma melhoria significativa na qualidade da fluoretação, com cerca de $85 \%$ das amostras analisadas classificadas como aceitáveis $(0,55$ a $0,84 \mathrm{mgF} / \mathrm{l}$ ), indicando ser o heterocontrole uma medida eficaz para este fim (RAMIRES et al., 2006). 
De especial interesse quando se analisa o impacto da presença de fluoreto na água, , são os estudos de coortes, realizados quando há interrupções temporárias na fluoretação das águas. Burt et al. (2000) avaliaram o impacto de uma interrupção não planejada de 11 meses, na fluoretação da água e concluíram que a fluorose no esmalte é sensível mesmo a pequenas alterações na exposição ao fluoreto a partir da água de beber, e esta sensibilidade é maior entre 1 e 3 anos que entre 4 e 5 anos. Entretanto, num estudo subseqüente (BURT et al. , 2003), a prevalência de fluorose no esmalte, que era esperado que aumentasse na próxima coorte examinada devido ao restabelecimento da fluoretação da água, permaneceu estável. Buzalaf et al.(2004) analisaram o efeito de uma interrupção de 7 anos na fluoretação da água, na prevalência de fluorose no esmalte, em Jaú, SP. Os autores encontraram uma prevalência mais baixa nos incisivos centrais superiores, das crianças que tinham 36, 27 e 18 meses de idade, quando a fluoretação foi interrompida, quando comparadas com as crianças que nasceram 18 meses após a paralisação da fluoretação. Esses resultados sugerem que a água fluoretada não é um importante fator de risco para a fluorose do esmalte, já que a prevalência desta foi mais baixa nas coortes que consumiram água fluoretada.

A prevalência de fluorose dentária está aumentando, tanto em áreas fluoretadas, quanto em áreas não fluoretadas (SELWITZ et al.1998, KHAN et al., 2005). Mas ainda assim, revisões sistemáticas têm relatado que a fluoretação ótima da água (em torno de $1 \mathrm{mg} \mathrm{F/L}$ ) está associada a um aumento de 12,5\% no risco de fluorose dentária (McDONAGH et al., 2000), portanto bem próximo aos relatos clássicos de Dean. No entanto, em regiões com mais que $1 \mathrm{mgF} / \mathrm{L}$ o risco de fluorose dentária é maior em relação a regiões subfluoretadas, (JACKSON et al., 1999; HELLER et al., 1997). Em um estudo feito com crianças brasileiras de 2-3 anos, onde se avaliou a ingestão de fluoreto a partir dos diferentes constituintes da dieta (sólidos, água e leite e outros líquidos) e do dentifrício, esse foi responsável por $81 \%$ da ingestão diária de fluoreto, enquanto que a dieta contribuiu com 19\%. Dentre os diferentes constituintes da dieta, a maior contribuição para a ingestão de fluoreto veio da água e do leite, que foram responsáveis por cerca de $60 \%$ da ingestão de fluoreto da dieta, quando comparada aos outros constituintes (ALMEIDA et al., 2007). No entanto, como a contribuição da dieta para a ingestão total de fluoreto é pequena, a água fluoretada provavelmente tem seu maior impacto na prevalência de fluorose indiretamente, através de seu uso no preparo de fórmulas infantis e outros 
alimentos e bebidas para crianças (BURT, 1992). Desta forma, não se justifica a não colocação de fluoreto na água de abastecimento público, visando à prevenção da fluorose dentária, principalmente em países como o Brasil, onde grande parte da população não tem acesso a outras fontes de fluoreto. No entanto, deve-se evitar o uso da água fluoretada para o preparo de leites e sucos em pó para crianças (BUZALAF; KOBAYASHI; PHILIPPI, 2008).

Em anos recentes, tem havido um aumento no consumo de água engarrafada no Brasil, bem como em outros países. O conteúdo de F presente em 104 marcas de água mineral comercialmente disponíveis no Brasil foi analisado por Villena; Borges; Cury (1996). Os valores encontrados variaram de 0 a 4,4 ppm, mas a grande maioria teve conteúdo de $\mathrm{F}$ abaixo de 0,1 ppm.

Em 2001, Bastos et al. avaliaram a concentração de $F$ existente nas fontes naturais e nas águas minerais engarrafadas das cidades de Águas de Lindóia, Lindóia e Serra Negra, região chamada de "Circuito das Águas". Todas as amostras apresentavam concentrações de $\mathrm{F}$ abaixo dos limites considerados preventivos de cárie, variando de 0 a 0,46 ppm. Os autores ressaltaram a necessidade de divulgação destes dados para que a população e os profissionais de saúde sejam alertados para tal fato, uma vez que tem ocorrido o aumento do consumo dessas águas minerais, que são vendidas em todo o território nacional. Além disso, a população da região, consome a água proveniente das fontes naturais, não sendo beneficiada pelo $\mathrm{F}$ presente na água de abastecimento público.

Ramires et al.(2004), verificaram a porcentagem da população da cidade de Bauru que consumia água mineral, as marcas consumidas e sua concentração de $F$ especificada no rótulo e a verificada na análise. De 1000 residências visitadas, em $312(31,2 \%)$ consumia-se água mineral e em 688 (68,8\%) não. Sendo assim, cerca de $29,72 \%$ da população da cidade consome água mineral e 70,28\% não. Em algumas marcas de água mineral, a concentração de $F$ especificada nos rótulos não foi a mesma encontrada nas análises de F. Segundo os autores os resultados deste estudo reforçam a importância e a necessidade de um controle bastante rigoroso, por parte da Vigilância Sanitária, na concentração de F nestas águas.

Grec et al.(2008), realizaram um estudo em que foi avaliado a concentração de $\mathrm{F}$ em água engarrafada comercializada, comparando-as com os valores impressos no rótulo da embalagem. Os pesquisadores coletaram 229 amostras de água das 35 marcas disponíveis em diversos pontos de venda, de grande 
circulação, nas diferentes regiões do município de São Paulo. Foram observadas concentrações de $F$ variando entre 0,01 e $2,04 \mathrm{mg} / \mathrm{L}$, com diferença significante entre os valores estipulados nos rótulos e os encontrados com a análise. Concluiuse ser necessário o controle dos níveis de $\mathrm{F}$ na água engarrafada por parte da vigilância sanitária.

A água fluoretada provavelmente tem um impacto maior na prevalência da fluorose indiretamente, por ser usada na industrialização de leites em pó e outros alimentos e bebidas infantis (BURT, 1992), além de ser utilizada para reconstituir fórmulas infantis. Buzalaf et al.(2001) realizaram um estudo que avaliou o conteúdo de $\mathrm{F}$ em 10 amostras de fórmulas infantis disponíveis no mercado. As amostras foram preparadas com água deionizada, água engarrafada (0,02 a 0,69 ppm) e água fluoretada $(0,9 \mathrm{ppm})$. Quando as fórmulas foram reconstituídas com água deionizada, somente a amostra da fórmula à base de soja apresentou uma concentração de $\mathrm{F}$ mais elevada $(0,75 \mathrm{ppm})$. Segundo os autores, este achado é coerente com a literatura em relação a produtos à base de soja. Ao utilizarem a água mineral como diluente da fórmula, apenas uma marca comercial de água mineral (Ibirá) apresentou alto teor de F. Mas, a água de abastecimento, o diluente mais utilizado no Brasil, especialmente pela população mais carente, tornou-se uma questão preocupante. Todas as marcas de fórmulas infantis, quando reconstituídas com água fluoretada, excederam a ingestão diária ótima de $\mathrm{F}$ recomendada e quase todas poderiam fornecer uma ingestão diária de $\mathrm{F}$ acima dos limiares sugeridos para a fluorose em crianças jovens.

\subsubsection{Suplementos fluoretados}

Em um Workshop, no Canadá em 1994 (Canadian Workshop Meeting), foi decidido que a suplementação de $\mathrm{F}$ não deveria ser recomendada para crianças mais jovens do que 3 anos de idade, e que, a dosagem para crianças de 3 a 5 anos deveria ser reduzida, de $0,5 \mathrm{mg} / \mathrm{dia}$ para $0,25 \mathrm{mg} / \mathrm{dia}$, uma vez que o uso do suplemento fluoretado é identificado como sendo o principal fator de risco para a fluorose dentária.

O consumo de suplementos fluoretados tem sido considerado como um fator de risco para fluorose dentária, tanto em regiões fluoretadas (KUMAR et al., 1989; PENDRYS et al., 1995, PENDRYS, KATZ, 1998) quanto em regiões não fluoretadas 
(HOLT et al., 1994; JACKSON et al., 1999; KUMAR et al., 1989; KUMAR, SWANGO, 1999; LALUMANDIER, ROZIER, 1995; PENDRYS, KATZ, 1989; PEDRYS et al., 1996; WANG et al., 1997). O uso de suplementos deveria ser mais conservador, considerando todas as fontes de água fluoretada, de abastecimento ou engarrafada (LEVY et al., 1993; TOUMBA, CURZON, 1994, LEVY et al., 1995b), restrito para crianças de alto risco à cárie e com baixa ingestão de $\mathrm{F}$ através de outras fontes (LEVY et al., 1995c). Levy et al., (1995a) afirmam que somente a concentração de $F$ na água pode não ser mais apropriada como parâmetro na indicação de suplementos, e que outras fontes deveriam ser levadas em consideração. De acordo com Fomon et al., (2000), suplementos não deveriam ser prescritos na primeira infância e deveria haver critérios mais rigorosos para sua administração. No Brasil, há vários trabalhos enfocando a alta prescrição de suplementos fluoretados por médicos pediatras (SCHALKA et al., 1996; FREIRE et al., 2000; MALTZ; LACERDA, 2001; SANTIAGO et al., 2002).

Os suplementos fluoretados são recomendados para crianças que moram em áreas com deficiência na fluoretação das águas. A dose diária recomendada é baseada na idade da criança e na concentração de $F$ na água de beber (Tabela 2) (SPUZNAR; BURT, 1988; PENDRYZ; MORSE, 1990; PENDRYZ; MORSE, 1995).

Tabela 2 - Dosagem de suplemento fluoretado recomendada por dia em $\mathrm{mg}$

\begin{tabular}{lccc}
\hline \multirow{2}{*}{ Idade } & \multicolumn{3}{c}{ Concentração de $\mathrm{F}$ na água beber } \\
\cline { 2 - 4 } & $<\mathbf{0 , 3}$ & $\mathbf{0 , 3 - 0 , 6}$ & $>\mathbf{0 , 6}$ \\
\hline Nascimento até $\mathbf{6}$ meses & zero & zero & zero \\
$\mathbf{6}$ meses a $\mathbf{3}$ anos & 0,25 & zero & zero \\
De $\mathbf{3}$ a $\mathbf{5}$ anos & 0,50 & 0,25 & zero \\
De $\mathbf{6}$ a $\mathbf{1 6}$ anos & 1 & 0,50 & zero \\
\hline
\end{tabular}

Fonte: (SPUZNAR; BURT, 1988; PENDRYZ; MORSE, 1990; PENDRYZ; MORSE, 1995).

Lalumandier, em 1992, associou a ocorrência de fluorose dentária em indivíduos residentes em áreas com fluoretação deficiente com a freqüente suplementação e a idade em que as crianças iniciaram a escovação dos dentes, enquanto que para os indivíduos, os quais bebiam água fluoretada, a fluorose foi associada somente com a idade quando se iniciou a escovação dos dentes com 
dentifrício fluoretado. O autor sugeriu que suplementos fluoretados e escovação dos dentes em idade precoce aumentaram o risco para a fluorose dentária.

Guha-chowdhury; Drummond; Smillie (1996) realizaram um estudo para testar a hipótese de que a quantidade total de $\mathrm{F}$ recebida através da dieta, dentifrício e suplementos fluoretados, por crianças residentes em áreas com baixos teores de $\mathrm{F}$ na água, era similar àquela recebida através da dieta e do dentifrício por crianças residentes em áreas fluoretadas. Os autores verificaram que, se algumas crianças da área de baixo teor de $F$ recebessem 0,50 ou até mesmo 0,25 mg $F / d i a$, receberiam uma quantidade total de $F$, superior à recebida pelas crianças das áreas fluoretadas. Desta maneira, este estudo suporta a redução das doses de $\mathrm{F}$ dos suplementos para diminuir o risco de fluorose nos dentes anteriores permanentes e primeiros molares.

O risco de fluorose dentária em áreas fluoretadas, quando há a utilização de suplemento fluoretado, é quase 4 vezes mais alto do que em áreas não fluoretadas (RIORDAN, BANKS, 1991; MASCARENHAS, 2000).

\subsubsection{Alimentos e bebidas}

A maioria dos alimentos tem concentração de $F$ menor que 0,5 ppm (TAVES, 1983), com exceção dos produtos à base de frutos do mar e frango, que podem conter altos níveis de $\mathrm{F}$, sendo que a inclusão de ossos, pele e conchas nestes produtos durante o processo de industrialização contribui muito para estes valores elevados. Os produtos à base de frango podem conter de 0,6 a 10,5 ppm de $F$ (LEVY; KIRITSY; WARREN, 1995; HEILMAN et al., 1997). Entretanto, Trautner; Siebert (1986) observaram uma reduzida biodisponibilidade do $\mathrm{F}$ para a maioria dos produtos à base de carnes e peixes, provavelmente devido ao alto conteúdo de cálcio destes alimentos.

Nas bebidas (refrigerantes, sucos de frutas e chás, entre outras), as concentrações de $\mathrm{F}$ nas bebidas refletem aquelas encontradas na água usada para o seu preparo (HEILMAN et al., 1999). Em geral, variam de 0,1 a 1,4 ppm, exceto para os chás, que podem conter até 7 ppm de F (CURY, 1981; CLOVIS; HARGREAVES, 1988; PANG; PHILIPPS; BAWDEN, 1992). 
Heintze; Bastos (1996) avaliaram a concentração de $\mathrm{F}$ de diversas bebidas encontradas no mercado brasileiro como: refrigerantes de vários sabores, sucos, leite, chás. Os resultados indicaram que todas as bebidas, com exceção do chá preto $(1,60 \mathrm{ppm})$ e uma água engarrafada, com gás (2,6 ppm), apresentaram concentrações de $F$ abaixo de $1 \mathrm{ppm}$, a maioria abaixo de 0,4 ppm.

$\mathrm{O}$ conteúdo de $\mathrm{F}$ de várias marcas comerciais de chás e sucos encontradas no mercado brasileiro foi avaliado também por Buzalaf et al.(2002). Foram avaliados os seguintes produtos: chá preto para infusão $(n=12)$, chá industrializado pronto para o consumo ( $n=15)$, suco em pó $(n=10)$, suco em pó contendo chá $(n=3)$ e suco pronto para o consumo $(n=4)$. Todas as amostras de chá preto para infusão e sucos em pó contendo chá, e duas amostras de chás industrializados pronto para o consumo apresentaram concentração de $F$ mais alta do que $0,7 \mu \mathrm{g} / \mathrm{mL}$. De qualquer modo, se as amostras dos outros produtos fossem reconstituídas com água fluoretada poderiam ser importantes contribuintes para a ingestão total diária de F. Assim, os autores concluíram que o consumo de alguns produtos analisados por crianças na idade de risco para a fluorose dentária deveria ser evitado e que a concentração de $\mathrm{F}$ destes produtos deveria ser informada em seus rótulos.

Buzalaf et al.(2003) analisaram a concentração de $\mathrm{F}$ em diversas marcas de chocolates e bolachas de chocolate encontradas no mercado nacional, visto que o chocolate e as bolachas de chocolate, são bastante apreciados pelas crianças e que alguns dos alimentos analisados podem ser importantes contribuintes para a ingestão diária total de F. Neste caso, foi observada em uma marca de bolacha (Danyt' s) uma maior concentração de $\mathrm{F}$, considerando que apenas 3 unidades poderiam fornecer $40 \%$ da ingestão diária máxima de $\mathrm{F}$ recomendada $(0,07 \mathrm{mg} / \mathrm{Kg}$ peso corporal) para uma criança de 2 anos de idade $(12 \mathrm{Kg}$ ), quando consumidas uma única vez por dia.

Em um estudo realizado por Buzalaf et al.(2002), com o objetivo de avaliar o conteúdo de $\mathrm{F}$ em produtos comumente utilizados por bebês e crianças jovens, foi encontrada na maioria dos produtos baixa concentração de $F$, exceto em dois cereais (Mucilon e Neston) que tiveram concentração média de $F$ de $2,430 \mu \mathrm{g} / \mathrm{g}$ e $6,160 \mu \mathrm{g} / \mathrm{g}$, respectivamente, e um achocolatado (Toddynho) que teve uma concentração média de $\mathrm{F}$ de $1,180 \mu \mathrm{g} / \mathrm{g}$. Surpreendentemente, os produtos que tiveram concentrações de $\mathrm{F}$ mais altas (Mucilon e Neston) foram fabricados em 
áreas não fluoretadas. Isto significa que a fonte de $\mathrm{F}$ destes produtos não é a água. Com base nos resultados, os autores concluíram que alguns alimentos e bebidas infantis podem ser importantes contribuintes para a ingestão diária total de $\mathrm{F}$ e que apenas uma porção de Neston ( $30 \mathrm{~g}$ em $200 \mathrm{~mL}$ de leite) ou um frasco do Toddynho (200 mL) correspondem, isoladamente, a 30\% da dose diária máxima de $\mathrm{F}$ para crianças de 2 anos. Os autores, também, ressaltaram que os rótulos dos produtos deveriam fornecer informações sobre seus conteúdos de F.

Buzalaf et al.(2006) avaliaram a quantidade de F fornecida para crianças préescolares, de 44 Escolas Municipais de Ensino Infantil (EMEIs) da cidade de Bauru através da merenda. A quantidade de $\mathrm{F}$ da água, utilizada no preparo da merenda, também foi avaliada, além do seu impacto na quantidade $F$ encontrada nas amostras de merenda. Foram coletadas amostras de merenda e de água, durante duas semanas consecutivas. A concentração média de $F$ encontrada nas amostras de água foi de $0,50 \mu \mathrm{g} / \mathrm{mL}$, variando de não detectável a $1,42 \mu \mathrm{g} / \mathrm{mL}$, enquanto que a quantidade média de $\mathrm{F}$ fornecida pela merenda foi $0,067 \mathrm{mg}$, variando de 0,007 a $0,580 \mathrm{mg}$. Uma correlação fraca, mas significativa foi observada entre a quantidade de $F$ na merenda e a concentração de $F$ na água de abastecimento público. Os autores concluíram que apesar de parecer pequena a contribuição da merenda para a ingestão diária total de $\mathrm{F}$, ela poderia contribuir para a ingestão total de $\mathrm{F}$, quando associada com outros produtos contendo $\mathrm{F}$.

Casarin et al.(2007) avaliaram a concentração de $F$ na refeição típica brasileira (arroz e feijão) e em alimentos industrializados, a fim de estimar suas contribuições para a fluorose dentária. Foram analisadas três marcas de arroz e feijão e 36 amostras de alimentos infantis divididos em cinco grupos: prontos para consumo, mingaus, alimentos formulados, leites em pó e outros alimentos.A concentração de $F$ encontrada nos grãos de arroz e feijão foi baixa. Porém, a concentração aumentou 100-200, vezes após cozimento em água fluoretada e mesmo assim, foi menor que a encontrada em alguns alimentos industrializados. Uma refeição com arroz e feijão preparada com água fluoretada seria responsável por $29 \%$ da dose limite de ingestão de $\mathrm{F}$ em termos de fluorose aceitável, enquanto que a contribuição de alguns alimentos industrializados poderia atingir $45 \%$. Os autores concluíram que a alimentação típica brasileira, mesmo preparada com água fluoretada, é mais segura em termos de risco de fluorose dentária, que alguns alimentos infantis industrializados. 
As concentrações $F$ de leites integrais, desnatados e achocolatados disponíveis no comércio do Brasil, foram avaliadas por Buzalaf et al.(2006) e a sua contribuição para ingestão de $F$ foi estimada. Foram avaliadas 23 marcas de leites e a ingestão provável de $\mathrm{F}$ por $\mathrm{Kg}$ de peso corporal, foi estimada, baseando-se em volumes sugeridos pelo fabricante de consumo de fórmulas infantis, para crianças de 1 e 12 meses de idade. As concentrações de $\mathrm{F}$ variaram de 0,02 a 1,6 $\mu \mathrm{g} / \mathrm{mL}$ para todas as marcas analisadas. Os leites integrais e desnatados apresentaram as menores concentrações de $F$, variando de 0,02 a $0,07 \mu \mathrm{g} / \mathrm{mL}$. Três marcas de achocolatados apresentaram concentrações de $F$ acima de $0,5 \mu \mathrm{g} / \mathrm{mL}$. Em vista das altas concentrações de $\mathrm{F}$ encontradas, em algumas marcas de leites achocolatados, os autores concluíram que muitos produtos podem contribuir significativamente para a ingestão total de $\mathrm{F}$, reforçando a necessidade de se avaliar o conteúdo de $\mathrm{F}$ em alimentos e bebidas consumidos por crianças pequenas.

Nohno et al.(2006) avaliaram a ingestão de F, através de alimentos e bebidas de crianças japonesas residentes em duas áreas com diferentes concentrações de $\mathrm{F}$ na água de abastecimento. Participaram do estudo 38 crianças com idade entre 2 e 8 anos, destas 21 crianças eram residentes em áreas com moderada concentração de $\mathrm{F}$ na água de abastecimento (0,56ppm), e 17 residentes em área com baixa concentração de $\mathrm{F}$ na água de abastecimento (variando entre 0,04 a 0,13 ppm). A estimativa da ingestão de $F$ foi realizada pela técnica da dieta duplicada. De acordo com os pesquisadores a ingestão de $F$ foi de 0,0252-0,0254 $\mathrm{mgF} / \mathrm{Kg} /$ dia em área com moderada concentração de $\mathrm{F}$ na água de abastecimento público, e de 0,0126-0,0144 mgF/Kg/dia em área com baixa concentração de $\mathrm{F}$ na água de abastecimento. Os autores concluíram que as diferentes concentrações de $\mathrm{F}$ na água de abastecimento público refletem a ingestão de $\mathrm{F}$ a partir da dieta em uma dieta típica de crianças japonesas.

Almeida, Cardoso e Buzalaf (2007) avaliaram a ingestão de F de 33 crianças de 2-3 anos de idade. Foram realizadas estimativas de ingestão de $F$ a partir da dieta e da escovação. A média $( \pm D P)$ da ingestão de $F$ a partir da dieta e escovação foi $0,025 \pm 0,013$ e 0,106 $\pm 0,085 \mathrm{mg} / \mathrm{Kg}$ peso corporal/ dia, respectivamente. A fim de verificarem a contribuição na ingestão total de $\mathrm{F}$ dos diferentes componentes da dieta, os alimentos foram divididos em 3 grupos: sólidos, água e leite, e os outros líquidos. Dentre os grupos de alimentos, a água e o leite tiveram uma contribuição 
maior para ingestão total de $\mathrm{F}(0,18 \pm 0,11 \mathrm{mgF} /$ dia $)$ em relação aos alimentos sólidos $(0,07 \pm 0,05 \mathrm{mgF} / \mathrm{dia})$ e aos outros líquidos $(0,07 \pm 0,04 \mathrm{mgF} / \mathrm{dia})$.

\subsubsection{Produtos odontológicos fluoretados}

Os produtos odontológicos fluoretados têm concentrações de $F$ variando entre 230 ppm nas soluções para bochecho até 23000 ppm nos vernizes fluoretados. Os dentifrícios, que são os produtos odontológicos mais freqüentemente usados, contêm uma concentração de $F$ variando geralmente de 500 e 1500 ppm, tanto na forma de fluoreto de sódio quanto na forma de monofluorfosfato de sódio (WHITFORD, 1994).

Em 1954, Muhler et al. publicaram o primeiro relato da capacidade de um dentifrício fluoretado em reduzir a incidência de cárie dentária em crianças. Seguindo-se à confirmação destes resultados, em 1964 foi aceito o primeiro dentifrício fluoretado pelo Conselho de Terapêutica Dentária da American Dental Association. A partir de então, houve a disseminação do uso de dentifrícios fluoretados, sendo que em 1980, todos os dentifrícios vendidos nos EUA continham $\mathrm{F}$.

No Brasil, a portaria $n^{\circ} 22$, de 20 de dezembro de 1989 estabeleceu normas que regulamentam a incorporação de $\mathrm{F}$ nos dentifrícios (sem obrigatoriedade), estabelecendo uma concentração mínima de 1000 e máxima de 1500 ppm de $F$ solúvel no momento da fabricação, um mínimo de 600 ppm de $F$ solúvel após um ano desta data e um mínimo de 450 ppm de $F$ pelo restante do prazo de validade.(BRASIL, 1989).

A efetividade dos dentifrícios fluoretados na redução da incidência de cárie dentária, tem sido extensivamente documentada em uma infinidade de pesquisas clínicas publicadas e em muitas outras não publicadas, as quais foram revisadas em várias ocasiões na década de 80 (MELLBERG; RIPA, 1983; BIESWANGER; STOOKEY, 1989). É claro que difícil documentar precisamente, devido ao uso disseminado da água fluoretada e de outras fontes de consumo do F. No entanto, não pode ser considerada uma simples coincidência o fato de que o primeiro relato de declínio de cárie dentária numa comunidade não fluoretada dos EUA (ZACHERL; LONG, 1979) ter ocorrido alguns anos após cerca de $90 \%$ das crianças escolares terem começado a usar dentifrícios fluoretados. Uma evidência ainda mais forte da 
importância dos dentifrícios fluoretados como medida de saúde pública foi trazida por estudos realizados na Inglaterra, onde menos que 10\% da população ingere água fluoretada. Nesses estudos o declínio na prevalência de cáries coincidiu com o aumento do uso de dentifrícios fluoretados (ANDLAW; BURCHELL; TUCKER, 1982; ALLEN; ASHLEY; MAINWARING ,NAYLOR, 1983; MANSBRIDGE; BROWN, 1985).

Vários estudos têm investigado o possível impacto do uso de dentifrício fluoretado no desenvolvimento da fluorose dentária. Muitos estudos sugerem uma relação entre 0 uso dos dentifrícios fluoretados por crianças jovens e o desenvolvimento de fluorose dentária (PENDRYS; KATZ, 1989; PENDRYS; KATZ; MORSE, 1996; PENDRYS; KATZ, 1998; MASCARENHAS; BURT, 1998; WARREN; LEVY, 1999; BUZALAF et al., 2002). Além do uso precoce de dentifrício fluoretado, outras variáveis, na escovação, têm sido relacionadas com o aumento de fluorose dentária, como: quantidade de dentifrício usado, freqüência de escovação e quantidade de dentifrício ingerida (RIORDAN; BANKS, 1991; EVANS; STAMM, 1991). De todas as variáveis o uso de dentifrício fluoretado, antes da idade de 2 anos, varia desde um leve aumento até um aumento de 11 vezes. As razões para esta ampla variação são as múltiplas fontes de $\mathrm{F}$ e os diferentes índices de fluorose dentária empregados nos diferentes estudos (MASCARENHAS, 2000). Um estudo onde somente o dentifrício fluoretado era a fonte de ingestão de $F$, mostrou uma associação entre o seu uso precoce e fluorose dentária (MASCARENHAS; BURT, 1998).

Também a concentração de $F$ presente no dentifrício é um fator a ser considerado. O estudo de Holt et al.(1994), que avaliou o risco de fluorose dentária em crianças que tinham participado previamente de uma pesquisa clínica, envolvendo o efeito preventivo de cáries e o uso de dentifrícios com baixa concentração de $F(550$ ppm), na idade entre 2 e 5 anos, mostrou que as crianças que tinham usado esse dentifrício, tinham uma probabilidade significantemente menor de desenvolver fluorose dentária.

Segundo Pessan; Silva; Buzalaf (2003), a ingestão de $F$ através da escovação é de $0,034 \mathrm{mg} / \mathrm{Kg}$ peso para crianças de $4-5$ anos e $0,041 \mathrm{mg} / \mathrm{Kg}$ para crianças de 6-7 anos de idade. Em um estudo realizado por Lima; Cury (2001) com crianças de 20-30 meses de idade residentes em áreas com água fluoretada mostrou que as mesmas ingeriam em média $0,09 \mathrm{mg} \mathrm{F} / \mathrm{Kg} / \mathrm{dia}$, tendo a dieta contribuído com $45 \%$, e o dentifrício com $55 \%$, deste modo excedendo a dose limite 
de $0,07 \mathrm{mg} \mathrm{F} / \mathrm{Kg} /$ dia. Os autores sugeriram três alternativas para esta dose ser reduzida: redução da concentração ótima de $F$ na água de abastecimento de 0,7 para 0,3-0,4 ppm; utilização de dentifrício contendo 600 ppm de F solúvel; utilização de, no máximo, 0,3 g de dentifrício por escovação. Do ponto de vista de risco e benefício do uso do $\mathrm{F}$, segundo os autores, a terceira possibilidade seria, a princípio, a mais viável. Na condição deste estudo, se as crianças utilizassem 0,3 g de dentifrício por escovação, seriam submetidas a uma dose segura para a fluorose dentária, considerando o limiar de 0,05 a 0,07 mg F/Kg/dia.

No entanto, segundo Richards; Banting (1996), a quantidade média de dentifrício aplicado na escova por crianças menores que 6 anos, é $0,55 \mathrm{~g}$ por escovação. Em média, 48\% desta quantidade é ingerida por crianças de 2-3 anos, $42 \%$ por crianças de 4 anos e $34 \%$ por crianças de 5 anos (ERICSSON; FORSMAN, 1969; HARGREAVES; INGRAM; WAGG, 1972; RICHARDS; BANTING, 1996). Assim, a quantidade de dentifrício usada na escova tende a aumentar com a idade, enquanto a quantidade ingerida tende a diminuir (LEVY; KIRITSY; WARREN, 1995).

No estudo de Almeida, Cardoso e Buzalaf (2007), a ingestão, somente a partir do dentifrício, foi de $0,106 \mathrm{mgF} / \mathrm{Kg}$ peso/ dia, sendo responsável por $81,5 \%$ da ingestão diária de $F$. Além disso, houve uma correlação positiva $(r=0,971 ; p<0,0001)$ entre a quantidade de dentifrício utilizada $(0,488 \pm 0,303 \mathrm{~g})$ e a de $F$ ingerido por escovação $(0,591 \pm 0,445 \mathrm{mg})$.

Para que seja reduzido o risco de desenvolvimento de fluorose dentária, dentifrícios sem F, ou então, com concentrações mais baixas, em torno de 500 ppm, deveriam ser recomendados para crianças muito pequenas ou pré-escolares. Outra possibilidade seria que o dentifrício contendo níveis acima de 1000 ppm, só deveria ser usado sob a supervisão dos pais, os quais deveriam colocar o dentifrício na escova (apenas uma porção do tamanho de uma ervilha) e supervisionar a escovação, para assegurar que a criança está expectorando e lavando a boca após a escovação (WARREN; LEVY, 1999; MASCARENHAS, 2000; TABARI et al., 2000). 


\subsection{Avaliação do consumo alimentar de crianças em relação ao $F$}

Nos últimos anos, estudos têm evidenciado mudanças no padrão dietético, como alto teor de gordura e colesterol, carboidratos refinados e baixo teor de fibra, normalmente associados a uma vida sedentária (MONTEIRO et al., 1995, BLEIL 1998).

Intimamente relacionado a este tipo de comportamento alimentar está o aumento da prevalência da obesidade, câncer, doenças cardiovasculares e outras enfermidades crônicas não transmissíveis. Entre 1975 e 1989, no Brasil, a proporção de adultos obesos aumentou de $5,7 \%$ para $9,6 \%$, sendo que, em 1989, a proporção de mulheres obesas excedeu a de desnutridas em todas as faixas de renda e entre os homens, isto ocorreu nos grupos com renda elevada (MONTEIRO e CONDE, 1999).

Livingstone e Robson (2000), em um artigo de revisão sobre investigações de consumo alimentar em crianças, verificaram que, após os dois primeiros anos de vida, a alimentação mantém-se razoavelmente constante até os cinco anos de vida, quando volta a ter mais variações de consumo. Aparentemente nesta fase a criança ajusta sua ingestão energética ao longo do dia, tornando-a relativamente constante.

Dados referentes a crianças menores de 5 anos, da cidade de São Paulo, mostram um declínio significativo da prevalência de desnutrição entre 1974 e 1996, enquanto, o risco à obesidade se manteve estável (MONTEIRO e CONDE 2000).

Estudos de ingestão alimentar são importantes ferramentas para a evolução do estado nutricional e planejamento das intervenções necessárias e recomendações dietéticas, para prevenção e manutenção da saúde das crianças (PHILIPPI 2002).

A criança deve consumir a quantidade de alimento necessária para alcançar seu potencial genético de crescimento. $O$ atraso no crescimento, devido às circunstâncias ambientais e nutricionais, está associado com maiores taxas de morbidade e mortalidade, com deficiências no aprendizado e com menor capacidade física e intelectual na vida adulta (PHILIPPI et al., 2003).

Aquino e Philippi (2002), fizeram um estudo sobre o consumo de alimentos industrializados, por crianças com idade até 59 meses. As autoras demonstraram que os mais estatisticamente significantes em termos de maior utilização na alimentação infantil, foram: leites (fluido, em pó modificado, em pó integral); iogurtes 
(observou-se que o iogurte foi um dos alimentos cuja produção e venda mais se elevaram nos últimos anos); biscoitos e salgadinhos (devido à praticidade); massas alimentícias (forte tendência no aumento do consumo de macarrão instantâneo); refrigerantes (significativo aumento, especialmente entre as crianças de maior renda); açúcar (notou-se que o consumo de açúcar é alto pelas crianças de menor renda).

Para se estimar a ingestão diária de F, por crianças, tem-se procurado avaliar a ingestão a partir da dieta (dieta duplicada) e da escovação, que representam as duas grandes fontes de ingestão. A estimativa da ingestão de $\mathrm{F}$ pelo método da dieta duplicada é um procedimento dificilmente executado, requerendo uma grande uma grande colaboração dos cuidadores das crianças, responsáveis pela coleta da dieta.

O QFA tornou-se um dos métodos essenciais na epidemiologia nutricional, sendo amplamente empregado para a avaliação da dieta habitual de indivíduos e populações. (WILLETT, 1990; MARTÍN-MORENO et al., 1993; JIMÉNEZ e MARTÍNMORENO, 1995)

Objetivando constatar qual a freqüência habitual de consumo de alimentos por um período de tempo determinado, o QFA é estruturado por meio da sistematização de uma lista de alimentos, consumidos pela população . (PERSSON e CARLGREN, 1984; WILLETT et al., 1985; LIU, 1994). Sendo assim, comparandose o QFA com outros métodos, como o Recordatório de 24 horas e o Diário Alimentar, observa-se que o QFA substitui a precisão da mensuração do consumo alimentar de um ou vários dias por uma informação global do consumo em um longo período de tempo. (JIMÉNEZ e MARTÍN-MORENO, 1995). Essa lista de alimentos pode variar em amplitude e complexidade, de acordo com os nutrientes que se objetiva analisar e a importância relativa dos alimentos, em diferentes subgrupos populacionais (COLUCCI, 2002; COLUCCI et al., 2004).

Estudos mostram a capacidade do QFA em identificar indivíduos com padrões extremos de consumo, classificar grupos populacionais de acordo com seu consumo alimentar habitual e monitorar tendências nos comportamentos alimentares ao longo do tempo. Com isso, afirma-se que é um instrumento especialmente aplicável em estudos que tenham por objetivo relacionar a dieta e efeitos na saúde a longo prazo (WILLETT et al., 1985; ZULKIFLI e YU, 1992; DWYER, 1999). 
De acordo com o que se pretende enfatizar, o QFA pode se apresentar sob três formas: qualitativo, semiquantitativo e quantitativo. No caso da necessidade de avaliar a freqüência e a quantidade de consumo, para estimar o conteúdo adequado de nutrientes, o QFA semiquantitativo é uma boa opção. É um método que inclui uma porção de referência, previamente determinada, para cada alimento. É importante que o tamanho dessa porção seja aquele comumente utilizado pela população e expresso em medidas caseiras (xícara, unidade, fatia) (IVACG, 1989; THOMPSON e BYERS, 1994; JIMÉNEZ e MARTÍN-MORENO, 1995; PHILIPPI et al., 2000).

O número de categorias de freqüência pode variar de quatro até treze, sendo importante considerar a facilidade de compreensão pelo entrevistado e, ainda, evitar a sobreposição de categorias (FROST ANDERSEN et al., 1995; CARDOSO et al., 1997).

No QFA, outro aspecto a ser levado em conta é a unidade de tempo precedente à aplicação do questionário. A mais comumente empregada para estimar o consumo habitual de alimentos, é o ano precedente, porém, alguns estudos adotam períodos de tempo mais curtos, dependendo da população em questão e do tempo de exposição ao fator dietético. (WILLETT et al., 1985;).

No Brasil, é um método relativamente novo, sendo que recentemente foram desenvolvidos e validados QFAs para indivíduos adultos (SICHIERI, 1998; FORNÉS et al., 2000; CARDOSO et al., 2001) e, ainda que, em menor número, também foram desenvolvidos estudos em grupos etários mais jovens (SLATER, 2001; COLUCCI, 2002; COLUCCl et al., 2004).

Os pesquisadores Jackson et. al, (1996) realizaram um estudo a fim de estimar a ingestão dietética de $\mathrm{F}$, de crianças residentes de áreas fluoretada e não fluoretada. Esse estudo foi realizado com adolescentes de 12 a 14 anos de idade. Os pesquisadores perguntavam para os pais desses jovens sobre a alimentação dos filhos quando os mesmos tinham de 3 a 5 anos. Para identificar os alimentos e bebidas mais consumidos, os pesquisadores aplicaram o QFA. Identificados, esses produtos, os mesmos, além da água, foram analisados para avaliação da concentração de F. Observou-se que a concentração de $F$ das amostras de alimentos e bebidas foi baixa, não havendo diferença significativa entre as duas áreas na concentração de $\mathrm{F}$ dos alimentos pré-processados ou prontos para 0 
consumo. Porém, houve uma diferença significativa entre as duas regiões nos alimentos preparados com as águas locais (JACKSON et al., 2002).

Em um outro estudo, Martins et al., (2002) aplicaram o questionário aos pais de crianças portadoras de fluorose dentária, com idades entre 6 e 12 anos. Da mesma forma que o estudo citado anteriormente, o questionário foi aplicado aos pais das crianças, referindo-se à história pregressa delas, quando tinham de 0 a 3 anos de idade. Observou-se que $80,92 \%$ das crianças bebiam chá, e a água de abastecimento público fluoretada $(0,74 \mathrm{ppm})$ era a principal fonte para o preparo da bebida $(74,91 \%)$, sendo que $78,62 \%$ utilizavam-na para consumo.

Recentemente, foi desenvolvido e validado um QFA para estimativa de ingestão de $\mathrm{F}$ a partir de crianças brasileiras de 2 a 6 anos de idade (MIZIARA, 2006). Dentre os 70 itens alimentares estudados, o arroz, a água de abastecimento público e o leite foram os mais consumidos. Os itens alimentares mais consumidos apresentaram, em média $( \pm D P)$, menor concentração de $F(0,017 \pm 0,029$ $\mathrm{mgF}$ /porção), porém não-significativo $(p=0,27)$. Os itens alimentares com maior concentração de $\mathrm{F}$ contribuíram significativamente $(p<0,001)$ para a ingestão do mineral $(0,020 \pm 0,039 \mathrm{mgF} / \mathrm{dia})$. A média da ingestão de $\mathrm{F}$ a partir dos alimentos sólidos e líquidos (exceto água), da água e da escovação foi de 0,017 $\pm 0,016 ; 0,011$ $\pm 0,004$ e $0,036 \pm 0,028 \mathrm{mgF} / \mathrm{Kg}$ peso/dia, respectivamente, totalizando 0,063 $\mathrm{mgF} / \mathrm{Kg}$ peso/dia. Das 379 crianças, $31,2 \%$ apresentaram risco de fluorose. $\mathrm{O}$ dentifrício e os itens alimentares (sólidos, água e líquidos somados) contribuíram com $57 \%$ e $43 \%$, respectivamente, para a ingestão de F. De acordo com a pesquisadora, o dentifrício foi a principal fonte para a ingestão de $F$ pelas crianças, porém, a concentração de $\mathrm{F}$ nos itens alimentares contribuiu diretamente para a ingestão do mineral pelas crianças, representando risco para fluorose dentária.

No entanto, este questionário não foi comparado com o método mais comum utilizado para avaliar a ingestão de $\mathrm{F}$ a partir da dieta, que é a dieta duplicada. Também não foi testado se o QFA teria sensibilidade suficiente para distinguir a ingestão de $\mathrm{F}$, a partir da dieta, em populações que consomem água fluoretada ou não. Essas avaliações preliminares são necessárias para que se possa utilizar 0 QFA com segurança, para a avaliação da ingestão de $\mathrm{F}$ a nível epidemiológico. 


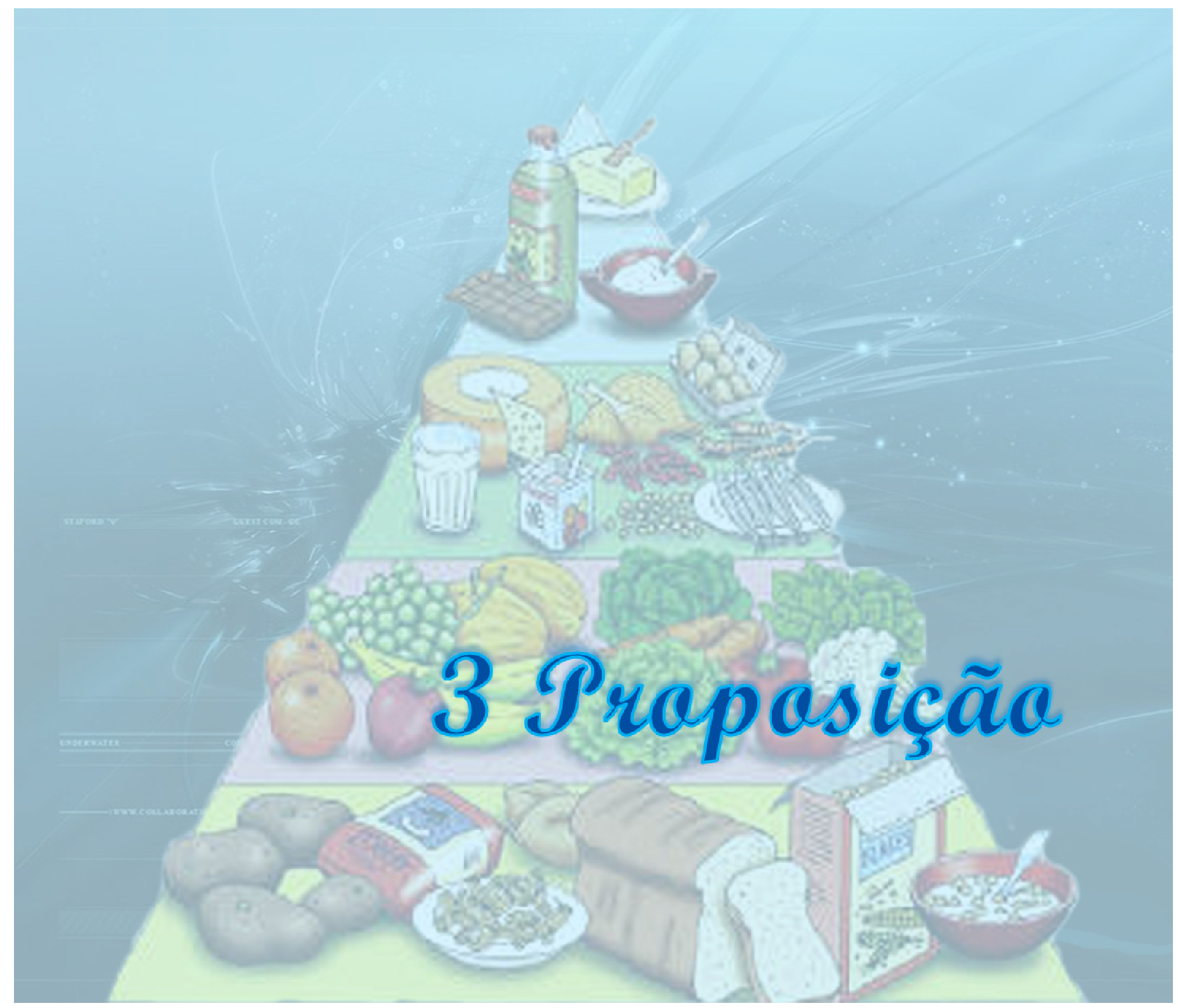




\section{PROPOSIÇÃO}

Este estudo teve como objetivo geral comparar a ingestão de $\mathrm{F}$ de crianças residentes em área fluoretada e não fluoretada, avaliada através do método da dieta duplicada associado à escovação simulada e do QFAsq associado ao questionário para estimativa de ingestão de dentifrício.

As hipóteses nulas a serem testadas foram:

$\checkmark$ O QFAsq não é capaz de detectar diferença significativa na ingestão de F pela dieta em crianças residentes em áreas fluoretadas e não fluoretadas;

$\checkmark$ O método da dieta duplicada não é capaz de detectar diferença significativa na ingestão de $\mathrm{F}$ pela dieta em crianças residentes em áreas fluoretadas $\mathrm{e}$ não fluoretadas;

$\checkmark$ Não há correlação significativa entre os dados de ingestão de $F$ a partir da dieta obtidos pelos métodos de dieta duplicada e QFAsq;

$\checkmark$ Não há correlação significativa entre os dados de ingestão de $F$ a partir do dentifrício obtidos pelos métodos de escovação simulada e questionário para estimativa de ingestão de dentifrício;

$\checkmark$ Não há correlação significativa entre os dados de ingestão total de F obtidos pelos métodos da dieta duplicada, associado à escovação simulada e QFAsq, associado a questionário para estimativa de ingestão de dentifrício. 


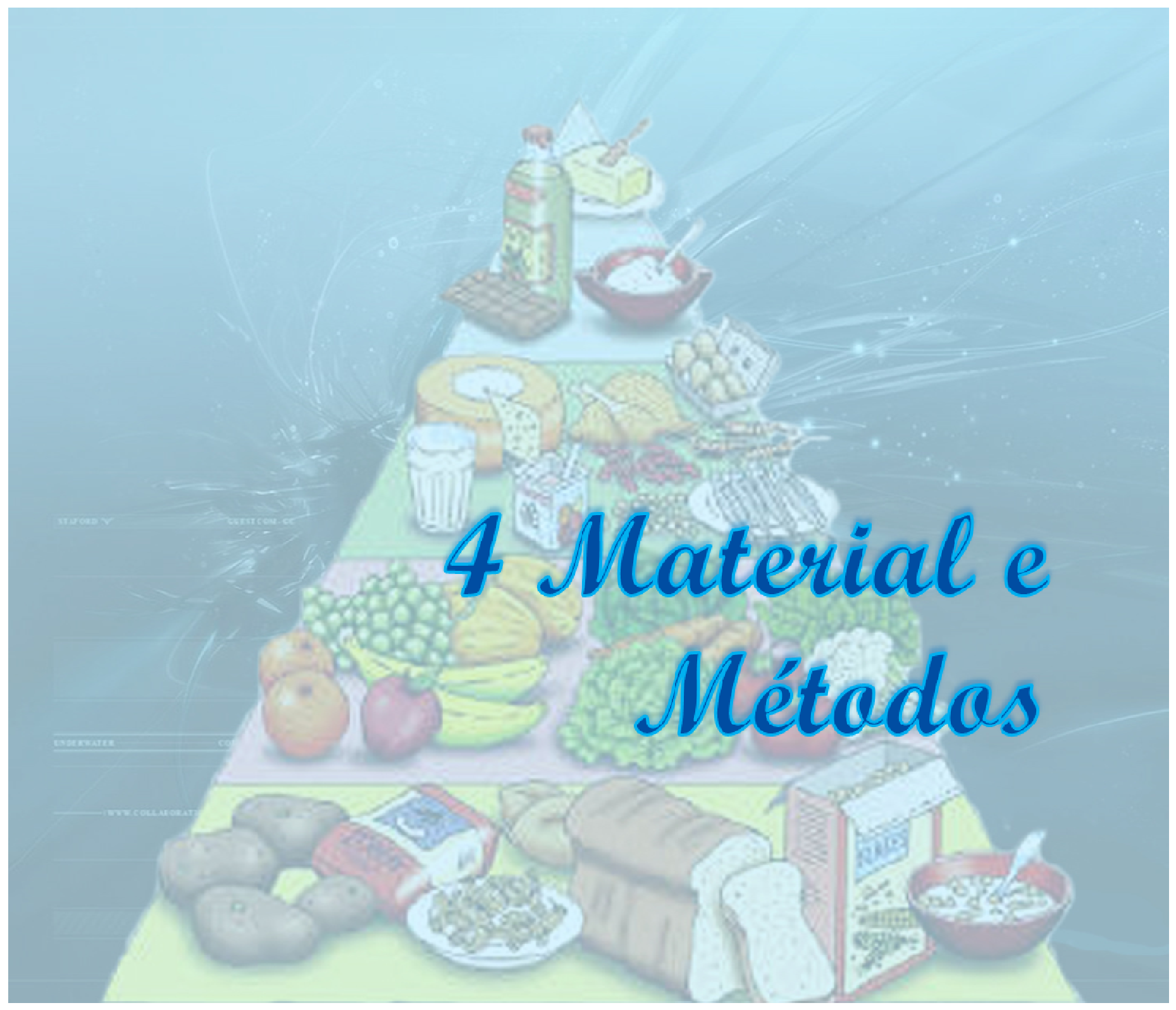




\section{MATERIAL E MÉTODOS}

\subsection{Material}

4.1.1. Material utilizado na leitura da concentração de $F$ do dentifrício, alimentos sólidos e outros líquidos

$\checkmark$ Placa de Petri plástica (Falcon, $n^{\circ} 1007$ )

$\checkmark$ Balança de precisão AND $( \pm 0,01 \mathrm{mg})$

$\checkmark$ Mesa agitadora - Nova técnica modelo NT 145

$\checkmark$ Eletrodo F-sensível Orion 9409

$\checkmark$ Micro eletrodo de referência calomelano (Accumet, $n^{\circ}$ de catálogo \# 13-62079)

$\checkmark$ Vaselina

$\checkmark$ Parafilme

$\checkmark$ Padrão de F contendo 0,1 M F (Orion)

$\checkmark$ Água deionizada

$\checkmark$ HMDS - hexametildisiloxano (Aldrich)

$\checkmark$ Ácido sulfúrico concentrado

$\checkmark \mathrm{NaOH} 0,05 \mathrm{M}$

$\checkmark$ Ácido acético 0,2 M

4.1.2 Material utilizado na leitura da concentração de $F$ na água

$\checkmark$ Eletrodo F sensível Orion 9609

$\checkmark$ Soluções padrão de fluoreto de sódio 100 ppm (Orion)

$\checkmark$ Água deionizada

$\checkmark$ Tisab (CDTA 0,4\%, pH 5,0)

4.1.3 Material utilizado na avaliação da ingestão de $F$ através do QFA

$\checkmark$ QFA (Anexo 3)

$\checkmark$ Balança de precisão marca Tanita $( \pm 0,1 \mathrm{Kg})$ 


\section{$\checkmark$ Estadiometro \\ $\checkmark$ Prancheta \\ $\checkmark$ Lápis}

\subsection{Métodos}

O estudo completo foi dividido em cinco etapas, sendo as duas primeiras realizadas por MIZIARA (2006) em seu trabalho de Mestrado. Por este motivo, serão apenas abordadas em detalhes as etapas três, quatro e cinco, que correspondem ao presente trabalho de tese.

\subsubsection{Aspectos éticos}

O presente estudo foi inicialmente submetido à avaliação pelo Comitê de Ética em Pesquisa da Faculdade de Odontologia de Bauru-USP, processo número 68/2004, recebendo parecer favorável (Anexo 1).

Os voluntários participaram após assinatura pelos seus responsáveis de um Termo de Consentimento Livre e Esclarecido. Ficou claro que a qualquer momento os voluntários poderiam desistir de participar da pesquisa e que os dados seriam confidenciais. Todas as informações constavam na Carta de Informação ao Paciente e no Termo de Consentimento Livre e Esclarecido (Anexo 2), que foram assinados em duas vias, sendo uma destinada aos pais e responsáveis pela criança e outra ao pesquisador.

\subsubsection{Locais Amostrados}

Como critério de inclusão dos municípios no estudo foi utilizado o IDH (Índice de Desenvolvimento Humano), estabelecido pelo Programa nas Nações Unidas para o Desenvolvimento (PNUD, 2003). O objetivo da elaboração do IDH é oferecer um contra-ponto a outro indicador muito utilizado, o PIB (Produto Interno Bruto) per capita, que considera apenas a dimensão econômica do desenvolvimento, sendo uma medida geral, sintética, do desenvolvimento humano. Trata-se de um índicechave dos Objetivos de Desenvolvimento do Milênio das Nações Unidas e, no Brasil tem sido utilizado pelo Governo Federal o IDH-M (Municipal), que pode ser consultado no Atlas do Desenvolvimento Humano no Brasil, um Banco de dados 
eletrônico com informações sócio-econômicas sobre os 5.507 municípios do país, os 26 Estados e o Distrito Federal. O IDH-M mede o nível de desenvolvimento humano dos municípios utilizando como critério indicadores de educação (alfabetização e taxa de matrícula), longevidade (esperança de vida ao nascer) e renda (PIB per capita). O índice varia de 0 (nenhum desenvolvimento humano) a 1 (desenvolvimento humano total).

Com base no exposto, foram selecionados para o estudo dois municípios com IDH-M semelhante, sendo um deles com água de abastecimento fluoretada e outro não. A princípio o intuito era incluir municípios com populações acima de 100.000 habitantes (já que o porte populacional é um indicador de complexidade/heterogeneidade da cidade). No entanto, como hoje a grande maioria dos municípios do Estado de São Paulo conta com água de abastecimento artificialmente fluoretada, não foi possível que este requisito critério fosse preenchido. Assim, os municípios selecionados, com suas principais características determinantes da seleção, foram descritos na Tabela 3. Para seleção foram usados dados do Atlas de Desenvolvimento Humano do Brasil (2000).

Tabela 3- Municípios selecionados, de acordo com a presença de $\mathrm{F}$ na água de abastecimento público e IDH-M.

Município (Estado)

Presença de F na água de abastecimento

\section{IDH-M}

Fluoretado artificialmente

0,825

Bauru (SP)

Sem fluoretação

0,779

Fonte: Átlas do Desenvolvimento Humano do Brasil, 2000).

Bauru é um município brasileiro, situado no estado de São Paulo. Possui uma população de 347.601 habitantes, (IBGE, 2007) área de $673,488 \mathrm{Km}^{2}$, altitude média de 526 metros (615-490 metros), clima subtropical e uma temperatura média de $26,3^{\circ} \mathrm{C}$, sendo a média no inverno de $17^{\circ} \mathrm{C}$ e no verão $30^{\circ} \mathrm{C}$. 


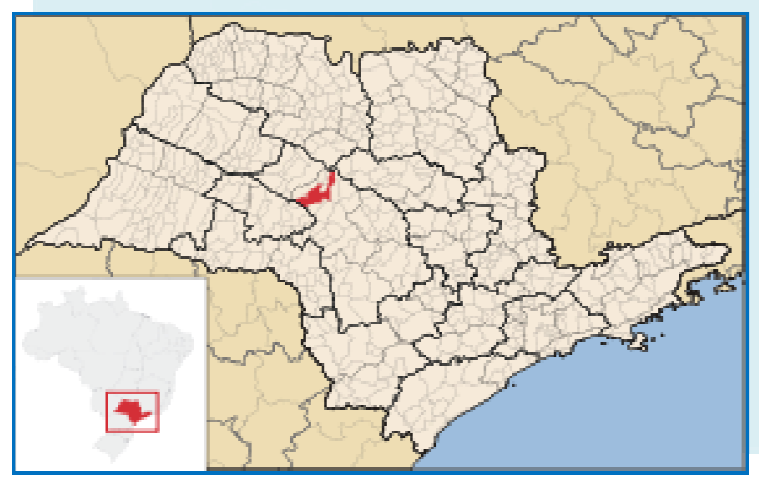

Fonte : www.ibge.gov.br/cidadesat/default.php

Figura 1 - Localização geográfica de Bauru, São Paulo

Pirajuí é um município do estado de São Paulo (Brasil). Possui uma população estimada de 20.035 habitantes (IBGE,2007), área de 819,432 $\mathrm{Km}^{2}$, altitude média de 468 metros, clima quente com inverno seco e uma temperatura média anual de $21^{\circ} \mathrm{C}$.

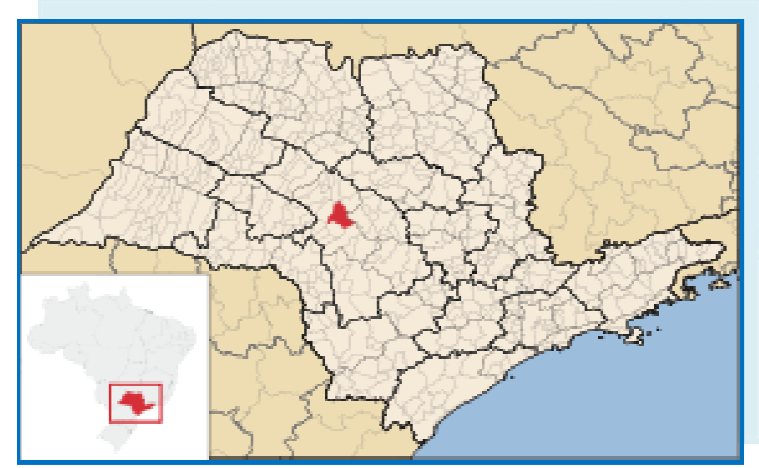

Fonte : www.ibge.gov.br/cidadesat/default.php

Figura 2 - Localização geográfica de Pirajuí, São Paulo

4.2.3 Primeira Etapa: Foi desenvolvido e testada a reprodutibilidade de um QFA (Anexo 3) para avaliação da ingestão de F de crianças (Miziara, 2006). 
4.2.4 Segunda Etapa: Foi aplicado o QFA descrito no item anterior e o questionário para estimativa de ingestão de dentifrício (Anexo 4), no município de Bauru-SP, aos pais de crianças de 2-6 anos de idade (Miziara, 2006).

4.2.5 Terceira Etapa: Foi aplicado o QFA (Anexo 3) aos pais de crianças de 2-6 anos de idade residentes no município de Pirajuí-SP.

\subsubsection{Delineamento amostral}

A avaliação da ingestão de $\mathrm{F}$ baseou-se na proporção de alimentos ingeridos pela população. Estimando-se um erro máximo de $5 \%$ na proporção de ingestão para cada alimento isto resultou em uma amostra necessária de 384 crianças. Para compensar eventuais variações amostrais decidiu-se fixar a amostra em $n=400$ crianças.

A amostra de conveniência foi selecionada entre crianças de 2-6 anos de idade matriculadas nas escolas municipais de educação infantil de Pirajuí. Após autorização das Diretoras das escolas, foi enviada uma carta para os pais das crianças, explicando o delineamento do estudo e marcando data e horário para as entrevistas. No total, participaram do estudo, após a assinatura do Termo de Consentimento Livre e Esclarecido pelos pais, 398 crianças.

\subsubsection{Aplicação do QFA}

Adaptando-se a este estudo, foi aplicado o Questionário de Freqüência Alimentar Semiquantitativo (QFA) desenvolvido por Colucci (2002), por apresentar correlações adequadas ao estudo e por apresentar-se como um instrumento adequado para a avaliação da dieta habitual de crianças de 2 a 6 anos de idade, (COLUCCI, 2002 e 2004). A validação desse questionário foi feita por MIZIARA (2006).

O QFA utilizado foi semiquantitativo (QFAsq), pois incluiu porções de referência previamente determinada para cada alimento. Para que seja possível estimar o conteúdo adequado de nutrientes, é importante que o tamanho da porção de referência do alimento seja comumente utilizado pela população e, preferencialmente, expresso em medidas habituais de consumo (medidas caseiras: xícara, unidade, fatia). (IVACG, 1989; THOMPSON e BYERS, 1994; JIMÉNEZ e MARTíN-MORENO 1995; PHILIPPI et al., 2000; COLUCCI, 2002). 
O QFAsq utilizado foi estruturado de acordo com a pirâmide alimentar adaptada para crianças de 2 a 3 anos de idade (PHILIPPI et al., 2003), contendo os alimentos mais comumente consumidos nessa faixa etária (Figura 3). Essa pirâmide é composta por 8 grupos, com o número de porções diárias para cada grupo:

a) grupo do arroz, pães, massas, batata, mandioca (fonte de carboidratos - 5 porções, sendo pelo menos uma de grãos integrais);

b) grupo das verduras e dos legumes (fonte de vitaminas e minerais -3 porções);

c) grupo das frutas (fonte de vitaminas e minerais - 3 porções);

d) grupo das carnes e ovos (fontes de proteínas, ferro, vitaminas - 2 porções);

e) grupo dos feijões (fonte de proteína vegetal - 1 porção);

f) grupo do leite, iogurte e queijo (fonte de proteínas, cálcio e vitaminas -3 porções);

g) grupo dos óleos e gorduras (fonte de gorduras - 1 porção);

h) grupo dos açúcares e doces (fonte de carboidratos - 1 porção).

Ao final deste questionário foi acrescentado um grupo, denominado "outros", que contém alimentos e bebidas, analisados em estudos anteriores (TRAUTNER e SIEBERT, 1986; McKNIGHT-HANES et al., 1988; PANG et al., 1992; NISHIJIMA et al., 1993; CHITTAISONG et al., 1995; SILVA e REYNOLDS, 1996; HEILMAN et al., 1997; BUZALAF et al., 2001b; BUZALAF et al., 2002b; BUZALAF et al., 2002c; BUZALAF et al., 2003; CARDOSO, 2003; BUZALAF et al., 2004), que podem contribuir significativamente com a ingestão total de $F$ na infância, representando fator de risco para fluorose dentária.

Os dados do QFAsq foram apresentados de acordo com este sistema de classificação por grupos de alimentos. Os alimentos industrializados foram agrupados com base em seu ingrediente primário ou fonte.

Cada alimento do QFAsq apresenta questões simples com respostas múltiplas e fechadas / objetivas, representando unidades de tempo/ freqüências de consumo. (COLUCCI, 2002; COLUCCI et al., 2004), como descrito no quadro 1. 


\begin{tabular}{l}
\multicolumn{1}{c}{$\begin{array}{c}\text { Alimento } \\
\text { (medida caseira) }\end{array}$} \\
(1) Nunca \\
(2) Menos de 1 vez por mês \\
(31 a 3 vezes por mês \\
(4) vez por semana \\
(5) a 4 vezes por semana \\
(61 vez por dia \\
(72 ou mais vezes por dia
\end{tabular}

Quadro 1. Demonstração da avaliação da freqüência de consumo alimentar utilizado no QFA.

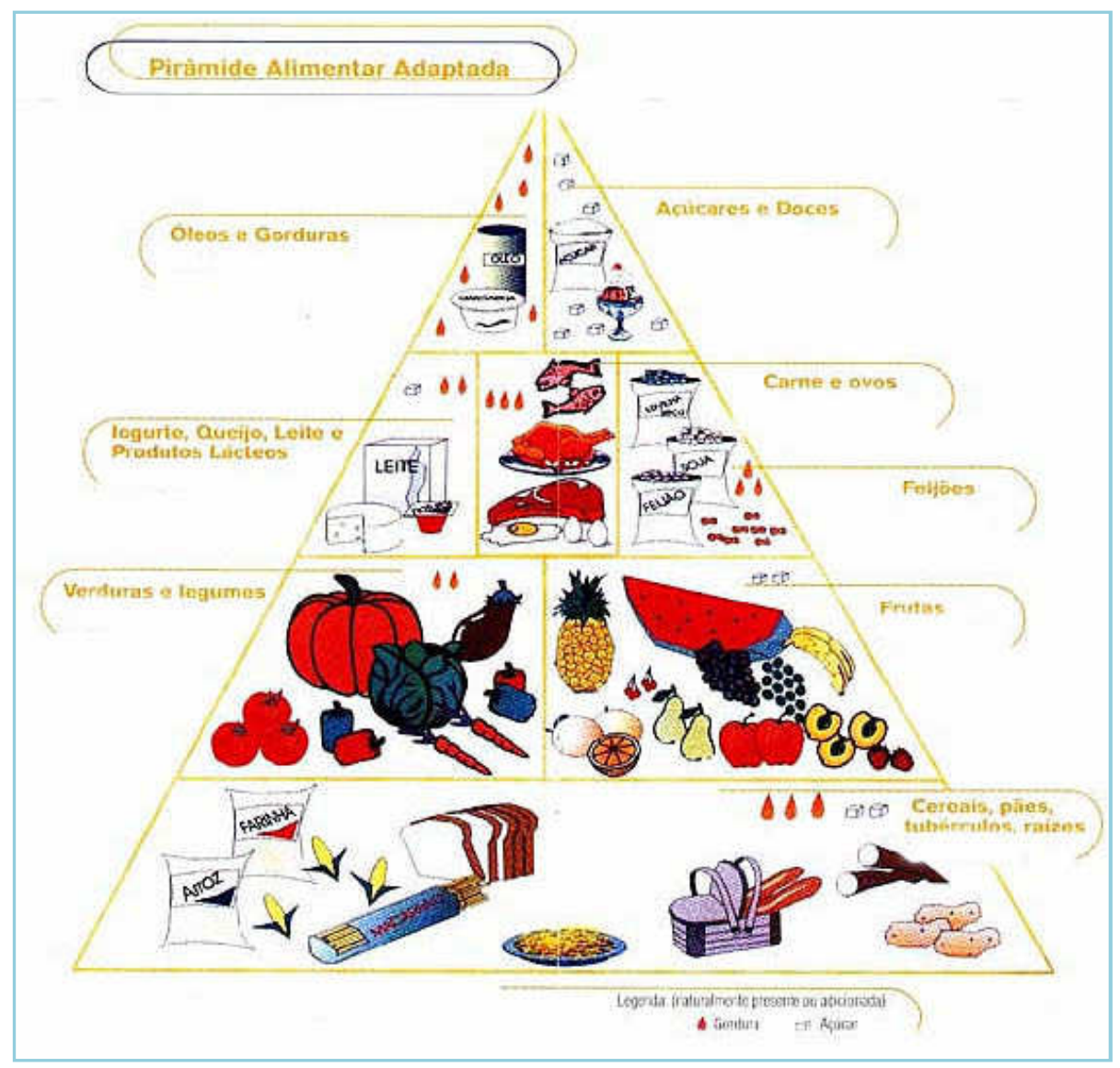

Fonte : Philippi, S. T. et al., 1999

Figura 3 - Pirâmide alimentar adaptada por PHILIPPI et al., (2003) 
Após a definição de todos os parâmetros (Miziara, 2006) o instrumento desenvolvido apresentou 70 itens alimentares, divididos em 10 grupos.( Anexo 3). 0 mesmo foi então aplicado aos pais ou responsáveis das 399 crianças participantes, através de entrevistas feitas por quatro pesquisadoras, devidamente treinadas.

\subsubsection{Processamento dos dados para a estimativa da ingestão diária de $F$ a partir da dieta, através do QFA}

O processamento dos dados foi feito como descrito por Miziara (2006), sendo necessário:

1. Transformar as categorias de freqüência presentes no QFAsq em freqüência diária de consumo. Para tanto, utilizaram-se os seguintes fatores multiplicadores para cada categoria de frequência de consumo, representado no Quadro 2 (COLUCCI, 2002; COLUCCl et al., 2004):

\begin{tabular}{|lcc|}
\hline Nunca & $=$ & 0 \\
1 a 3 vezes por mês & $=$ & 0 \\
Menos de 1 vez por mês & $=$ & $\mathbf{0 , 0 7}$ \\
1 vez por semana & $=$ & $\mathbf{0 , 1 4}$ \\
2 a 4 vezes por semana & $=$ & $\mathbf{0 , 4 3}$ \\
1 vez por dia & $=$ & $\mathbf{1}$ \\
2 ou mais vezes por dia & $=$ & 2 \\
\hline
\end{tabular}

2. Transformar a medida caseira de cada alimento do QFAsq em peso médio (g) . Anexo 5).

3. Estabelecer a concentração de $F$, em $\mu \mathrm{g} \mathrm{F}$, por 100 gramas / $\mathrm{mL}$ de parte comestível de cada alimento sólido e líquido e por $100 \mathrm{~mL}$ de água, para padronização.

4. Dividir os itens alimentares em três grupos: alimentos sólidos, água e outros líquidos, para análises (Anexo 6). 
5. Padronizar a denominação dos itens alimentares .

6. Padronizar os seguintes termos:

a. Itens alimentares: referiu-se aos 70 itens de alimentos do QFAsq, que, quando necessário, foram divididos em 3 grupos: alimentos sólidos, água e outros líquidos.

b. Consumo alimentar: referiu-se ao número médio de porções que as crianças consumiram por dia, de cada alimento.

\section{Exemplo:}

\begin{tabular}{|cccc|}
\hline Alimento $=$ & $\begin{array}{c}\text { Peso médio (g) da da } \\
\text { porção de } \\
\text { referência }\end{array}$ & $\begin{array}{c}\text { Consumo diário médio } \\
\text { (g)/ criança / alimento }\end{array}$ & $\begin{array}{c}\text { Consumo } \\
\text { alimentar } \\
\text { (porções / dia) }\end{array}$ \\
\hline Arroz & 82 & 143,3 & $\mathbf{1 , 7 4 7}$ \\
\hline
\end{tabular}

Fórmula:

$\frac{\text { Consumo alimentar }}{\text { (porções / dia) }}=\frac{\text { Consumo diário médio }(\mathrm{g}) \text { /criança /alimento }}{\text { Peso médio }(\mathrm{g}) \text { da porção de referência }}$

Padronizou-se como itens alimentares mais consumidos aqueles que apresentaram um consumo médio, pelas crianças, de uma ou mais porções, préestabelecidas no QFAsq, por dia.

C. Concentração de F: referiu-se à concentração de $F$ nas porções de referência (pré-estabelecidas no QFAsq) de cada alimento.

Exemplo:

\begin{tabular}{|lcccc|}
\hline Alimento & Arroz & $\begin{array}{c}\text { Pg F / g alimento) } \\
\text { estabão de referência pré- }\end{array}$ & $\begin{array}{c}\text { Peso médio } \\
(\mathbf{g})\end{array}$ & $\begin{array}{c}\text { Quantidade de F } \\
(\mathbf{m g ~ F})\end{array}$ \\
\hline 0,117 & 3 colheres de sopa & 82 & $\mathbf{0 , 0 0 9 5 9 4}$ \\
\hline
\end{tabular}


Fórmula:

$$
\frac{\text { Concentração de } F}{(m g \mathrm{~F} / \text { porção de referência) }}=\frac{\mu \mathrm{g} F / g \text { alimento } \times \text { peso médio(g) }}{1000}
$$

d. Contribuição para ingestão diária de $F(\mathbf{m g} F /$ dia): referiu-se à análise combinada dos parâmetros "consumo alimentar" e "concentração de F nos itens alimentares".

Exemplo:

\begin{tabular}{|cccc|}
\hline Alimento & $\begin{array}{c}\text { Consumo } \\
\text { alimentar } \\
\text { (porções/ dia) }\end{array}$ & $\begin{array}{c}\text { Concentração de } \mathbf{F} \text { (mg } \\
\mathbf{F} / \text { porção de referência) }\end{array}$ & $\begin{array}{c}\text { Contribuição para } \\
\text { ingestão diária de F } \\
\text { (mg F / dia) }\end{array}$ \\
Arroz & 1,747 & 0,009594 & 0,016762 \\
\hline
\end{tabular}

Fórmula:

Contribuição (mg F/ dia) $=$ ํo porções/ dia x mg F/porção de referência

e. Grupos de alimentos: 10 grupos em que os itens alimentares do QFAsq foram divididos:

- Arroz, pão, massa, batata

- Feijão

- Verduras e legumes

- Frutas

- Carnes e ovos

- Leite, queijo e iogurte

- Açúcar, doces e salgadinhos

- Salgados e preparações

- Bebidas

- Outros 
Para o cálculo da estimativa da ingestão média diária de F, com base nesses grupos, foram utilizadas as seguintes fórmulas:

Concentração de $F([F])$ média para cada um dos 10 grupos:

$$
\text { Média }=\frac{\Sigma[\mathrm{F}] \text { dos itens alimentares }(\mu \mathrm{g} F / \mathrm{g})}{\mathrm{n}^{\circ} \text { de itens alimentares do grupo }}
$$

Ingestão de $F$ média por meio de cada um dos 10 grupos:

Média $=\underline{\Sigma \text { contribuição para ingestão de } F(\mathrm{mg} F / \text { dia })}$

$\mathrm{n}^{\circ}$ de itens alimentares do grupo

A fim de se identificar os alimentos e bebidas mais e menos consumidos em Pirajui, a resposta média para cada item no questionário de freqüência de alimentos foi calculada. Estas médias foram então ranqueadas em cada município. Todos os alimentos constantes no QFA sq foram comprados para análise de $F$, que foi realizada na quarta etapa. Esse procedimento foi realizado para Pirajuí, sendo os dados comparados com aqueles obtidos por Miziara (2006), referentes ao município de Bauru.

4.2.6 Quarta Etapa: Análise laboratorial dos alimentos e bebidas

\subsubsection{Preparação dos alimentos e bebidas}

No momento de preparação para análise, números aleatórios foram atribuídos a todas as amostras de alimentos e bebidas coletadas, de forma que os responsáveis pela análise não tinham conhecimento acerca da natureza da amostra. Todos os alimentos e bebidas foram processados, codificados e congelados antes das análises, e no momento da análise, os alimentos e bebidas processados foram analisados em ordem numérica.

Os itens de alimentos foram processados por homogeneização antes da análise. Os vegetais cozidos $e$ as massas foram drenados antes da homogeneização. Uma quantidade suficiente de água deionizada foi adicionada a uma quantidade pré-pesada de cada amostra de alimentos, e o peso total da água e do alimento foi registrado, de forma a se poder calcular a quantidade em gramas do 
alimento por grama de homogenado. Cada amostra de alimento foi então homogeneizada e alíquotas de $20 \mathrm{~mL}$ foram congeladas em duplicata até 0 momento da análise. Todas as análises, sem exceção, foram feitas em duplicata, no Laboratório de Bioquímica da Faculdade de Odontologia de Bauru. Alíquotas em duplicata de cada amostra de bebida foram também guardadas e congeladas.

Água deionizada foi utilizada no preparo dos alimentos que requeriam cozimento (cereais cozidos, massa, vegetais) ou reconstituição (sucos, bebidas em pó, sopas) antes da análise.

\subsubsection{Análise de flúor}

\subsubsection{1 Água e bebidas carbonatadas}

Foram analisadas para o $\mathrm{F}$ pelo método direto, usando o eletrodo íonespecífico combinado (Orion 9609), acoplado a um potenciômetro (Orion EA 940). Previamente à análise, as bebidas carbonatadas foram mantidas à temperatura ambiente por 6-8 horas, a fim de permitir a descarbonatação. Uma alíquota de $1 \mathrm{~mL}$ de cada amostra foi misturada com um volume igual de TISAB II (Tampão de ajuste da força iônica total) e colocada diretamente em contato com o eletrodo.

Validação da análise

Foi feita uma curva de calibração com $1 \mathrm{~mL}$ de soluções-padrão contendo 0,05 , $0,1,0,2,0,4,0,8,1,6,3,2$ e 6,4 $\mu \mathrm{g} F$. As soluções-padrão empregadas na realização da curva de calibração foram preparadas por diluição seriada de um estoque-padrão contendo $100 \mathrm{ppm} F$ (Orion). As leituras obtidas em milivoltagem $(\mathrm{mV})$, foram convertidas para $\mu \mathrm{g}$ de $\mathrm{F}$, através do Programa Excel (Microsoft). A média das leituras obtidas a partir dos padrões foi inserida na planilha, e então foi calculada a porcentagem de variação entre a quantidade de $\mathrm{F}$ medida e a esperada pelos padrões. Somente curvas de calibração com porcentagem de variação de até $5 \%$ para todos os padrões e r $\geq 0,99$ foram aceitas, contemplando a exatidão do método.

\subsection{Outras bebidas e alimentos}

Todos os homogenados de alimentos e bebidas que não puderem ser analisados diretamente, como sucos e leite, foram analisados para o $\mathrm{F}$ após difusão 
facilitada por HMDS (hexametil-disiloxano), pelo método de TAVES (1968), como modificado por WHITFORD (1996). Para tanto, $2 \mathrm{~mL}$ das amostras foram colocados na base de uma placa de Petri (Falcon 1007). Na tampa das placas, foram colocados $50 \mu \mathrm{L}$ de $\mathrm{NaOH} 0,05 \mathrm{M}$, distribuídos em 5 gotas. As placas foram então fechadas e vedadas com vaselina, e por um orifício feito previamente na tampa foi colocado HMDS (Aldrich, 2,0 mL, em ácido sulfúrico $3 \mathrm{M}$ ). $\mathrm{O}$ orifício foi imediatamente vedado com vaselina e parafilme. As placas foram colocadas então numa mesa agitadora orbital plana (Nova Técnica, modelo NT 145) em velocidade 2 3 , durante a noite. No dia seguinte, as tampas foram removidas, invertidas e as gotas de $\mathrm{NaOH}$ foram combinadas numa única gota. $\mathrm{O} \mathrm{NaOH}$ foi tamponado pela adição de $25 \mu \mathrm{L}$ de ácido acético $0,2 \mathrm{M}$. O volume total foi então ajustado para $75 \mu \mathrm{L}$ com água deionizada usando uma pipeta. A gota, que contém todo o $\mathrm{F}$ foi analisada com o eletrodo íon específico Orion 9409 e um micro-eletrodo de referência calomelano (Accumet, número de catálogo \#13-620-79), ambos acoplados ao potenciômetro Orion EA 940 (Figura 7). Durante a leitura, os dois eletrodos foram mantidos unidos através de bandas de borracha e colocados em contato com a gota na parte interna da tampa da placa.

Todas as análises, sem exceção, foram feitas em duplicata. As figuras 4, 5, 6 e 7 demonstram a análise para dosagem de $\mathrm{F}$ nas dietas por esse método.

Validação da análise:

A técnica de difusão facilitada por HMDS apresenta as vantagens de separar o F da amostra, eliminando interferentes, e ao mesmo tempo concentrá-la, o que incrementa o limite de detecção do $\mathrm{F}$ pelo eletrodo sensível, que é de $0,02 \mu \mathrm{g} / \mathrm{mL}$, conforme consta no manual do fabricante.

As soluções-padrão (contendo 0,0095, 0,019, 0,095, 0,190 e 0,950 $\mu \mathrm{g} \mathrm{F}$ ) empregadas na realização da curva de calibração foram preparadas por diluição seriada de um estoque-padrão contendo 0,1 M F (Orion) e difundidas em triplicata, em concomitância com as amostras. Foi feita a primeira leitura antes de se começar a ler as amostras, a segunda quando a metade das amostras já tiver sido lida e a terceira após o término da leitura das amostras. 
As leituras obtidas em milivoltagem $(\mathrm{mV})$, foram convertidas para $\mu \mathrm{g}$ de $\mathrm{F}$, através do Programa Excel (Microsoft). A média das leituras obtidas a partir dos padrões foi inserida na planilha, e então foi calculada a porcentagem de variação entre a quantidade de F medida e a esperada pelos padrões. Somente curvas de calibração com porcentagem de variação de até $5 \%$ para todos os padrões e r $r 0,99$ foram aceitas, contemplando a exatidão do método.

Além disto, padrões que não sofrerão difusão foram preparados usando-se as mesmas soluções $(\mathrm{NaOH}$ 0,05 $\mathrm{M}$ e ácido acético 0,20 M) que forem usadas para se preparar os padrões e amostras que sofreram difusão. Estes padrões não difundidos foram feitos de modo a ter exatamente a mesma $[F]$ que os padrões que sofreram difusão. A comparação das leituras de $\mathrm{mV}$ mostrava que o $\mathrm{F}$ nos padrões difundidos foi completamente captado e analisado.

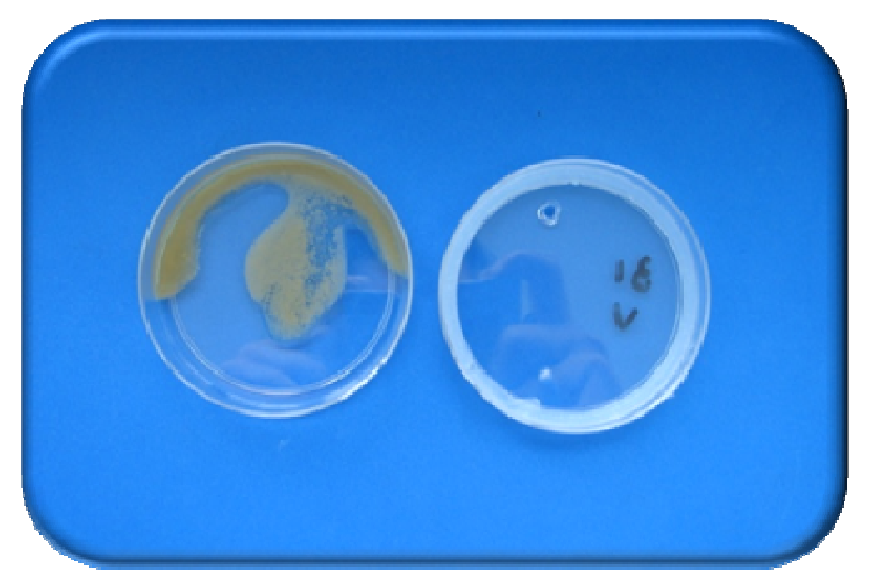

Figura 4 - Placa de Petri vaselinada. Adição das amostras de dieta. 


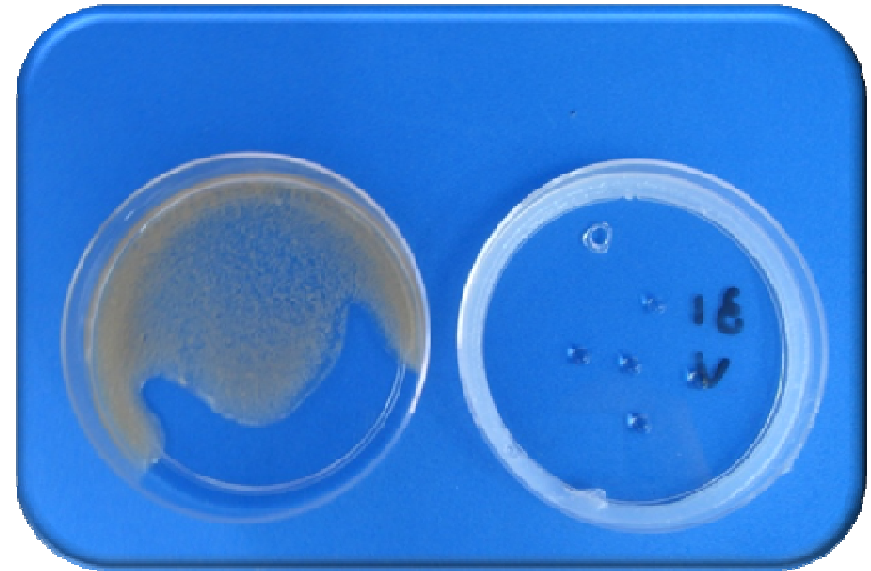

Figura 5 - Adição de $2 \mathrm{~mL}$ de água deionizada e 50 $\mu \mathrm{L}$ de $\mathrm{NaOH} 0,05 \mathrm{M}$ na tampa da placa de Petri.

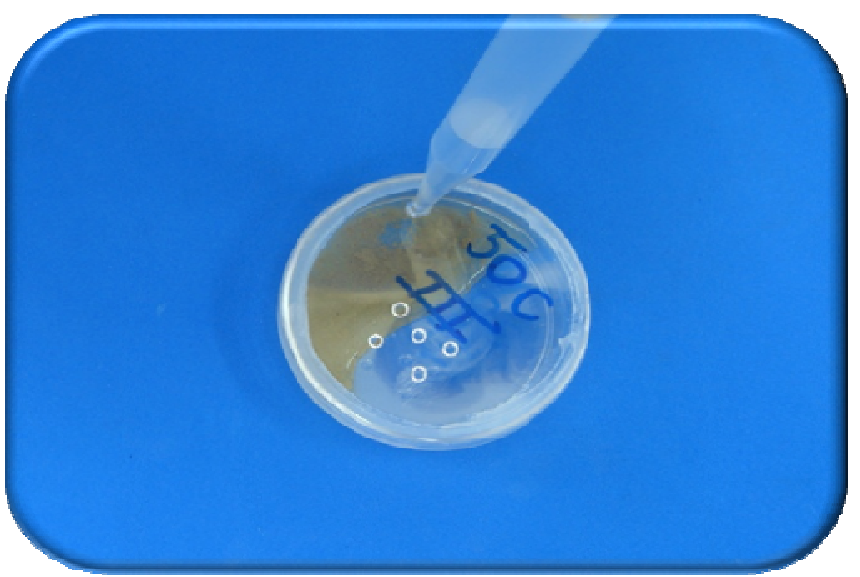

Figura 6 - Fechamento das placas e adição de $2 \mathrm{~mL}$ de HMDS

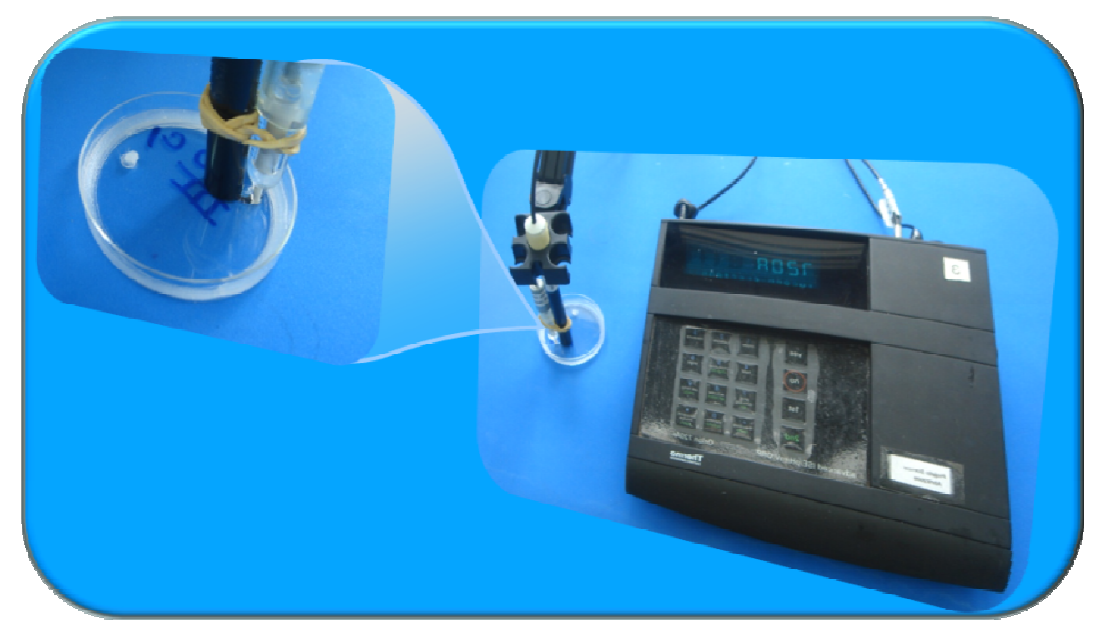

Figura 7 - Eletrodo Orion 9409 e um micro eletrodo calomelano de referência para leitura de $\mathrm{F}$ 
4.2.7 Quinta Etapa: Estimativa da ingestão de F a partir da dieta duplicada e escovação simulada.

Dentre as crianças avaliadas pelo QFA nas etapas dois (Bauru-SP) e três (Pirajuí), foram aleatoriamente selecionadas 25 e 24 crianças, respectivamente, para a realização da estimativa da ingestão de $\mathrm{F}$ a partir da dieta duplicada e escovação simulada.

Todas as crianças participantes (de ambos os gêneros) dessa etapa tinham idade entre 2 a 6 anos, eram residentes por toda a vida das respectivas comunidades e consumiam apenas água de abastecimento público.

\subsubsection{Obtenção das amostras}

\subsection{Dieta}

Foi feita em dois dias consecutivos da semana, pela técnica de prato duplicado (GUHA-CHOWDHURY; DRUMMOND; SMILLIE, 1996; ALMEIDA ET AL., 2007). As instruções dadas aos pais quanto ao método de coleta de todos os alimentos e bebidas ingeridos por seus filhos num período de 24 horas foram similares às descritas por GUHA-CHOWDHURY; DRUMMOND; SMILLIE (1996), com exceção de que toda a água consumida pelas crianças nos 3 dias avaliados foi coletada e analisada em separado, assim como outras bebidas que não a água. Portanto, para cada voluntário, houve dados de ingestão de $\mathrm{F}$ a partir da água, outras bebidas e alimentos, permitindo a avaliação do impacto individual de cada um destes itens na ingestão diária de F. A importância de se manter os hábitos dietéticos usuais em casa e de se duplicar a dieta o mais precisamente possível pela observação do que a criança realmente comia e bebia foi enfatizada. Foi pedido aos pais para removerem as partes dos alimentos que normalmente não são ingeridas, como sementes, cascas e ossos, antes de colocá-los no recipiente.

Os pais, por observação visual, estimaram a quantidade de alimentos consumidos o mais precisamente possível, usando medidas caseiras, como colher de chá, colher de sobremesa, xícara de chá, etc., para aproximar as quantidades de alimentos ingeridos. No caso das refeições, foi pedido para os pais servirem duas porções similares em dois pratos separados, esperar até que a criança terminasse a sua refeição e então adicionar ou remover porções similares no prato que haviam separado (figura 8). Além disto, os pais forneceram também uma relação contendo 
todos os alimentos e bebidas ingeridos pela criança nestas 24 horas. No dia seguinte, as amostras da dieta armazenadas em frascos plásticos foram recolhidas e pesadas. As amostras foram então homogeneizadas em liquidificador com volumes conhecidos de água deionizada, e o volume final foi medido. Posteriormente, foram armazenadas em recipientes plásticos devidamente rotulados a $-20^{\circ} \mathrm{C}$ até a análise de F.

As crianças foram pesadas em balança de precisão (Tanita, $\pm 0,1 \mathrm{Kg}$ ) a fim de que 0 valor encontrado para ingestão de $F$ pudesse ser expresso em $\mathrm{mg} / \mathrm{Kg}$ peso corporal.

A finalidade da coleta da dieta duplicada foi estimar a ingestão de $\mathrm{F}$ pelas crianças, a fim de estabelecer uma correlação com os dados de ingestão obtidos pela aplicação do QFA.

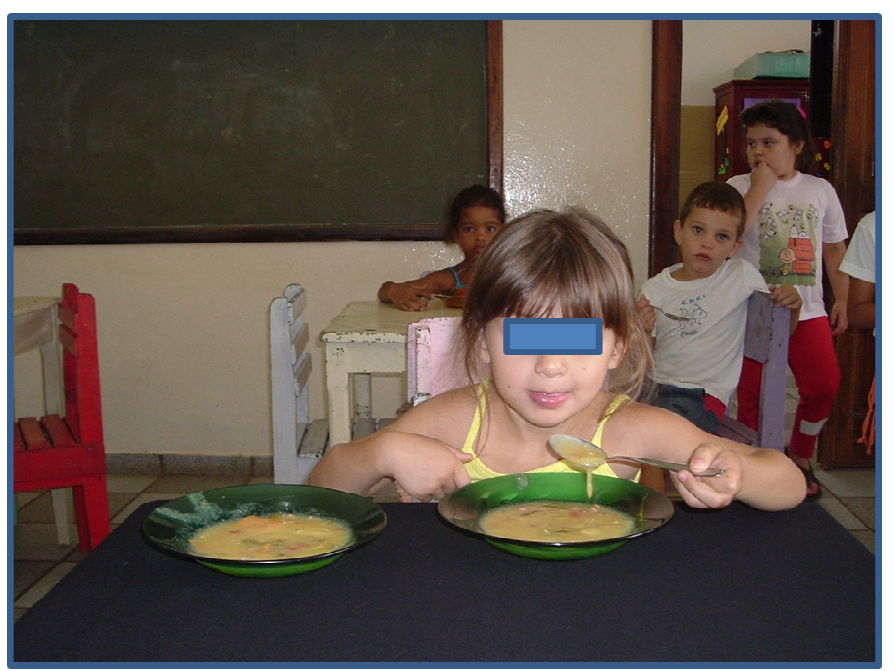

Figura 8 - Método da dieta duplicada 


\subsection{Coleta de água}

Amostras da água da torneira das casas dos voluntários foram coletadas nos mesmos dias quando as dietas duplicadas foram coletadas. As amostras de água foram colocadas em frascos plásticos e armazenadas na temperatura de $-20^{\circ} \mathrm{C}$ até a análise do $F$.

\subsection{Dentifrício}

Foi realizada conforme descrito por Guha-Chowdhurry et al. (1996), nos mesmos dias das coletas de dieta duplicada. Procurou-se simular as condições de casa (se os pais ou a criança realiza a escovação, tamanho da escova de dente usada, quanto de dentifrício é colocado na escova, se é colocado pelos pais ou pela criança, se a criança expectora após a escovação e a duração da escovação). Pediu-se aos pais para trazer a escova de dente utilizada em casa. A escova foi molhada e pesada numa balança eletrônica (AND, modelo EK-200, $\pm 0,01 \mathrm{~g}$ ). $O$ dentifrício foi colocado na escova pelo pai ou pela criança e foi medido o peso da escova mais dentifrício, dando informação da quantidade de $\mathrm{F}$ colocada na escova. A escovação foi realizada pela criança com ou sem o auxílio do pais, sob a observação do examinador. Dependendo do seu hábito, a criança expectorou ou não, ou enxaguou a boca com água deionizada. Qualquer saliva expectorada foi coletada num recipiente plástico de boca larga. A escova de dente foi lavada abundantemente com volume conhecido de água deionizada $(50 \mathrm{~mL})$ e este lavado foi acrescentado no recipiente com a saliva expectorada pela criança anteriormente (Figura 9). Também foi coletada uma amostra de dentifrício utilizado pela criança para posterior análise de $\mathrm{F}$, a fim de que pudesse fornecer informação acerca da quantidade de $\mathrm{F}$ colocada na escova. A análise do $\mathrm{F}$ forneceu informações acerca da quantidade de $\mathrm{F}$ não engolido, ou seja, a quantidade expectorada somada à quantidade de $\mathrm{F}$ deixada na escova. Foram obtidas informações quanto à freqüência de escovação, as quais foram usadas para se calcular a ingestão diária de $\mathrm{F}$ a partir do dentifrício, para cada criança. 

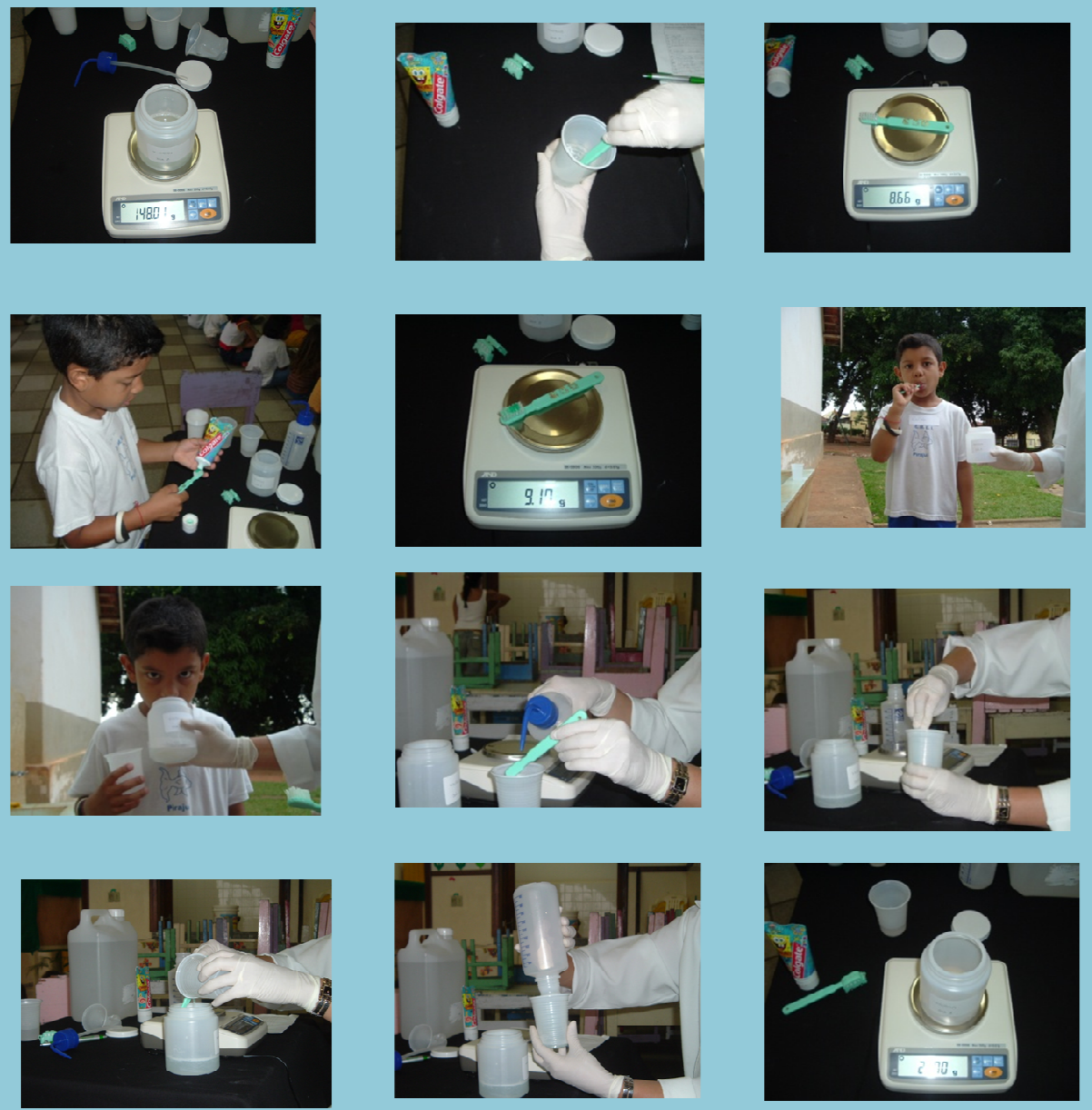

Figura 9 - Seqüência da técnica da estimativa de ingestão de F através do dentifrício

\subsection{Processamento das amostras}

Quanto às amostras de água, alíquotas de $20 \mathrm{~mL}$ em duplicata foram armazenadas em recipientes plásticos e congeladas até a análise. Já para outras bebidas e alimentos, o processamento foi realizado conforme descrito na quarta etapa. As amostras das soluções de dentifrício recuperadas foram homogeneizadas por 2 minutos. O homogenado resultante foi então centrifugado e amostras em duplicata (aproximadamente $3 \mathrm{~mL}$ ) foram congeladas $\left(-20^{\circ} \mathrm{C}\right.$ ), permanecendo assim até a análise. 


\subsection{Análise de flúor}

Para as amostras de água foi feita pelo método direto, e para as outras amostras, após difusão facilitada por HMDS, conforme descrito na quarta etapa.

\subsubsection{Aplicação do questionário para avaliação da ingestão de $F$ a partir do dentifrício}

A fim de se comparar os dados da estimativa de ingestão do $F$ a partir do dentifrício descrita acima, foi ainda aplicado às crianças participantes da quinta etapa um questionário (Anexo 4), contendo perguntas relacionadas aos hábitos de escovação dentária das crianças (SAMPAIO, 2000).

As marcas de dentifrício utilizadas apresentaram uma concentração de $\mathrm{F}$ variando entre 0 e 1500 ppm. Os valores para cada marca citada foram retirados dos rótulos. $\mathrm{Na}$ análise de ingestão de $\mathrm{F}$ para cada criança, considerou-se a concentração de F da marca citada pelos responsáveis.

Com relação à quantidade de dentifrício foram utilizadas no questionário as seguintes representações:
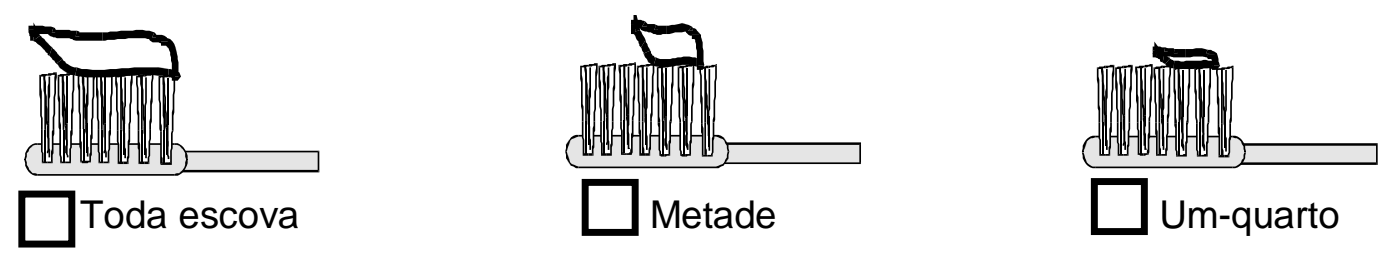

A partir delas, os responsáveis pelas crianças apontavam qual quantidade de dentifrício era a usualmente utilizada (toda escova, metade ou umquarto). Atribuiu-se, a cada quantidade demonstrada, um valor em gramas, alcançado com o auxílio de uma balança de precisão $( \pm 0,01 \mathrm{~g})$. A pesagem foi realizada em triplicata e três voluntários do laboratório colocavam o dentifrício na escova a partir do que entendiam do desenho. Foi obtida a média, chegando-se aos seguintes valores: toda a escova, 1,2 g; metade da escova, 0,6 g; e um quarto da escova, 0,3 g. De acordo com Richards e Banting (1996), crianças de 2 a 3 anos, 4 anos e 5 a 6 anos de idade ingerem em média 48, 42 e 34\% da quantidade de dentifrício colocada na escova, respectivamente, sendo esses dados utilizados para o cálculo da quantidade de $F$ ingerida a partir da escovação. 


\subsubsection{Análise estatística}

Foi utilizado o software GraphPad InStat versão 3.0 para Windows (Graph Pad Software, San Diego, EUA). Quando os dados passaram no teste de normalidade (Kolmogorov-Smirnov), a diferença entre os valores encontrados pela estimativa de ingestão de F obtida a partir do QFA e da dieta duplicada (para, água, outros líquidos, sólidos e dieta total) foi avaliada através do teste $t$ pareado. Também foi checada a existência de correlação entre os dados obtidos a partir do QFA e da dieta duplicada, utilizando regressão linear. Para os dados obtidos a partir dos questionários e da escovação simulada, os mesmos não passaram no teste de normalidade, tendo sido avaliado através do teste de Wilcoxon pareado. Foi ainda avaliada a diferença existente entre Bauru e Pirajuí através da ingestão de $\mathrm{F}$ avaliada tanto pelo QFAsq quanto pela dieta duplicada (para a subamostra de crianças), também utilizando o teste $t$ não pareado. Com relação à diferença entre os valores encontrados pela estimativa de ingestão de F obtida a partir do QFA aplicado em Bauru e Pirajuí (todas as crianças participantes), os dados não apresentaram distribuição normal, sendo avaliados através do teste não paramétrico de MannWhitney. O mesmo ocorreu para as concentrações de $\mathrm{F}$ presentes nos alimentos $\mathrm{e}$ bebidas de Bauru e Pirajuí. O nível de significância de $5 \%$ foi selecionado a priori para todos os casos. 


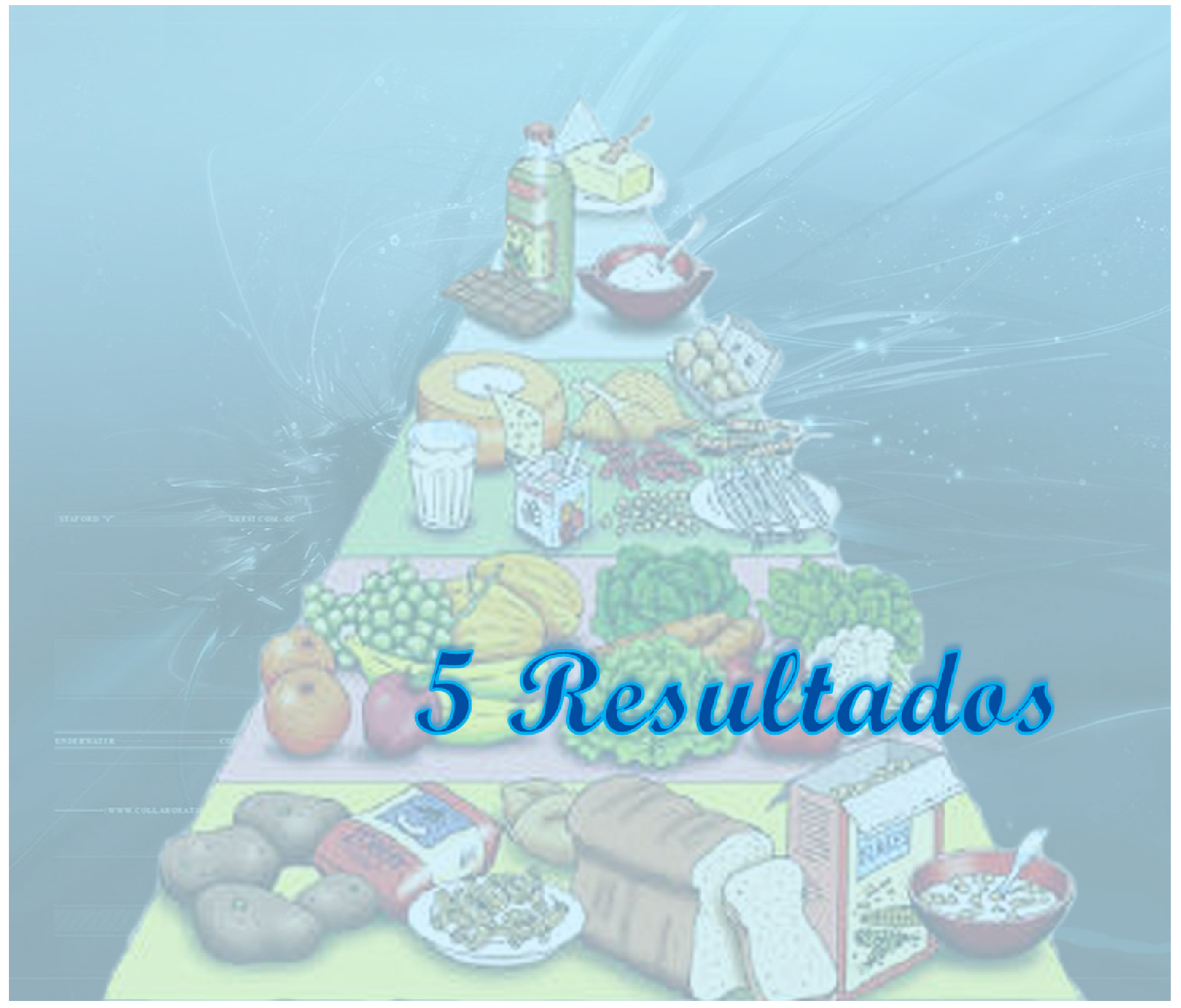




\section{Resultados}

Os resultados da primeira e segunda etapas foram descritos por Miziara (2006). A ingestão total média ( $\pm D P$ ) diária (intervalo de confiança 95\%) de $\mathrm{F}$ estimada pelo QFA para as crianças de Bauru $(n=404)$ foi de $0,463 \pm 0,224(0,441$ $0,484) \mathrm{mg}$, variando de 0,107 a 3,099.

\section{Terceira Etapa}

O QFAsq foi aplicado em 398 crianças de Pirajuí-SP. A Tabela 4 mostra o gênero, a idade, o peso corporal e a altura média $(\mathrm{cm})$ das crianças avaliadas.

Tabela 4 - Gênero (M-masculino, F-feminino), idade média (anos), peso médio (Kg) e altura média $(\mathrm{cm})$ das crianças residentes em Pirajuí-SP $(n=398)$, às quais o QFAsq foi aplicado.

\begin{tabular}{cc}
\hline VARIÁVEL & CATEGORIA \\
\hline Gênero & $198 \mathrm{M}$ \\
& $200 \mathrm{~F}$ \\
Idade média ( $\pm \mathrm{DP})$ & $4,8 \pm 0,9$ \\
Peso médio $( \pm \mathrm{DP})$ & $18,5 \pm 4,8$ \\
Altura média $( \pm \mathrm{DP})$ & $110 \pm 11,0$ \\
\hline
\end{tabular}

A Tabela 5 mostra os valores médios, desvios-padrão, mínimo, máximo e intervalo de confiança $95 \%$ da estimativa de ingestão total de $\mathrm{F}$ estimada pela aplicação do QFAsq em Bauru (Miziara, 2006) e Pirajuí. Os valores médios encontrados para Pirajuí, município não fluoretado foram significativamente menores que os obtidos previamente para Bauru, sendo a diferença encontrada entre os municípios significativa $(U=35490, p<0.0001)$. 
Tabela 5 - Média, desvio-padrão, mínimo, máximo e intervalo de confiança 95\% da estimativa de ingestão total de $\mathrm{F}$ (mg) estimada pela aplicação do QFAsq a crianças de 2-6 anos de idade, residentes em Bauru-SP e Pirajuí-SP.

\begin{tabular}{lccccc}
\hline & Média & DP & Mínimo & Máximo & IC $95 \%$ \\
\cline { 2 - 6 } Bauru & 0,463 & 0,224 & 0,107 & 3,099 & $0,441-0,484$ \\
Pirajuí & 0,323 & 0,184 & 0,057 & 2,392 & $0,305-0,341$ \\
\hline
\end{tabular}

n=404 para Bauru e 398 para Pirajuí.

A Tabela 6 mostra os alimentos do grupo sólidos mais consumidos em Pirajuí, de acordo com a freqüência do consumo. Neste grupo, o arroz foi o alimento mais consumido, sendo que 313 crianças consumiram este item 2 ou mais vezes por dia, seguido pelo feijão e pelo achocolatado em pó. $O$ item menos consumido foi 0 Neston, sendo que 365 crianças relataram nunca consumi-lo, seguido pela bolacha Danyt's e pelos espessantes.

Tabela 6 - Freqüência de consumo dos itens alimentares do grupo sólidos obtida através da aplicação do QFA sq a 398 crianças de 2-6 anos de idade, residentes em Pirajuí-SP

\begin{tabular}{|c|c|c|c|c|c|c|c|}
\hline \multirow[b]{2}{*}{ Alimentos } & \multicolumn{7}{|c|}{ Freqüência de consumo } \\
\hline & $\begin{array}{c}2 \text { ou mais } \\
\text { vezes por } \\
\text { dia }\end{array}$ & $\begin{array}{l}1 \text { vez } \\
\text { por } \\
\text { dia }\end{array}$ & $\begin{array}{c}2 \text { a } 4 \\
\text { vezes } \\
\text { por } \\
\text { semana }\end{array}$ & $\begin{array}{l}1 \text { vez por } \\
\text { semana }\end{array}$ & $\begin{array}{c}1 \text { a } 3 \\
\text { vezes } \\
\text { por mês }\end{array}$ & $\begin{array}{l}\text { Menos } \\
\text { de } 1 \text { vez } \\
\text { por mês }\end{array}$ & nunca \\
\hline Arroz & 313 & 56 & 16 & 6 & 2 & 1 & 4 \\
\hline Feijão & 242 & 84 & 30 & 9 & 4 & 1 & 28 \\
\hline Achocolatado em pó & 200 & 63 & 25 & 14 & 11 & 22 & 63 \\
\hline Açúcar & 127 & 116 & 34 & 12 & 13 & 21 & 75 \\
\hline Pão & 91 & 185 & 78 & 20 & 10 & 5 & 9 \\
\hline Margarina/manteiga & 86 & 142 & 55 & 35 & 12 & 12 & 56 \\
\hline Biscoito com recheio & 22 & 74 & 123 & 66 & 46 & 15 & 52 \\
\hline Biscoito sem recheio & 16 & 75 & 94 & 64 & 30 & 25 & 94 \\
\hline Batata cozida & 6 & 11 & 124 & 125 & 42 & 20 & 70 \\
\hline Ovo & 0 & 44 & 204 & 67 & 30 & 8 & 45 \\
\hline Batata frita & 1 & 7 & 101 & 117 & 86 & 39 & 47 \\
\hline Macarrão cozido & 0 & 5 & 102 & 201 & 55 & 6 & 29 \\
\hline Banana & 11 & 80 & 179 & 70 & 21 & 11 & 26 \\
\hline Maça/pêra & 5 & 46 & 154 & 88 & 35 & 17 & 53 \\
\hline Bife & 0 & 30 & 164 & 109 & 36 & 22 & 37 \\
\hline Carne cozida & 3 & 17 & 182 & 121 & 19 & Cc & $\begin{array}{c}35 \\
\text { ntinua }\end{array}$ \\
\hline
\end{tabular}




\begin{tabular}{|c|c|c|c|c|c|c|c|}
\hline \multirow[b]{2}{*}{ Alimentos } & \multicolumn{7}{|c|}{ Freqüência de consumo } \\
\hline & $\begin{array}{l}2 \text { ou mais } \\
\text { vezes por } \\
\text { dia }\end{array}$ & $\begin{array}{l}1 \text { vez } \\
\text { por } \\
\text { dia }\end{array}$ & $\begin{array}{c}2 \text { a } 4 \\
\text { vezes } \\
\text { por } \\
\text { semana }\end{array}$ & $\begin{array}{l}1 \text { vez por } \\
\text { semana }\end{array}$ & $\begin{array}{c}1 \text { a } 3 \\
\text { vezes } \\
\text { por mês }\end{array}$ & $\begin{array}{l}\text { Menos } \\
\text { de } 1 \text { vez } \\
\text { por mês }\end{array}$ & nunca \\
\hline Frango & 2 & 8 & 204 & 122 & 24 & 13 & 25 \\
\hline logurte de frutas & 9 & 73 & 102 & 89 & 45 & 22 & 58 \\
\hline Bolo comum & 11 & 21 & 91 & 149 & 71 & 27 & 28 \\
\hline Salgadinho/batata Chips & 3 & 37 & 114 & 80 & 95 & 34 & 35 \\
\hline Salgados & 0 & 2 & 38 & 99 & 109 & 89 & 61 \\
\hline Laranja & 5 & 46 & 154 & 80 & 30 & 22 & 71 \\
\hline Sopa com carne & 0 & 10 & 89 & 105 & 79 & 41 & 74 \\
\hline Tomate & 5 & 64 & 160 & 68 & 10 & 4 & 87 \\
\hline Danoninho/chambinho & 5 & 59 & 72 & 101 & 49 & 25 & 87 \\
\hline Presunto/mortadela & 0 & 13 & 114 & 93 & 51 & 37 & 90 \\
\hline Pizza & 0 & 2 & 26 & 87 & 93 & 99 & 91 \\
\hline Chocolate/bombom & 1 & 13 & 72 & 84 & 87 & 48 & 93 \\
\hline Sanduíche & 0 & 0 & 10 & 17 & 89 & 86 & 107 \\
\hline Molho de tomate & 2 & 5 & 72 & 170 & 23 & 15 & 111 \\
\hline Alface & 3 & 39 & 147 & 59 & 24 & 10 & 116 \\
\hline Macarrão instantâneo & 2 & 7 & 85 & 59 & 70 & 52 & 123 \\
\hline Chocolate em barra & 1 & 14 & 22 & 56 & 73 & 105 & 127 \\
\hline Sopa sem carne & 0 & 6 & 63 & 82 & 49 & 68 & 133 \\
\hline Peixe & 0 & 0 & 19 & 63 & 94 & 68 & 154 \\
\hline Queijo prato/mussarela & 0 & 25 & 62 & 51 & 40 & 58 & 156 \\
\hline Cenoura & 4 & 12 & 97 & 89 & 23 & 8 & 165 \\
\hline Mamão & 4 & 6 & 45 & 66 & 53 & 31 & 193 \\
\hline Requeijão & 31 & 29 & 39 & 19 & 27 & 47 & 206 \\
\hline Chocolate M\&Ms & 0 & 0 & 8 & 30 & 63 & 85 & 212 \\
\hline Goiaba & 1 & 8 & 24 & 26 & 54 & 59 & 226 \\
\hline Risoto/polenta & 0 & 0 & 20 & 22 & 60 & 63 & 228 \\
\hline Acelga/repolho/couve & 0 & 7 & 63 & 63 & 32 & 5 & 238 \\
\hline Mandioquinha & 1 & 3 & 27 & 69 & 29 & 15 & 254 \\
\hline Abóbora & 0 & 2 & 35 & 65 & 26 & 13 & 257 \\
\hline Cereal matinal & 2 & 8 & 21 & 46 & 32 & 25 & 264 \\
\hline Chuchu & 1 & 2 & 27 & 56 & 30 & 9 & 273 \\
\hline Bife de fígado de boi & 0 & 3 & 20 & 35 & 34 & 31 & 275 \\
\hline Espessantes & 26 & 14 & 11 & 10 & 7 & 12 & 318 \\
\hline Bolachas Danyt's & 0 & 1 & 9 & 16 & 15 & 31 & 323 \\
\hline Neston & 4 & 3 & 3 & 7 & 6 & 10 & 365 \\
\hline
\end{tabular}

A Tabela 7 mostra os itens alimentares do grupo dos outros líquidos de acordo com a freqüência de consumo em Pirajuí. Neste grupo, o item mais consumido foi o café com açúcar, sendo que 33 crianças consumiram este item 2 ou 
mais vezes por dia, seguido pelo iogurte de frutas e o leite em pó integral diluído com água de abastecimento público. O item menos consumido foi o leite em pó à base de soja diluído com água mineral, sendo que todas as crianças relataram nunca consumi-lo, seguido pelo leite em pó à base de soja diluído com água de abastecimento público.

Tabela 7 - Freqüência de consumo dos itens alimentares do grupo outros líquidos obtida através da aplicação do QFA sq a 398 crianças de 2-6 anos de idade, residentes em Pirajuí-SP.

\begin{tabular}{|c|c|c|c|c|c|c|c|}
\hline \multirow[b]{2}{*}{ Alimentos } & \multicolumn{7}{|c|}{ Freqüência de consumo } \\
\hline & $\begin{array}{c}2 \text { ou } \\
\text { mais } \\
\text { vezes } \\
\text { por dia }\end{array}$ & $\begin{array}{l}1 \mathrm{vez} \\
\text { por dia }\end{array}$ & $\begin{array}{c}2 \text { a } 4 \\
\text { vezes } \\
\text { por } \\
\text { semana }\end{array}$ & $\begin{array}{l}1 \text { vez por } \\
\text { semana }\end{array}$ & $\begin{array}{c}1 \text { a } 3 \\
\text { vezes por } \\
\text { mês }\end{array}$ & $\begin{array}{l}\text { Menos } \\
\text { de } 1 \text { vez } \\
\text { por mês }\end{array}$ & Nunca \\
\hline Café com açúcar & 33 & 72 & 57 & 30 & 25 & 33 & 148 \\
\hline logurte de frutas & 9 & 73 & 102 & 89 & 45 & 22 & 58 \\
\hline $\begin{array}{l}\text { Leite em pó integral diluído } \\
\text { com água de abastecimento } \\
\text { público }\end{array}$ & 8 & 3 & 4 & 4 & 2 & 1 & 376 \\
\hline Suco de laranja & 6 & 27 & 118 & 75 & 40 & 32 & 100 \\
\hline Suco artificial & 1 & 89 & 119 & 44 & 21 & 17 & 83 \\
\hline Suco de outras frutas & 3 & 19 & 63 & 52 & 36 & 60 & 185 \\
\hline Leite fermentado & 3 & 38 & 77 & 65 & 59 & 33 & 123 \\
\hline Toddynho & 1 & 3 & 36 & 52 & 89 & 60 & 157 \\
\hline Chá industrializado & 5 & 12 & 23 & 23 & 20 & 28 & 287 \\
\hline Gatorade & 0 & 1 & 2 & 15 & 24 & 50 & 306 \\
\hline Chá preto & 2 & 2 & 5 & 4 & 3 & 14 & 368 \\
\hline $\begin{array}{l}\text { Leite em pó à base de soja } \\
\text { diluído com água de } \\
\text { abastecimento público }\end{array}$ & 1 & 0 & 0 & 3 & 2 & 6 & 388 \\
\hline $\begin{array}{l}\text { Leite em pó diluído com água } \\
\text { mineral }\end{array}$ & 3 & 2 & 0 & 0 & 0 & 0 & 393 \\
\hline $\begin{array}{l}\text { Leite em pó à base de soja } \\
\text { diluído com água mineral }\end{array}$ & 0 & 0 & 0 & 0 & 0 & 0 & 398 \\
\hline
\end{tabular}

A Tabela 8 mostra os itens alimentares do grupo água, de acordo com a freqüência de consumo em Pirajui-SP. A água de abastecimento foi a mais consumida, sendo que 337 crianças relataram consumi-la 2 ou mais vezes ao dia, seguida pela água mineral e água de poço, com consumo de 2 ou mais vezes ao dia relatado por apenas 22 e 6 crianças, respectivamente. 
Tabela 8 - Freqüência de consumo dos itens alimentares do grupo água, obtida através da aplicação do QFA sq a 398 crianças de 2-6 anos de idade, residentes em Pirajuí-SP.

\begin{tabular}{lccccccc}
\hline \multicolumn{1}{c}{ Alimentos } & \multicolumn{7}{c}{ Freqüência de consumo } \\
\cline { 2 - 8 } & $\begin{array}{c}\text { 2 ou mais } \\
\text { vezes por } \\
\text { dia }\end{array}$ & $\begin{array}{c}\mathbf{1} \text { vez } \\
\text { por dia }\end{array}$ & $\begin{array}{c}\mathbf{2} \text { a 4 } \\
\text { vezes } \\
\text { por } \\
\text { semana }\end{array}$ & $\begin{array}{c}\mathbf{1} \text { vez por } \\
\text { semana }\end{array}$ & $\begin{array}{c}\mathbf{1} \text { a 3 } \\
\text { vezes } \\
\text { por mês }\end{array}$ & $\begin{array}{c}\text { Menos } \\
\text { de 1 } \\
\text { vez por } \\
\text { mês }\end{array}$ & Nunca \\
\hline $\begin{array}{l}\text { Água de } \\
\text { abastecimento }\end{array}$ & 337 & 28 & 2 & 0 & 0 & 0 & 31 \\
Água mineral & 22 & 1 & 1 & 0 & 0 & 0 & 374 \\
Agua de poço & 6 & 1 & 0 & 0 & 0 & 0 & 391 \\
\hline
\end{tabular}

\section{Quarta etapa}

A Tabela 9 mostra a concentração de $\mathrm{F}$ (em $\mu \mathrm{g} / 100 \mathrm{~g}$ para alimentos ou $\mu \mathrm{g} / 100 \mathrm{~mL}$ para bebidas) dos alimentos e bebidas presentes no QFA das cidades de Pirajuí-SP e Bauru-SP. A concentração média (amplitude) de $F$ encontrada nas amostras de Pirajuí e Bauru foi de 48,59 (0,25-683,50) e 54,74 (0,40-706,00) $\mu \mathrm{g} / 100$ $\mathrm{g}$ ou $\mu \mathrm{g} / 100 \mathrm{~mL}$, respectivamente, sendo que a diferença entre os municípios não foi estatisticamente significativa $(U=2152,5, p=0,684)$. 
Tabela 9- Concentração de $F$ (em $\mu \mathrm{g} / 100 \mathrm{~g}$ para alimentos ou $\mu \mathrm{g} / 100 \mathrm{~mL}$ para bebidas) dos alimentos e bebidas presentes no QFA das cidades de Pirajuí-SP e Bauru-SP.

\begin{tabular}{|c|c|c|}
\hline \multirow{2}{*}{ Alimento ou bebida ( $100 \mathrm{~g}$ ou $100 \mathrm{~mL}$ ) } & \multicolumn{2}{|c|}{$\begin{array}{l}\text { Concentração de Flúor } \\
(\mu \mathrm{g} / 100 \mathrm{~g} \text { ou } \mu \mathrm{g} / 100 \mathrm{~mL})\end{array}$} \\
\hline & Pirajuí & Bauru* $^{*}$ \\
\hline 1 - Arroz Cozido & 11,49 & 11,70 \\
\hline 2 - Batata Cozida / Purê & 9,32 & 14,20 \\
\hline 3 - Batata Frita & 6,45 & 6,36 \\
\hline 4 - Biscoitos sem Recheio Tucs ${ }^{\circledR}$ & 175,4 & 91,40 \\
\hline 5 - Biscoitos com Recheio Chocolate / Wafer & 10,69 & 3,30 \\
\hline 6 - Cereal Matinal tipo Snowflakes $\AA^{\circledR}$ & 113,70 & 164,00 \\
\hline 7 - Macarrão Cozido / ao Sugo & 12,23 & 15,54 \\
\hline 8 - Macarrão Instantâneo tipo Miojo & 32,40 & 51,10 \\
\hline 9 - Pão Francês / Forma / Bisnaguinha & 71,01 & 43,30 \\
\hline 10 - Espessantes - Maizena®, Farinha Láctea $\AA$, Mucilon $®$, Cremogema® & 55,70 & 144,30 \\
\hline $11-$ Feijão & 11,68 & 3,80 \\
\hline 12 - Abóbora & 2,50 & 3,50 \\
\hline $13-$ Alface & 0,76 & 2,50 \\
\hline 14 - Acelga / Repolho / Couve & 0,64 & 5,00 \\
\hline $15-$ Tomate & 0,66 & 2,00 \\
\hline 16 - Molho de Tomate & 2,20 & 4,20 \\
\hline $17-$ Cenoura & 0,29 & 0,70 \\
\hline 18 - Chuchu & 0,54 & 1,70 \\
\hline 19 - Mandioquinha & 6,60 & 11,90 \\
\hline 20 - Banana & 0,25 & 1,00 \\
\hline 21 - Maçã / Pêra & 0,29 & 1,80 \\
\hline 22 - Laranja & 0,70 & 0,40 \\
\hline 23 - Suco de Laranja (caldo) & 0,70 & 0,40 \\
\hline 24 - Suco de outras frutas Maracujá, Abacaxi (concentrados) & 2,70 & 0,60 \\
\hline 25 - Mamão & 0,81 & 1,10 \\
\hline 26 - Goiaba & 4,20 & 4,30 \\
\hline 27 - Bife & 4,10 & 3,00 \\
\hline 28 - Carne Cozida (Panela / Moída) & 4,06 & 3,00 \\
\hline 29 - Lingüiça / Salsicha Perdigão ${ }^{\circledR}$ & 138,87 & 65,80 \\
\hline 30 - Presunto / Mortadela Sadia $\AA^{\circledR}$ & 0,98 & 9,50 \\
\hline 31 - Bife de Fígado de Boi & 3,87 & 5,00 \\
\hline 32 - Frango (Cozido / Frito / Grelhado / Assado) & 82,00 & 96,00 \\
\hline 33 - Peixe (Cozido / Frito) & 10,60 & 9,20 \\
\hline 34 - Ovo (Frito / Cozido) Omelete (com 1 ovo) & 3,92 & 1,00 \\
\hline 35 - Leite Fluido Integral & 4,20 & 1,50 \\
\hline 36 - Leite em Pó Integral diluído com água de abastecimento público * & 58,60 & 141,49 \\
\hline 37 - Leite em Pó Integral diluído com água mineral * & 49,50 & 43,97 \\
\hline 38 - logurte de Frutas & 52,10 & 86,00 \\
\hline 39 - Danoninho $\AA /$ Chambinho $\AA$ & 54,20 & 32,30 \\
\hline 40 - Leite Fermentado (Yakult $\Theta$ / Chamyto $\circledast)$ & 25,35 & 13,20 \\
\hline 41 - Margarina / Manteiga & 26,00 & 68,20 \\
\hline 42 - Queijo Prato / Mussarela Tirolez $\circledast$ & 7,54 & 6,80 \\
\hline & & Continua \\
\hline
\end{tabular}


Continuação

\begin{tabular}{|c|c|c|}
\hline \multirow{2}{*}{ Alimento ou bebida ( $100 \mathrm{~g}$ ou $100 \mathrm{~mL}$ ) } & \multicolumn{2}{|c|}{$\begin{array}{l}\text { Concentração de Flúor } \\
(\mu \mathrm{g} / 100 \mathrm{~g} \text { ou } \mu \mathrm{g} / 100 \mathrm{~mL})\end{array}$} \\
\hline & Pirajuí & Bauru* \\
\hline 43 - Requeijão & 4,95 & 12,90 \\
\hline 44 - Açúcar & 8,60 & 20,88 \\
\hline 45 - Achocolatado em Pó (Nescau® / Toddy $\AA)$ & 19,00 & 21,70 \\
\hline 46 - Bolo Comum / Chocolate Dona Benta ${ }^{\circledR}$ & 39,08 & 25,30 \\
\hline 47 - Chocolate / Bombom & 36,75 & 11,00 \\
\hline 48 - Salgadinho / Batata Chips & 9,45 & 31,80 \\
\hline 49 - Risoto / Polenta & 3,85 & 5,60 \\
\hline 50 - Sopa com Carne (Legumes / Feijão / Macarrão) & 3,50 & 11,00 \\
\hline 51 - Sopa sem Carne (Legumes / Feijão / Macarrão) & 7,20 & 8,00 \\
\hline 52 - Salgados (Pão de Queijo) & 19,50 & 25,60 \\
\hline 53 - Pizza Mussarela Perdigão® & 19,90 & 20,90 \\
\hline 54 - Sanduíche (Misto / Hambúrguer / Simples) & 7,80 & 7,70 \\
\hline 55 - Café com Açúcar & 18,00 & 18,49 \\
\hline 56 - Refrigerante Coca-Cola ${ }^{\circledR}$ & 20,45 & 24,00 \\
\hline 57 - Suco Artificial tipo Tang ${ }^{\circledR}$ & 34,90 & 25,80 \\
\hline 58 - Chá Industrializado & 31,50 & 33,50 \\
\hline 59 - Chá Preto (Apichá) & 294,02 & 302,10 \\
\hline $\begin{array}{l}60 \text { - Leite em Pó à base de soja diluído com água de abastecimento } \\
\text { público }\end{array}$ & 160,90 & 183,70 \\
\hline 61 - Leite em Pó à base de soja diluído com água mineral ${ }^{*}$ & 154,90 & 86,18 \\
\hline 62 - Achocolatado Toddynho® & 109,37 & 118,70 \\
\hline 63 - Bebida Esportiva Gatorade® & 7,65 & 2,30 \\
\hline 64 - Cereal Neston $\AA$ & 435,80 & 616,30 \\
\hline 65 - Biscoito Danyt's® & 683,50 & 706,00 \\
\hline 66 - Chocolate em Barra & 21,70 & 12,00 \\
\hline 67 - Chocolate M\&Ms® & 43,76 & 160,00 \\
\hline
\end{tabular}

* Dados obtidos por Miziara, 2006

* $30 \mathrm{~g}$ de pó para $184 \mathrm{~mL}$ de água (Buzalaf et al,, 2001),

** Os alimentos e bebidas são mostrados na ordem em que aparecem no QFAsq,

\section{Quinta etapa}

A Tabela 10 mostra as características da população estudada, em relação ao gênero, idade média, peso médio, altura média e número de voluntários (n) por comunidade, Pode-se observar que as populações estudadas apresentam características semelhantes, 
Tabela 10 - Gênero (M-masculino, F-feminino), idade média, peso médio ( $\mathrm{Kg}$ ), altura média $(\mathrm{cm})$, e número de voluntários que participaram da estimativa de ingestão de F obtida através do QFAsq e da dieta duplicada, em Bauru-SP e Pirajuí-SP.

\begin{tabular}{lccc}
\hline & & Bauru & Pirajuí \\
\cline { 3 - 4 } \multicolumn{1}{r}{ Gênero } & $\mathrm{M}$ & 16 & 15 \\
& $\mathrm{~F}$ & 9 & 9 \\
\hline Idade média & & 5,6 & 5,3 \\
Peso médio & 19,4 & 21,6 \\
Altura média & & 111,0 & 117,0 \\
\hline $\mathbf{N}$ & 25 & 24 \\
\hline
\end{tabular}

A Tabela 11 mostra as concentrações médias $( \pm D P)$ e as variações de $F$ na água de abastecimento público coletada nas residências dos voluntários, durante os dois dias de coletas.

Tabela 11 - Médias e desvios-padrão (amplitude) das concentrações de $\mathrm{F}$ ( $\mathrm{mg} / \mathrm{L}$ ) na água de abastecimento público coletada nas residências dos voluntários residentes em Bauru e Pirajuí, durante os dois dias de coletas.

\begin{tabular}{ll}
\hline Comunidades & $\begin{array}{l}\text { [F] na água } \\
\text { (amplitude) }\end{array}$ \\
\hline Bauru & $0,70 \pm 0,07$ \\
(Água artificialmente $F, 0,6-0,8 \mathrm{mgF} / \mathrm{L})$ & $(0,55-0,79)$ \\
Pirajuí & $0,08 \pm 0,01$ \\
(não fluoretada) & $(0,10-0,06)$ \\
\hline
\end{tabular}

As Tabelas 12 e 13 relatam os valores individuais, bem como as médias da estimativa de ingestão de $\mathrm{F}(\mathrm{mg})$ através da dieta, obtida pelo método da dieta duplicada, em ambos os dias de coleta, para Bauru e Pirajuí, respectivamente. A dieta foi avaliada através da contribuição dos seus diferentes constituintes como a água, os sólidos e outros líquidos, nos dois dias de coletas. A média para os dois dias, bem como as contribuições dos diferentes constituintes da dieta para a 
ingestão de $F$, encontram-se descritas nas tabelas 14 e 15 . Entre os constituintes da dieta, a água foi o que mais contribuiu para a ingestão de F em Bauru $(42,6 \%)$ enquanto que em Pirajuí, a maior contribuição foi dada pelos alimentos sólidos $(44,8 \%)$.

Tabela 12 - Estimativa da ingestão de $\mathrm{F}(\mathrm{mg})$ das crianças de Bauru (água artificialmente fluoretada), Brasil, através da água, sólidos e outros líquidos, obtida a partir do método da dieta duplicada, nos dois dias de coletas.

\begin{tabular}{ccccccc}
\hline \multirow{2}{*}{ Voluntários } & \multicolumn{2}{c}{ Água } & \multicolumn{2}{c}{ Sólidos } & \multicolumn{2}{c}{ Outros líquidos } \\
& Dia 1 & Dia 2 & Dia 1 & Dia 2 & Dia 1 & Dia 2 \\
\hline $\mathbf{1}$ & 0,37 & 0,37 & 0,214 & 0,119 & 0,114 & 0,052 \\
$\mathbf{2}$ & 0,66 & 0,46 & 0,102 & 0,450 & 0,003 & 0,052 \\
$\mathbf{3}$ & 0,60 & 0,34 & 0,365 & 0,152 & 0,003 & 0,294 \\
$\mathbf{4}$ & 0,29 & 0,17 & 0,519 & 0,330 & 0,032 & 0,133 \\
$\mathbf{5}$ & 0,37 & 0,13 & 0,304 & 0,112 & 0,078 & 0,002 \\
$\mathbf{6}$ & 0,33 & 0,43 & 0,182 & 0,266 & 0,055 & 0,052 \\
$\mathbf{7}$ & 0,44 & 0,35 & 0,162 & 0,198 & 0,219 & 0,209 \\
$\mathbf{8}$ & 0,41 & 0,40 & 0,372 & 0,360 & 0,106 & 0,160 \\
$\mathbf{9}$ & 0,38 & 0,16 & 0,156 & 0,261 & 0,229 & 0,300 \\
$\mathbf{1 0}$ & 0,50 & 0,31 & 0,439 & 0,345 & 0,176 & 0,279 \\
$\mathbf{1 1}$ & 0,43 & 0,46 & 0,384 & 0,290 & 0,139 & 0,106 \\
$\mathbf{1 2}$ & 0,29 & 0,23 & 0,386 & 0,185 & 0,264 & 0,267 \\
$\mathbf{1 3}$ & 0,17 & 0,11 & 0,128 & 0,207 & 0,024 & 0,014 \\
$\mathbf{1 4}$ & 0,31 & 0,06 & 0,378 & 0,451 & 0,203 & 0,129 \\
$\mathbf{1 5}$ & 0,20 & 0,32 & 0,284 & 0,367 & 0,245 & 0,313 \\
$\mathbf{1 6}$ & 0,21 & 0,20 & 0,992 & 0,067 & 0,114 & 0,137 \\
$\mathbf{1 7}$ & 0,23 & 0,32 & 0,368 & 0,401 & 0,130 & 0,244 \\
$\mathbf{1 8}$ & 0,22 & 0,26 & 0,392 & 0,177 & 0,060 & 0,353 \\
$\mathbf{1 9}$ & 0,66 & 0,68 & 0,386 & 0,308 & 0,037 & 0,053 \\
$\mathbf{2 0}$ & 0,20 & 0,10 & 0,647 & 0,266 & 0,052 & 0,049 \\
$\mathbf{2 1}$ & 0,33 & 0,35 & 0,375 & 0,185 & 0,165 & 0,103 \\
$\mathbf{2 2}$ & 0,37 & 0,37 & 0,350 & 0,349 & 0,017 & 0,257 \\
$\mathbf{2 3}$ & 0,36 & 0,23 & 0,308 & 0,315 & 0,028 & 0,326 \\
$\mathbf{2 4}$ & 0,64 & 0,45 & 0,251 & 0,240 & 0,004 & 0,009 \\
$\mathbf{2 5}$ & 0,43 & 0,40 & 0,676 & 0,833 & 0,170 & 0,156 \\
\hline Média & $\mathbf{0 , 3 8}$ & $\mathbf{0 , 3 1}$ & $\mathbf{0 , 3 6 5}$ & $\mathbf{0 , 2 8 9}$ & $\mathbf{0 , 1 0 7}$ & $\mathbf{0 , 1 6 2}$ \\
$\mathbf{D P}$ & $\mathbf{0 , 1 5}$ & $\mathbf{0 , 1 4}$ & $\mathbf{0 , 1 9 3}$ & $\mathbf{0 , 1 5 3}$ & $\mathbf{0 , 0 8 3}$ & $\mathbf{0 , 1 1 3}$ \\
\hline & & & & & & \\
\hline
\end{tabular}


Tabela 13 - Estimativa da ingestão de $F(\mathrm{mg})$ das crianças de Pirajuí (não-fluoretada), através da água, sólidos e outros líquidos, obtida a partir do método da dieta duplicada, nos dois dias de coletas.

\begin{tabular}{ccccccc}
\hline \multirow{2}{*}{ Voluntários } & \multicolumn{2}{c}{ Água } & \multicolumn{2}{c}{ Sólidos } & \multicolumn{2}{c}{ Outros líquidos } \\
& Dia 1 & Dia 2 & Dia 1 & Dia 2 & Dia 1 & Dia 2 \\
\hline $\mathbf{1}$ & 0,02 & 0,02 & 0,063 & 0,048 & 0,062 & 0,026 \\
$\mathbf{2}$ & 0,08 & 0,11 & 0,058 & 0,048 & 0,022 & 0,008 \\
$\mathbf{3}$ & 0,06 & 0,07 & 0,108 & 0,094 & 0,008 & 0,012 \\
$\mathbf{4}$ & 0,03 & 0,04 & 0,200 & 0,129 & 0,006 & 0,007 \\
$\mathbf{5}$ & 0,09 & 0,07 & 0,112 & 0,160 & 0,032 & 0,078 \\
$\mathbf{6}$ & 0,04 & 0,05 & 0,026 & 0,030 & 0,012 & 0,011 \\
$\mathbf{7}$ & 0,07 & 0,07 & 0,163 & 0,035 & 0,018 & 0,009 \\
$\mathbf{8}$ & 0,04 & 0,03 & 0,040 & 0,014 & 0,016 & 0,009 \\
$\mathbf{9}$ & 0,04 & 0,02 & 0,032 & 0,049 & 0,024 & 0,066 \\
$\mathbf{1 0}$ & 0,08 & 0,06 & 0,032 & 0,010 & 0,031 & 0,022 \\
$\mathbf{1 1}$ & 0,06 & 0,06 & 0,037 & 0,021 & 0,022 & 0,017 \\
$\mathbf{1 2}$ & 0,04 & 0,04 & 0,069 & 0,030 & 0,018 & 0,022 \\
$\mathbf{1 3}$ & 0,05 & 0,08 & 0,042 & 0,029 & 0,062 & 0,006 \\
$\mathbf{1 4}$ & 0,07 & 0,03 & 0,066 & 0,011 & 0,036 & 0,033 \\
$\mathbf{1 5}$ & 0,05 & 0,05 & 0,031 & 0,063 & 0,019 & 0,021 \\
$\mathbf{1 6}$ & 0,04 & 0,04 & 0,040 & 0,063 & 0,019 & 0,019 \\
$\mathbf{1 7}$ & 0,04 & 0,02 & 0,062 & 0,028 & 0,028 & 0,016 \\
$\mathbf{1 8}$ & 0,04 & 0,05 & 0,008 & 0,010 & 0,073 & 0,049 \\
$\mathbf{1 9}$ & 0,05 & 0,04 & 0,106 & 0,131 & 0,079 & 0,080 \\
$\mathbf{2 0}$ & 0,02 & 0,02 & 0,114 & 0,058 & 0,058 & 0,012 \\
$\mathbf{2 1}$ & 0,03 & 0,04 & 0,172 & 0,047 & 0,020 & 0,013 \\
$\mathbf{2 2}$ & 0,09 & 0,06 & 0,049 & 0,041 & 0,077 & 0,017 \\
$\mathbf{2 3}$ & 0,08 & 0,06 & 0,079 & 0,122 & $\star \star$ & 0,038 \\
$\mathbf{2 4}$ & 0,03 & 0,03 & 0,049 & 0,052 & 0,027 & 0,012 \\
\hline Média & $\mathbf{0 , 0 5}$ & $\mathbf{0 , 0 5}$ & $\mathbf{0 , 0 7 3}$ & $\mathbf{0 , 0 5 5}$ & $\mathbf{0 , 0 3 3}$ & $\mathbf{0 , 0 2 5}$ \\
DP & $\mathbf{0 , 0 2}$ & $\mathbf{0 , 0 2}$ & $\mathbf{0 , 0 5 0}$ & $\mathbf{0 , 0 4 2}$ & $\mathbf{0 , 0 2 3}$ & $\mathbf{0 , 0 2 2}$ \\
\hline & & & & & & \\
\hline
\end{tabular}


Tabela 14 - Estimativa de ingestão de $F(\mathrm{mg})$ das crianças de Bauru (água artificialmente fluoretada). Brasil, através da água, sólidos e outros líquidos, obtida a partir do método da dieta duplicada, e a contribuição dos diferentes constituintes da dieta para a ingestão de F.

\begin{tabular}{cccc}
\hline Voluntários & Água & Sólidos & $\begin{array}{c}\text { Outros } \\
\text { Líquidos }\end{array}$ \\
\hline $\mathbf{1}$ & 0,370 & 0,167 & 0,083 \\
$\mathbf{2}$ & 0,560 & 0,276 & 0,028 \\
$\mathbf{3}$ & 0,470 & 0,259 & 0,149 \\
$\mathbf{4}$ & 0,230 & 0,425 & 0,083 \\
$\mathbf{5}$ & 0,250 & 0,208 & 0,040 \\
$\mathbf{6}$ & 0,380 & 0,224 & 0,054 \\
$\mathbf{7}$ & 0,400 & 0,180 & 0,214 \\
$\mathbf{8}$ & 0,410 & 0,366 & 0,133 \\
$\mathbf{9}$ & 0,270 & 0,209 & 0,265 \\
$\mathbf{1 0}$ & 0,410 & 0,392 & 0,228 \\
$\mathbf{1 1}$ & 0,450 & 0,337 & 0,123 \\
$\mathbf{1 2}$ & 0,260 & 0,286 & 0,266 \\
$\mathbf{1 3}$ & 0,140 & 0,168 & 0,019 \\
$\mathbf{1 4}$ & 0,190 & 0,415 & 0,166 \\
$\mathbf{1 5}$ & 0,260 & 0,326 & 0,279 \\
$\mathbf{1 6}$ & 0,210 & 0,530 & 0,126 \\
$\mathbf{1 7}$ & 0,280 & 0,385 & 0,187 \\
$\mathbf{1 8}$ & 0,240 & 0,285 & 0,207 \\
$\mathbf{1 9}$ & 0,670 & 0,347 & 0,045 \\
$\mathbf{2 0}$ & 0,150 & 0,457 & 0,051 \\
$\mathbf{2 1}$ & 0,340 & 0,280 & 0,134 \\
$\mathbf{2 2}$ & 0,370 & 0,350 & 0,137 \\
$\mathbf{2 3}$ & 0,300 & 0,312 & 0,177 \\
$\mathbf{2 4}$ & 0,550 & 0,246 & 0,007 \\
$\mathbf{2 5}$ & 0,420 & 0,755 & 0,163 \\
\hline Média & $\mathbf{0 , 3 4 0}$ & $\mathbf{0 , 3 2 7}$ & $\mathbf{0 , 1 3 5}$ \\
$\mathbf{D P}$ & $\mathbf{0 , 1 3 0}$ & $\mathbf{0 , 1 2 9}$ & $\mathbf{0 , 0 8 1}$ \\
\hline \% do total & $\mathbf{4 2 , 6 \%}$ & $\mathbf{4 0 , 7 \%}$ & $\mathbf{1 6 , 7 \%}$ \\
\hline & & & \\
\hline & &
\end{tabular}

As médias referem-se às coletas dos dois dias consecutivos. 
Tabela 15 - Estimativa de ingestão de $F(\mathrm{mg})$ das crianças de Pirajuí (não fluoretada), através da água, sólidos e outros líquidos, obtida a partir do método da dieta duplicada, e a contribuição dos diferentes constituintes da dieta para a ingestão total de $\mathrm{F}$ através da dieta.

\begin{tabular}{|c|c|c|c|}
\hline Voluntários & Água & Sólidos & $\begin{array}{l}\text { Outros } \\
\text { Líquidos }\end{array}$ \\
\hline 1 & 0,020 & 0,056 & 0,044 \\
\hline 2 & 0,100 & 0,053 & 0,015 \\
\hline 3 & 0,060 & 0,101 & 0,010 \\
\hline 4 & 0,040 & 0,165 & 0,006 \\
\hline 5 & 0,080 & 0,136 & 0,055 \\
\hline 6 & 0,040 & 0,028 & 0,011 \\
\hline 7 & 0,070 & 0,099 & 0,013 \\
\hline 8 & 0,040 & 0,027 & 0,013 \\
\hline 9 & 0,030 & 0,041 & 0,045 \\
\hline 10 & 0,070 & 0,021 & 0,026 \\
\hline 11 & 0,060 & 0,029 & 0,019 \\
\hline 12 & 0,040 & 0,050 & 0,020 \\
\hline 13 & 0,070 & 0,036 & 0,034 \\
\hline 14 & 0,050 & 0,039 & 0,034 \\
\hline 15 & 0,050 & 0,047 & 0,020 \\
\hline 16 & 0,040 & 0,052 & 0,019 \\
\hline 17 & 0,030 & 0,045 & 0,022 \\
\hline 18 & 0,050 & 0,009 & 0,061 \\
\hline 19 & 0,040 & 0,119 & 0,080 \\
\hline 20 & 0,020 & 0,086 & 0,035 \\
\hline 21 & 0,030 & 0,110 & 0,017 \\
\hline 22 & 0,080 & 0,045 & 0,047 \\
\hline 23 & 0,070 & 0,101 & 0,038 \\
\hline 24 & 0,030 & 0,051 & 0,020 \\
\hline Média & 0,050 & 0,064 & 0,029 \\
\hline DP & 0,020 & 0,040 & 0,018 \\
\hline$\%$ do total & $34,9 \%$ & $44,8 \%$ & $20,3 \%$ \\
\hline
\end{tabular}

As médias referem-se às coletas dos dois dias consecutivos.

As Tabelas 16 e 17 relatam os valores individuais, bem como as médias da estimativa de ingestão de $\mathrm{F}(\mathrm{mg})$ através da dieta, obtidos através do QFAsq, para Bauru e Pirajuí, respectivamente, A dieta foi avaliada através da contribuição dos seus diferentes constituintes (água, sólidos e outros líquidos), À semelhança do perfil relatado para os dados obtidos a partir da dieta duplicada, a água foi o que mais contribuiu para a ingestão de $\mathrm{F}$ a partir da dieta em Bauru $(50,0 \%)$ enquanto que em Pirajuí, a maior contribuição foi dada pelos alimentos sólidos (55,9\%), 
Tabela 16 - Estimativa de ingestão de F (mg) das crianças de Bauru ( água artificialmente fluoretada), através da água, sólidos e outros líquidos, e a contribuição dos diferentes constituintes da dieta para a ingestão total de $F$, estimada através do QFAsq.

\begin{tabular}{cccc}
\hline Voluntários & Água & Sólidos & $\begin{array}{c}\text { Outros } \\
\text { Líquidos }\end{array}$ \\
\hline $\mathbf{1}$ & 0,210 & 0,053 & 0,046 \\
$\mathbf{2}$ & 0,210 & 0,089 & 0,095 \\
$\mathbf{3}$ & 0,210 & 0,074 & 0,025 \\
$\mathbf{4}$ & 0,210 & 0,075 & 0,023 \\
$\mathbf{5}$ & 0,210 & 0,110 & 0,091 \\
$\mathbf{6}$ & 0,210 & 0,100 & 0,052 \\
$\mathbf{7}$ & 0,210 & 0,161 & 0,042 \\
$\mathbf{8}$ & 0,210 & 0,070 & 0,078 \\
$\mathbf{9}$ & 0,210 & 0,059 & 0,135 \\
$\mathbf{1 0}$ & 0,210 & 0,157 & 0,091 \\
$\mathbf{1 1}$ & 0,210 & 0,154 & 0,067 \\
$\mathbf{1 2}$ & 0,210 & 0,097 & 0,070 \\
$\mathbf{1 3}$ & 0,210 & 0,114 & 0,248 \\
$\mathbf{1 4}$ & 0,210 & 0,163 & 0,052 \\
$\mathbf{1 5}$ & 0,210 & 0,105 & 0,169 \\
$\mathbf{1 6}$ & 0,210 & 0,135 & 0,327 \\
$\mathbf{1 7}$ & 0,210 & 0,127 & 0,249 \\
$\mathbf{1 8}$ & 0,210 & 0,096 & 0,125 \\
$\mathbf{1 9}$ & 0,210 & 0,093 & 0,120 \\
$\mathbf{2 0}$ & 0,210 & 0,115 & 0,074 \\
$\mathbf{2 1}$ & 0,210 & 0,127 & 0,049 \\
$\mathbf{2 2}$ & 0,210 & 0,109 & 0,097 \\
$\mathbf{2 3}$ & 0,210 & 0,104 & 0,149 \\
$\mathbf{2 4}$ & 0,210 & 0,066 & 0,039 \\
$\mathbf{2 5}$ & 0,210 & 0,151 & 0,041 \\
\hline Média & $\mathbf{0 , 2 1 0}$ & $\mathbf{0 , 1 0 8}$ & $\mathbf{0 , 1 0 2}$ \\
$\mathbf{D P}$ & 0 & 0,033 & 0,077 \\
\hline do total & $\mathbf{5 0 , 0 \%}$ & $\mathbf{2 5 , 7 \%}$ & $\mathbf{2 4 , 3 \%}$ \\
\hline & & & \\
\hline
\end{tabular}


Tabela 17 - Estimativa de ingestão de $F(\mathrm{mg})$ das crianças de Pirajuí (não fluoretada), através da água, sólidos e outros líquidos e a contribuição dos diferentes constituintes da dieta para a ingestão total de F através do QFA.

\begin{tabular}{cccc}
\hline Voluntários & Água & Sólidos & $\begin{array}{c}\text { Outros } \\
\text { Líquidos }\end{array}$ \\
\hline $\mathbf{1}$ & 0,024 & 0,103 & 0,031 \\
$\mathbf{2}$ & 0,024 & 0,140 & 0,030 \\
$\mathbf{3}$ & 0,012 & 0,199 & 0,146 \\
$\mathbf{4}$ & 0,024 & 0,197 & 0,048 \\
$\mathbf{5}$ & 0,024 & 0,138 & 0,046 \\
$\mathbf{6}$ & 0,024 & 0,089 & 0,073 \\
$\mathbf{7}$ & 0,024 & 0,117 & 0,120 \\
$\mathbf{8}$ & 0,024 & 0,069 & 0,048 \\
$\mathbf{9}$ & 0,012 & 0,060 & 0,063 \\
$\mathbf{1 0}$ & 0,024 & 0,123 & 0,135 \\
$\mathbf{1 1}$ & 0,024 & 0,075 & 0,033 \\
$\mathbf{1 2}$ & 0,024 & 0,116 & 0,235 \\
$\mathbf{1 3}$ & 0,024 & 0,110 & 0,051 \\
$\mathbf{1 4}$ & 0,024 & 0,117 & 0,037 \\
$\mathbf{1 5}$ & 0,024 & 0,193 & 0,067 \\
$\mathbf{1 6}$ & 0,024 & 0,170 & 0,067 \\
$\mathbf{1 7}$ & 0,024 & 0,147 & 0,060 \\
$\mathbf{1 8}$ & 0,012 & 0,095 & 0,084 \\
$\mathbf{1 9}$ & 0,024 & 0,116 & 0,081 \\
$\mathbf{2 0}$ & 0,024 & 0,140 & 0,096 \\
$\mathbf{2 1}$ & 0,024 & 0,133 & 0,062 \\
$\mathbf{2 2}$ & 0,024 & 0,195 & 0,143 \\
$\mathbf{2 3}$ & 0,024 & 0,134 & 0,078 \\
$\mathbf{2 4}$ & $\mathbf{0 , 0 2 4}$ & 0,065 & 0,023 \\
\hline Média & $\mathbf{0 , 0 2 3}$ & $\mathbf{0 , 1 2 7}$ & $\mathbf{0 , 0 7 7}$ \\
$\mathbf{D P}$ & $\mathbf{0 , 0 4 0}$ & $\mathbf{0 , 0 4 2}$ & $\mathbf{0 , 0 4 9}$ \\
\hline of total & $\mathbf{1 0 , 1 \%}$ & $\mathbf{5 5 , 9} \%$ & $\mathbf{3 4 , 0} \%$ \\
\hline
\end{tabular}

A Tabela 18 mostra os valores médios $( \pm D P)$ obtidos para a ingestão de $F$ estimada a partir da dieta duplicada e do QFAsq, para ambos os municípios, considerando-se a dieta total e os diferentes componentes avaliados. Para o município de Bauru, o teste t pareado encontrou uma diferença significativa entre a estimativa de ingestão de F obtida a partir do QFAsq e da dieta duplicada para a água, sólidos e dieta total $(p<0,01)$, mas não para outros líquidos $(n, s$,$) . Já para Pirajuí, foi encontrada$ uma diferença significativa entre os valores obtidos pelos dois métodos tanto para a dieta total como para os seus componentes $(p<0,01)$, Considerando-se a dieta total, tanto o QFAsq quanto o método da dieta duplicada foram capazes de detectar diferenças significativas entre a ingestão de $F$ no município fluoretado (Bauru) e não 
fluoretado (Pirajuí), ( $t=8,44, \quad p<0,0001$ e $t=16,54, \quad p<0,0001$ para QFAsq e dieta duplicada, respectivamente).

Tabela 18 - Média ( \pm DP) da ingestão de F estimada a partir do QFAsq e da dieta duplicada, para Bauru e Pirajuí, considerando-se a dieta total e os diferentes componentes avaliados.

\begin{tabular}{lcccccc}
\hline \multicolumn{1}{c}{$\begin{array}{c}\text { Dieta e } \\
\text { componentes }\end{array}$} & QFAsq & Dieta Duplicada & $\mathbf{t} / \mathbf{p}$ & QFAsq & Dieta Duplicada & t/ $\mathbf{p}$ \\
\hline Água & $0,210 \pm 0,000$ & $0,340 \pm 0,130$ & $5,02 /<0,01$ & $0,023 \pm 0,040$ & $0,050 \pm 0,020$ & $6,49 /<0,01$ \\
Sólidos & $0,108 \pm 0,033$ & $0,327 \pm 0,129$ & $9,21 /<0,01$ & $0,127 \pm 0,042$ & $0,064 \pm 0,040$ & $7,12 /<0,01$ \\
Outros líquidos & $0,102 \pm 0,077$ & $0,135 \pm 0,081$ & $1,52 / 0,14$ & $0,077 \pm 0,049$ & $0,029 \pm 0,018$ & $4,47 /<0,01$ \\
Dieta total & $0,420 \pm 0,087$ & $0,805 \pm 0,190$ & $9,07 /<0,01$ & $0,227 \pm 0,072$ & $0,144 \pm 0,050$ & $5,27 /<0,01$ \\
\hline
\end{tabular}

* Tanto o QFAsq quanto o método da dieta duplicada encontraram diferenças significativas entres municípios fluoretado e não fluoretado (teste $t, p<0,0001$ ).

A Tabela 19 mostra as correlações entre os dados de ingestão de $\mathrm{F}$ a partir da dieta obtidos através do QFAsq e dieta duplicada, tanto para a dieta total quanto para seus componentes. Somente foi obtida uma correlação significativa no caso dos sólidos, para ambos os municípios $(p<0,05)$, Em todos as outras situações, não foram obtidas correlações significativas (n,s,),

Tabela 19 - Correlação entre os dados de ingestão de F a partir da dieta obtidos através do QFAsq e da dieta duplicada.

\begin{tabular}{lcc}
\hline \multirow{2}{*}{ Dieta e componentes } & \multicolumn{2}{c}{ Correlação entre QFAsq e dieta duplicada } \\
\cline { 2 - 3 } & \multicolumn{1}{c}{ Bauru } & Pirajuí \\
\hline Água & $\mathrm{r}=0,000, \mathrm{p}=1$ & $\mathrm{r}=0,069, \mathrm{p}=0,748$ \\
Sólidos & $\mathrm{r}=0,422, \mathrm{p}=0,036$ & $\mathrm{r}=0,456, \mathrm{p}=0,025$ \\
Outros líquidos & $\mathrm{r}=0,095, \mathrm{p}=0,653$ & $\mathrm{r}=-0,031, \mathrm{p}=0,887$ \\
Dieta total & $\mathrm{r}=-0,04, \mathrm{p}=0,832$ & $\mathrm{r}=0,259, \mathrm{p}=0,222$ \\
\hline
\end{tabular}

A Tabela 20 mostra os dados de estimativa de ingestão de $\mathrm{F}$ a partir do dentifrício, obtidos pela aplicação do questionário e da escovação simulada. Para a comunidade de Bauru, o valor médio encontrado quando se aplicou o questionário foi de 0,718 $\pm 0,564 \mathrm{mg}$, que não diferiu significativamente do valor obtido através da 
escovação simulada $(0,544 \pm 0,593)$ (teste de Wilcoxon pareado, $W=103,0, p=0,173$ ). Não houve correlação entre os dados obtidos pelas estimativas feitas pelos diferentes métodos avaliados $(r=0,064, p=0,763)$, Já para a comunidade de Pirajuí, o valor médio encontrado quando se aplicou o questionário foi de $0,490 \pm 0,261 \mathrm{mg}$, que foi significativamente menor quando comparado ao valor obtido através da escovação simulada $(1,034 \pm 0,800)$ (teste $t$ pareado, $t=2,894, p=0,008$ ). À semelhança do encontrado para Bauru, não houve correlação entre os dados obtidos pelas estimativas feitas pelos diferentes métodos avaliados $(r=-0,276, p=0,192)$.

Tabela 20 - Estimativa de ingestão de F a partir do dentifrício (mg) obtida pela aplicação do questionário e da escovação simulada.

\begin{tabular}{|c|c|c|c|c|}
\hline \multirow[b]{2}{*}{ Voluntários } & \multicolumn{2}{|c|}{ Bauru } & \multicolumn{2}{|c|}{ Pirajuí } \\
\hline & QFA & $\begin{array}{c}\text { Escovação } \\
\text { simulada }\end{array}$ & QFA & $\begin{array}{l}\text { Escovação } \\
\text { simulada }\end{array}$ \\
\hline 1 & 0,459 & 0,178 & 1,224 & 0,219 \\
\hline 2 & 1,836 & 0,493 & 0,612 & 0,544 \\
\hline 3 & 0,337 & 0,854 & 0,459 & 2,340 \\
\hline 4 & 0,918 & 0,141 & 0,306 & 2,523 \\
\hline 5 & 0,756 & 1,517 & 0,459 & 1,558 \\
\hline 6 & 0,337 & 0,444 & 0,612 & 1,138 \\
\hline 7 & 0,756 & 0,337 & 0,277 & 1,082 \\
\hline 8 & 0,459 & 0,656 & 0,337 & 0,108 \\
\hline 9 & 0,277 & 0,320 & 0,918 & 0,770 \\
\hline 10 & 0,449 & 0,368 & 0,306 & 2,229 \\
\hline 11 & 0,554 & 0,405 & 0,459 & 0,000 \\
\hline 12 & 0,950 & 0,426 & 0,459 & 2,174 \\
\hline 13 & 0,918 & 0,311 & 0,673 & 0,441 \\
\hline 14 & 0,277 & 1,788 & 0,378 & 0,479 \\
\hline 15 & 0,306 & 0,074 & 0,612 & 2,186 \\
\hline 16 & 1,346 & 0,412 & 0,378 & 0,942 \\
\hline 17 & 1,109 & 0,127 & 0,306 & 0,795 \\
\hline 18 & 2,592 & 0,351 & 0,306 & 0,106 \\
\hline 19 & 0,449 & 0,415 & 0,306 & 0,631 \\
\hline 20 & 0,224 & 0,017 & 0,306 & 0,991 \\
\hline 21 & 1,224 & 2,500 & 1,134 & 0,155 \\
\hline 22 & 0,306 & 0,061 & 0,378 & 1,802 \\
\hline 23 & 0,378 & 0,402 & 0,306 & 0,409 \\
\hline 24 & 0,432 & 0,000 & 0,459 & 1,203 \\
\hline 25 & 0,306 & 0,997 & * & * \\
\hline Média & 0,718 & 0,544 & 0,491 & 1,034 \\
\hline DP & 0,564 & 0,593 & 0,261 & 0,800 \\
\hline
\end{tabular}

*Em Pirajuí não tem o voluntário n 25,

Quando os dados de estimativa de ingestão de F obtidos para Bauru e Pirajuí foram compilados, os valores médios obtidos para o questionário e a escovação 
simulada foram de $0,611 \pm 0,452 \mathrm{mg}$ e $0,784 \pm 0,737 \mathrm{mg}$, respectivamente, não havendo diferença significativa entre os métodos (Wilcoxon pareado, $W=-185,0, p=0,360$ ), Entretanto, também não foi observada correlação entre os mesmos $(r=-0,133$, $\mathrm{p}=0,361)$.

Os valores individuais, médias e desvios-padrão (amplitude) da ingestão total diária de $\mathrm{F}$ ( $\mathrm{mg} / \mathrm{Kg}$ de peso corporal), estimados através do QFAsq associado ao questionário para ingestão de dentifrício e da dieta duplicada associada à escovação simulada, são reportados na Tabela 21. Através da utilização dos questionários, foi possível detectar diferença significativa na ingestão total de $\mathrm{F}$ entre Bauru (fluoretada) e Pirajuí (não fluoretada (t com correção de Welch=2,869, $p=0,0074$ ), Entretanto, utilizando-se o método da dieta duplicada associado à escovação simulada, não foi possível detectar diferença significativa entre os municípios ( $t=1,040, p=0,304)$.

Não houve correlação entre as estimativas de ingestão total de $F(\mathrm{mg} / \mathrm{Kg}$ de peso corporal) quando se compararam o método de questionários com o da dieta duplicada associada à escovação simulada $(r=0,151$, e $p=0,471 ; r=-0,182$, $p=0,396 ; r=0,104, p=0,476$ para Bauru, Pirajuí e ambos os municípios, respectivamente). 
Tabela 21 - Valores individuais, médias e desvios-padrão (amplitude) da ingestão total diária de $\mathrm{F}$ ( $\mathrm{mg} / \mathrm{Kg}$ de peso corporal), estimados através do QFAsq associado ao questionário para ingestão de dentifrício e da dieta duplicada associada à escovação simulada.

\begin{tabular}{|c|c|c|c|c|}
\hline \multirow{3}{*}{ Voluntários } & \multicolumn{4}{|c|}{ Ingestão F total (mg/Kg peso corporal) } \\
\hline & \multicolumn{2}{|c|}{ Bauru } & \multicolumn{2}{|c|}{ Pirajuí } \\
\hline & QFA & Simulação & QFA & Simulação \\
\hline 1 & 0,032 & 0,033 & 0,062 & 0,016 \\
\hline 2 & 0,111 & 0,068 & 0,034 & 0,034 \\
\hline 3 & 0,032 & 0,087 & 0,034 & 0,116 \\
\hline 4 & 0,059 & 0,042 & 0,020 & 0,111 \\
\hline 5 & 0,078 & 0,134 & 0,029 & 0,090 \\
\hline 6 & 0,024 & 0,039 & 0,041 & 0,065 \\
\hline 7 & 0,054 & 0,052 & 0,019 & 0,050 \\
\hline 8 & 0,039 & 0,075 & 0,034 & 0,014 \\
\hline 9 & 0,032 & 0,051 & 0,063 & 0,053 \\
\hline 10 & 0,045 & 0,070 & 0,024 & 0,109 \\
\hline 11 & 0,049 & 0,066 & 0,025 & 0,005 \\
\hline 12 & 0,063 & 0,059 & 0,027 & 0,088 \\
\hline 13 & 0,075 & 0,032 & 0,032 & 0,023 \\
\hline 14 & 0,035 & 0,128 & 0,028 & 0,033 \\
\hline 15 & 0,036 & 0,043 & 0,030 & 0,087 \\
\hline 16 & 0,101 & 0,064 & 0,029 & 0,054 \\
\hline 17 & 0,074 & 0,043 & 0,030 & 0,052 \\
\hline 18 & 0,159 & 0,057 & 0,025 & 0,013 \\
\hline 19 & 0,040 & 0,067 & 0,021 & 0,040 \\
\hline 20 & 0,028 & 0,031 & 0,023 & 0,054 \\
\hline 21 & 0,085 & 0,171 & 0,066 & 0,016 \\
\hline 22 & 0,034 & 0,044 & 0,040 & 0,123 \\
\hline 23 & 0,042 & 0,060 & 0,029 & 0,038 \\
\hline 24 & 0,037 & 0,040 & 0,024 & 0,058 \\
\hline 25 & 0,031 & 0,104 & * & * \\
\hline Média & $0,056^{\mathrm{a}}$ & $0,066^{\mathrm{a}}$ & $0,033^{a}$ & $0,056^{b}$ \\
\hline DP & 0,032 & 0,035 & 0,013 & 0,036 \\
\hline Amplitude & $0,024-0,159$ & $0,031-0,171$ & $0,019-0,066$ & $0,005-0,123$ \\
\hline
\end{tabular}

* Em Pirajuí participaram apenas 24 voluntários. Letras distintas nas mesmas linhas indicam diferenças significativas entre os métodos de avaliação da ingestão de $F$ para os mesmos municípios $(p<0,05)$. Os questionários detectaram diferenças significativas na ingestão total de $\mathrm{F}$ entre os dois municípios, mas a simulação não $(n, s$,$) .$ 


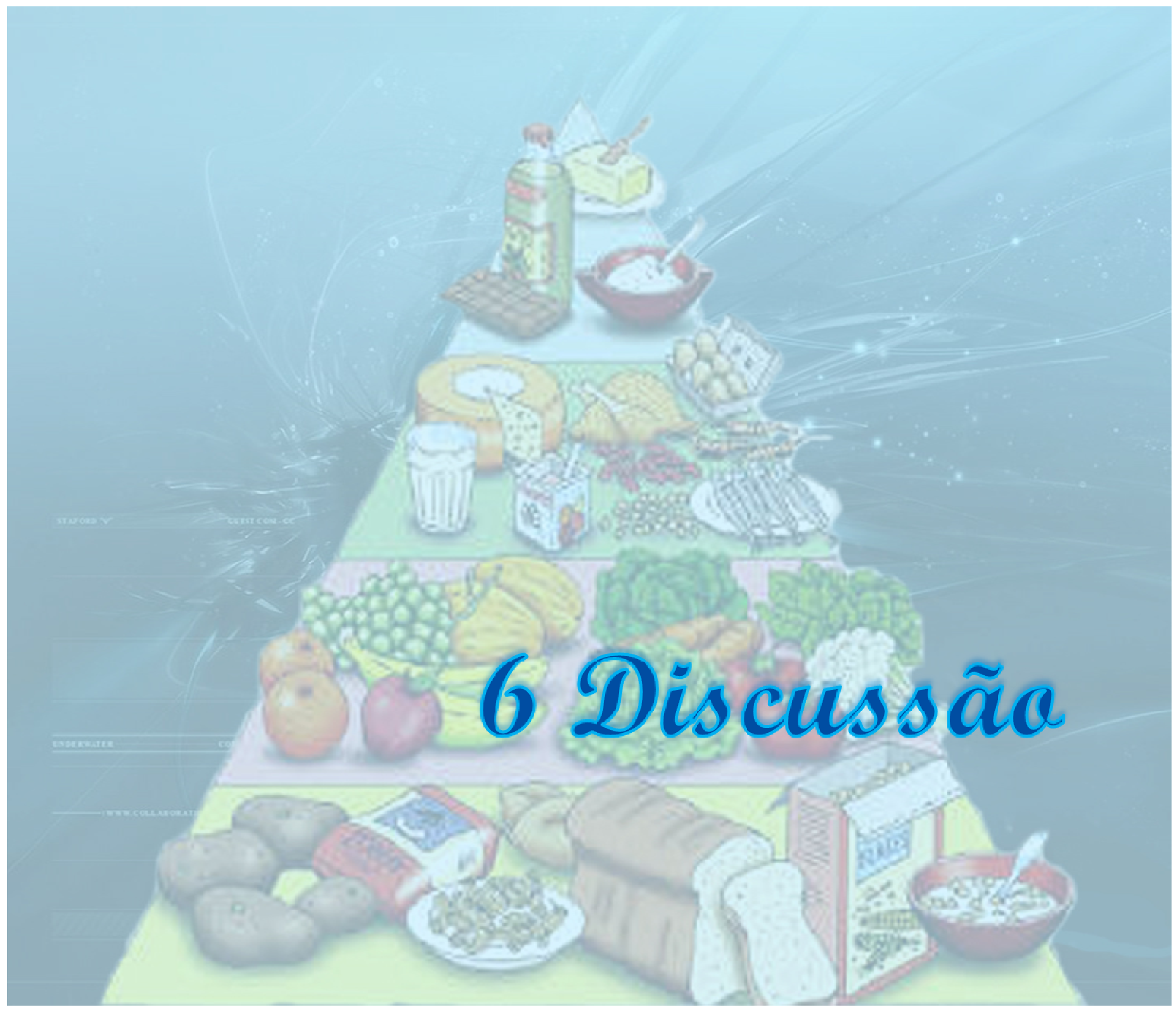




\section{DISCUSSÃO}

O aumento da prevalência da fluorose dentária em vários países Jackson, 1999; Leverett, 1986; Tabari, 2000; Tsutsui et al., 2000; Pereira et al. 2000), em decorrência da exposição ao $\mathrm{F}$ através de várias fontes (MASCARENHAS et al., 2000), tem despertado o interesse em se monitorar a ingestão de $F$ por crianças na faixa etária de risco para a fluorose, que vai de 1 a 7 anos de idade para toda a dentição permanente.

A metodologia mais utilizada atualmente para avaliação da ingestão de $\mathrm{F}$ por crianças através da dieta é a realização da dieta duplicada (GUHA-CHODHURRY et al., 1996). Esse método, entretanto, envolve a coleta de todos os alimentos e bebidas que a criança ingere num intervalo de $24 \mathrm{~h}$, requerendo uma grande colaboração por parte dos pais e/ou responsáveis pelas crianças, no sentido de monitorá-las o tempo todo durante as $24 \mathrm{~h}$ em que as coletas são feitas. Adicionalmente, o método leva ainda a um custo adicional, pela necessidade de se ressarcirem os voluntários em virtude dos alimentos e bebidas cedidos para a avaliação. Por esses motivos, esta técnica vem sendo utilizada em algumas pesquisas envolvendo número restrito de voluntários (LIMA; CURY, 2000; LEVY et al., 2004; PESSAN et al., 2005; ALMEIDA et al., 2007; RODRIGUES, 2007), mas sua aplicabilidade a nível epidemiológico é limitada.

Em virtude do exposto, torna-se necessário encontrar um método alternativo para avaliação da ingestão de $\mathrm{F}$ por crianças, com aplicabilidade a nível epidemiológico. Para esse fim foi utilizado no presente estudo o QFAsq, considerado como o mais prático e informativo método de avaliação da ingestão dietética, além de ser um método de baixo custo e fundamentalmente importante em estudos epidemiológicos que relacionam a dieta habitual com a ocorrência de doenças crônicas (PERSSON e CARLGREN, 1984; WILLET et al., 1985; LIU 1994; COLUCCI, 2002; SLATER et al., 2003), possibilitando ainda maior facilidade na análise dos dados gerados (BLOCK 1989; ZULKIFLI e YU 1992; THOMPSON e BYERS, 1994; DWYER, 2003; SLATER et al, 2003).

$O$ instrumento utilizado nesse estudo foi desenvolvido por Colucci et al. (2004), por ter sido elaborado para crianças na faixa etária em questão e por apresentar correlações adequadas ao estudo. A inclusão, no QFAsq, de alimentos específicos, sabidamente com alta concentração de $F$, em um grupo denominado 
"outros", foi de grande valia, porque possibilitou que eles fossem referidos e considerados no consumo das crianças (TRAUTNER e SIEBERT, 1986; McKNIGHT-HANES et al., 1988; PANG et al., 1992; NISHIJIMA et al., 1993; CHITTAISONG et al., 1995; SILVA e REYNOLDS., 1996; HEILMAN et al., 1997; BUZALAF et al., 2001b; BUZALAF et al., 2002b; BUZALAF et al., 2002c; BUZALAF et al., 2003; CARDOSO, 2003; BUZALAF et al., 2004). A reprodutibilidade do instrumento utilizado foi testada por MIZIARA (2006) em um grupo de 78 crianças, tendo se mostrado adequada $(0,95)$, já que WILLETT (1998) ressalta que os coeficientes de correlação variam entre 0,50 e 0,70. Num estudo prévio (MIZIARA, 2006), o questionário foi aplicado a crianças residentes em Bauru-SP, uma cidade com água de abastecimento artificialmente fluoretada.

No presente estudo, para comparação, o QFAsq foi aplicado a crianças residentes em Pirajuí-SP, cidade com água não fluoretada. A ingestão média ( $₫ D P$ ) de F pela dieta estimada a partir do QFAsq para Pirajuí foi de $0,323 \pm 0,184 \mathrm{mg}$, sendo significativamente menor que os valores relatados por Miziara (2006) para Bauru $(0,463 \pm 0,224 \mathrm{mg})$. Os intervalos de confiança $95 \%$ obtidos para os dois municípios não apresentaram sobreposição, indicando que o QFAsq é capaz de distingüir entre cidades fluoretadas e não fluoretadas com relação à ingestão de $F$.

Para análise da freqüência de consumo dos itens alimentares presentes no QFAsq, os mesmos foram divididos nas categorias "sólidos", "outros líquidos" e "água" a fim de que a ingestão de $\mathrm{F}$ estimada a partir dessas 3 categorias pudesse ser avaliada separadamente, bem como comparada com os dados obtidos a partir da dieta duplicada (quinta etapa), os quais também foram analisados separadamente, conforme descrito por ALMEIDA et al. (2007) e RODRIGUES (2007). A aplicação do QFAsq permitiu ainda que fossem avaliados os alimentos mais e os menos consumidos, dentro das 3 categorias descritas acima. Essa abordagem parece ser mais adequada, pois permite avaliar as contribuições individuais de cada um dos componentes da dieta, o que torna mais fácil a detecção de fatores de risco para fluorose dentária em populações com diferentes características de exposição ao F.

Com relação ao grupo dos sólidos, o item mais consumido foi o arroz, seguido pelo feijão. Isto era esperado, já que o arroz com feijão, na proporção aproximada de 2:1, representa o prato típico brasileiro (CASARIN et al., 2007). A concentração de $F$ presente no arroz e feijão (Tabela 9), nas porções de referência 
usualmente consumidas por crianças nessa faixa etária (3 colheres de sopa de arroz e meia concha de feijão) é baixa, trazendo pequena contribuição para a ingestão total de $\mathrm{F}$ das crianças. Casarin et al. (2007) relataram que o arroz com feijão, mesmo se preparados com água fluoretada, são mais seguros em termos de fluorose dentária que alguns alimentos infantis industrializados. Mlziara (2006), através da aplicação do QFAsq a crianças de 2-6 anos de Bauru, observou que os itens alimentares com maior concentração de $F$ são, em média os menos consumidos, assim como os itens alimentares mais consumidos são, em média, os de menor concentração de F. Em concordância, no presente estudo os itens menos consumidos da categoria sólidos foram o Neston e a bolacha Danyt's. Isso traz uma certa segurança em relação ao risco de fluorose dentária, já que esses alimentos possuem alta concentração de F (BUZALAF et al., 2002; BUZALAF et al., 2004), conforme se denota na tabela 9.

No estudo de Aquino e Philippi (2002), em que se observou o consumo de alimentos industrializados pela população infantil, o resultado mostrou que os itens alimentares industrializados de maior utilização foram: leite, iogurte, biscoitos e salgadinhos, massas alimentícias, refrigerantes e açúcar. Para os itens alimentares da categoria outros líquidos, os mais consumidos foram o café com açúcar, iogurte de frutas e leite em pó diluído com água de abastecimento público. Se a cidade de Pirajuí tivesse água de abastecimento público fluoretada, a utilização dessa água para o preparo de leites em pó poderia trazer risco para a ocorrência de fluorose dentária, conforme tem sido relatado na literatura (SILVA; REYNOLDS, 1996; BUZALAF et al., 2001, 2004).

Em relação ao consumo de água, 367 das 398 crianças residentes em Pirajuí avaliadas consomem água de abastecimento público (92,2\%), enquanto que 24 (6\%) consomem água mineral e apenas 7 (1,8\%) consomem água de poço. Estes valores foram bastante parecidos com os relatados por MIZIARA (2006) para a cidade de Bauru. A autora observou que o consumo de água de abastecimento público, água mineral e água de poço por crianças de 2-6 anos de idade foi de 86,8\%, 11,9\% e $1,3 \%$, respectivamente. Tem sido relatada uma ampla variação para os níveis de $\mathrm{F}$ presentes nas águas minerais disponíveis no comércio brasileiro (VILLENA et al., 1996; RAMIRES et al., 2004; GREC et al., 2008), bem como uma grande discrepância entre os valores estipulados nos rótulos e aqueles realmente presentes. A água mineral engarrafada é considerada por muitos pais um produto mais 
saudável (RAMIRES et al., 2004) e por isto é muito utilizada entre a população infantil, sendo o diluente de escolha para o leite em pó nos locais em que a água de abastecimento público é otimamente fluoretada, a fim de se evitar a fluorose dentária. Entretanto, devido aos problemas apontados acima, o seu uso em cidades não fluoretadas, como é o caso de Pirajuí, não deve ser indicado.

Com relação à análise da concentração de $\mathrm{F}$ nos alimentos que constavam no QFAsq, os valores encontrados para Pirajuí foram semelhantes aos relatados por MIZIARA (2006) para Bauru. Esse resultado pode ser explicado pelo efeito de difusão do $\mathrm{F}$ (efeito "halo"), pelo qual os alimentos fabricados numa área fluoretada (e que portanto contêm níveis mais altos de F) são consumidos em áreas não fluoretadas.

A fim de se comparar a estimativa de ingestão de $\mathrm{F}$ a partir da dieta obtida através do QFAsq com o método mais utilizado para esse fim, que é a dieta duplicada, ambos os métodos foram realizados numa subamostra de crianças (24 para Pirajuí e 25 para Bauru, com características semelhantes nos dois municípios). Nessa etapa foram ainda coletadas amostras da água de abastecimento nas residências dos voluntários em dois dias diferentes, confirmando o estado de fluoretação dos municípios estudados.

Tanto pela utilização do QFAsq como pelo método da dieta duplicada, os maiores contribuintes para a ingestão de $F$ através da dieta em Bauru e Pirajuí foram a água e os sólidos, respectivamente. Esse dado era esperado, pelas características das comunidades em relação à fluoretação da água de abastecimento. No estudo de Almeida et al. (2007), a contribuição da água mais leite, sólidos e outros líquidos para a ingestão de $\mathrm{F}$ pela dieta (avaliada através da dieta duplicada) de crianças de 1-3 anos de idade residentes em Bauru foi de 54\%, 23 e 23\%, respectivamente, o que pode ser considerado de certa forma semelhante aos resultados obtidos para Bauru, levando-se em conta os diferentes delineamentos de ambos os estudos (faixa etária e forma de separação dos componentes da dieta).

Uma dificuldade encontrada nesse estudo foi a utilização de um método "padrão-ouro" para se avaliar a ingestão de $F$ por crianças. O método que foi escolhido para comparação é o da dieta duplicada por ser o mais relatado na literatura. Entretanto, não há nenhum método que possa ser considerado "padrãoouro", a partir do qual a confiabilidade do QFAsq posa ser completamente validada. Através do emprego do método da dieta duplicada, procurou-se compará-lo com o 
QFAsq de duas maneiras: testando-se se haveria diferenças significativas entre os dados obtidos pelo dois métodos, bem como se haveria correlação entre os dados obtidos através de ambos. Pela análise da tabela 18, pode-se observar que houve diferenças significativas entre os dados obtidos a partir do QFAsq e da dieta duplicada, tanto considerando-se a dieta total quanto seus componentes, para ambas os municípios, com exceção do caso dos outros líquidos (Bauru) . Um dado interessante é que no município fluoretada (Bauru), as estimativas obtidas através do QFAsq foram sempre menores quando comparadas àquelas obtidas a partir da dieta duplicada. Isto poderia ser devido ao fato de que, para a realização da dieta duplicada, solicita-se aos pais para prepararem porções alimentares idênticas às que serão servidas para as crianças, porém em recipientes separados e que depois separem a porção que a criança eventualmente não ingere, coletando apenas aquela efetivamente ingerida. Pode ter ocorrido de os pais não separarem a porção que a criança não ingeriu, coletando assim porções maiores. Entretanto, em Pirajuí, com exceção do grupo da água, observou-se uma tendência inversa, ou seja, as estimativas obtidas a partir do QFAsq foram significativamente maiores em relação àquelas encontradas com a utilização do método da dieta duplicada. A razão para os perfis distintos encontrados no município fluoretado e no não fluoretado não está clara.

Um aspecto do QFAsq que precisa ser melhor trabalhado quando se pensa na utilização do mesmo como instrumento para avaliar a ingestão de $\mathrm{F}$ é a forma de avaliar a freqüência de ingestão de água, especialmente em comunidades fluoretadas. De acordo com a estrutura do QFAsq utilizado, para todos os itens alimentares, sem exceção, os fatores multiplicadores para cada categoria de freqüência de consumo são os mesmos. A maior freqüência de consumo é "2 ou mais vezes ao dia", ou seja, o instrumento não é capaz de distinguir entre as categorias de consumo acima de 2 vezes ao dia. No caso da água de abastecimento, por ser um item consumido geralmente mais que duas vezes ao dia (337 crianças relataram consumi-la mais que 2 vezes ao dia, tabela 8) e por conter níveis significativos de $F$ (no caso de municípios fluoretados), parece ser importante que sejam inclusas maiores freqüências de consumo para uma avaliação mais precisa. Essa observação pode ser corroborada pela observação da tabela 19, onde podem ser denotados os baixos coeficientes de correlação obtidos para o grupo da água, especialmente no município fluoretado. Nesta mesma tabela, pode-se 
observar que foram obtidas correlações significativas entre as estimativas de ingestão de F obtidas através do QFAsq e da dieta duplicada para o grupo dos sólidos (para ambos os municípios). Mesmo não se podendo considerar o método da dieta duplicada como um "padrão-ouro", como foi relatado anteriormente, esses dados sugerem que o QFAsq empregado encontra-se adequado para estimar a ingestão de $\mathrm{F}$ a partir do grupo dos alimentos sólidos, que compreendem a grande maioria dos itens alimentares inclusos.

Nos estudos que avaliam a ingestão total de $F$ através da dieta e da escovação por crianças na idade de risco para a fluorose dentária, tem-se relatado que a maior contribuição é dada pelo dentifrício fluoretado (LIMA; CURY, 2001; PESSAM et al., 2005; ALMEIDA et al., 2007). Por este motivo, no presente estudo procurou-se ainda comparar a estimativa de ingestão de $\mathrm{F}$ pelo dentifrício avaliada por um questionário, com o método da escovação simulada (GUHA-CHOWDHURY et al.,1996), que é o método mais amplamente empregado. Entretanto, à semelhança do que foi relatado para o método da dieta duplicada, a escovação simulada tem várias limitações, que não permitem que a mesma seja empregada como um "padrão-ouro" para fins de comparação. Apesar de na estimativa se tentar reproduzir ao máximo as condições normais da escovação usual, é possível que algumas diferenças em relação à escovação normal ocorram, devido à inibição causada pela presença dos pesquisadores. Em adição, a concentração de $F$ nas amostras de dentifrício não ingeridas é bastante variável, sendo recomendável fazer um screening prévio das amostras, para que as mesmas sejam ordenadas de acordo com a concentração crescente de $F$ na análise definitiva, evitando-se 0 "efeito memória" do eletrodo, como tem sido relatado por Cochran et al. (2004). Um outro problema associado à escovação simulada é que uma parte do dentifrício pode ficar em contato com a face durante a avaliação, levando a uma super-estimativa de ingestão. Tem sido ainda relatado que os pais tendem a super-estimar o número de escovações diárias realizadas pelas crianças, o que interferirá nos cálculos da quantidade de dentifrício ingerida. Esse problema, entretanto, é comum também à avaliação feita por questionários.

Quando se comparam as estimativas de ingestão de $\mathrm{F}$ a partir do dentifrício obtidas pelos métodos do questionário e da escovação simulada, houve uma tendência para obtenção de valores maiores com o questionário em Bauru, embora a diferença para a escovação simulada não tenha sido significativa. Para Pirajuí, 
observou-se um perfil inverso, ou seja, os valores encontrados pela aplicação do questionário foram significativamente menores em relação ao método da escovação simulada (Tabela 20). Em ambos os municípios, não houve correlação entre os métodos empregados. Convém ressaltar que os desvios-padrão obtidos para ambos os métodos foram grandes. Considerando-se esse aspecto, seria uma vantagem a utilização do questionário para avaliação da ingestão de $\mathrm{F}$ pela escovação, devido ao baixo custo e facilidade de aplicação, além do potencial para uso a nível epidemiológico.

Pensando-se na aplicação dos questionários para avaliação da ingestão de $\mathrm{F}$ a nível epidemiológico, na Tabela 21 são apresentados os dados da dieta e dentifrício, em mgF/Kg peso corporal. Embora não seja cientificamente comprovado, acredita-se que uma dose diária de ingestão de $\mathrm{F}$ em torno de 0,05 a 0,07 mg/Kg peso corporal/dia seja considerada ótima (BURT, 1992). Pela análise da tabela, observa-se que as estimativas de ingestão total de $\mathrm{F}$ obtidas pelos dois métodos em Bauru foram similares, sem diferença significativa, embora em Pirajuí tenha-se observado uma ingestão de $F$ significativamente menor para o método dos questionários, em relação ao das simulações, não havendo correlação entre os métodos em nenhum dos casos. Esses resultados parecem ser mais devidos à estimativa de ingestão de $\mathrm{F}$ a partir do dentifrício, já que os desvios-padrão encontrados nesse caso foram maiores. Foi ainda observado que os métodos dos questionários permitiram que fossem detectadas diferenças significativas na ingestão total de $\mathrm{F}$ entre o município fluoretado e o não fluoretado, mas o mesmo não ocorreu com o método da dieta duplicada associado à escovação simulada.

Face aos resultados obtidos, o QFAsq associado a um questionário para estimativa da ingestão de $\mathrm{F}$ a partir do dentifrício parece ter um bom potencial para utilização a nível epidemiológico, para se avaliar o risco de grupos de crianças à fluorose dentária. Alguns parâmetros do QFAsq podem ser melhor trabalhados para uma análise mais fidedigna, principalmente com relação à freqüência de ingestão de água e outros líquidos. Em adição, a aplicabilidade desses questionários a nível individual para detecção de risco à fluorose dentária ainda precisa ser melhor estudada. 


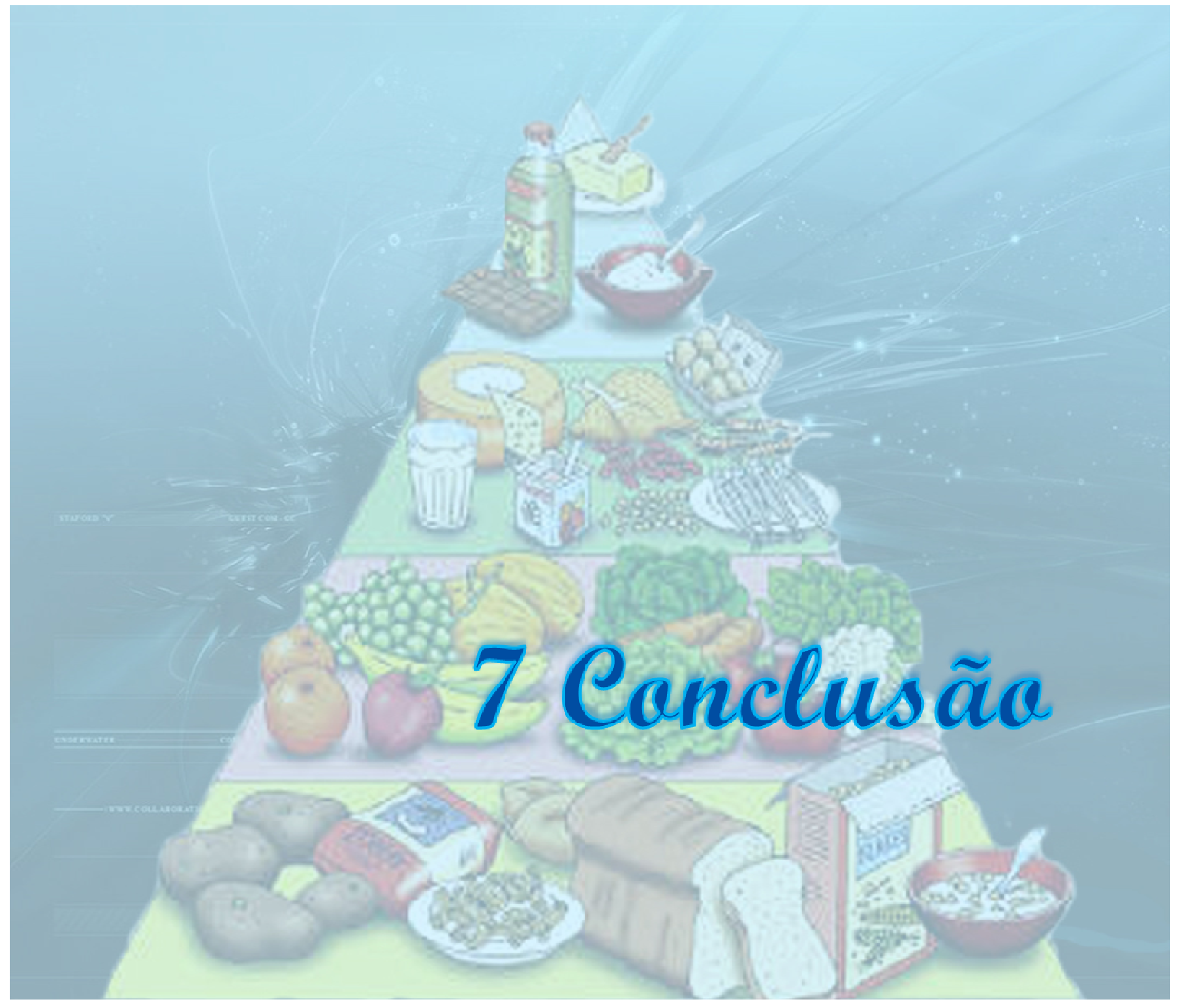




\section{CONCLUSÃO}

Os resultados do presente estudo mostraram que:

a) O QFAsq foi capaz de detectar diferença significativa na ingestão de $F$ pela dieta em crianças residentes em área fluoretada e não fluoretada;

b) $O$ método da dieta duplicada foi capaz de detectar diferença significativa na ingestão de $\mathrm{F}$ pela dieta em crianças residentes em área fluoretada e não fluoretada;

c) Não houve correlação significativa entre os dados de ingestão de $\mathrm{F} \mathrm{a}$ partir do dentifrício obtidos pelos métodos de escovação simulada e questionário para estimativa de ingestão de dentifrício;

d) Com exceção do grupo dos sólidos, não houve correlação significativa entre os dados de ingestão de $\mathrm{F}$ a partir da dieta obtidos pelos métodos da dieta duplicada e QFAsq;

e) Não houve correlação significativa entre os dados de ingestão total de $\mathrm{F}$ obtidos pelos métodos da dieta duplicada, associado à escovação simulada e QFAsq, associado a questionário para estimativa de ingestão de dentifrício.

Esses resultados permitiram rejeitar completamente as duas primeiras hipóteses nulas, rejeitar parcialmente a terceira e aceitar completamente as duas últimas. 


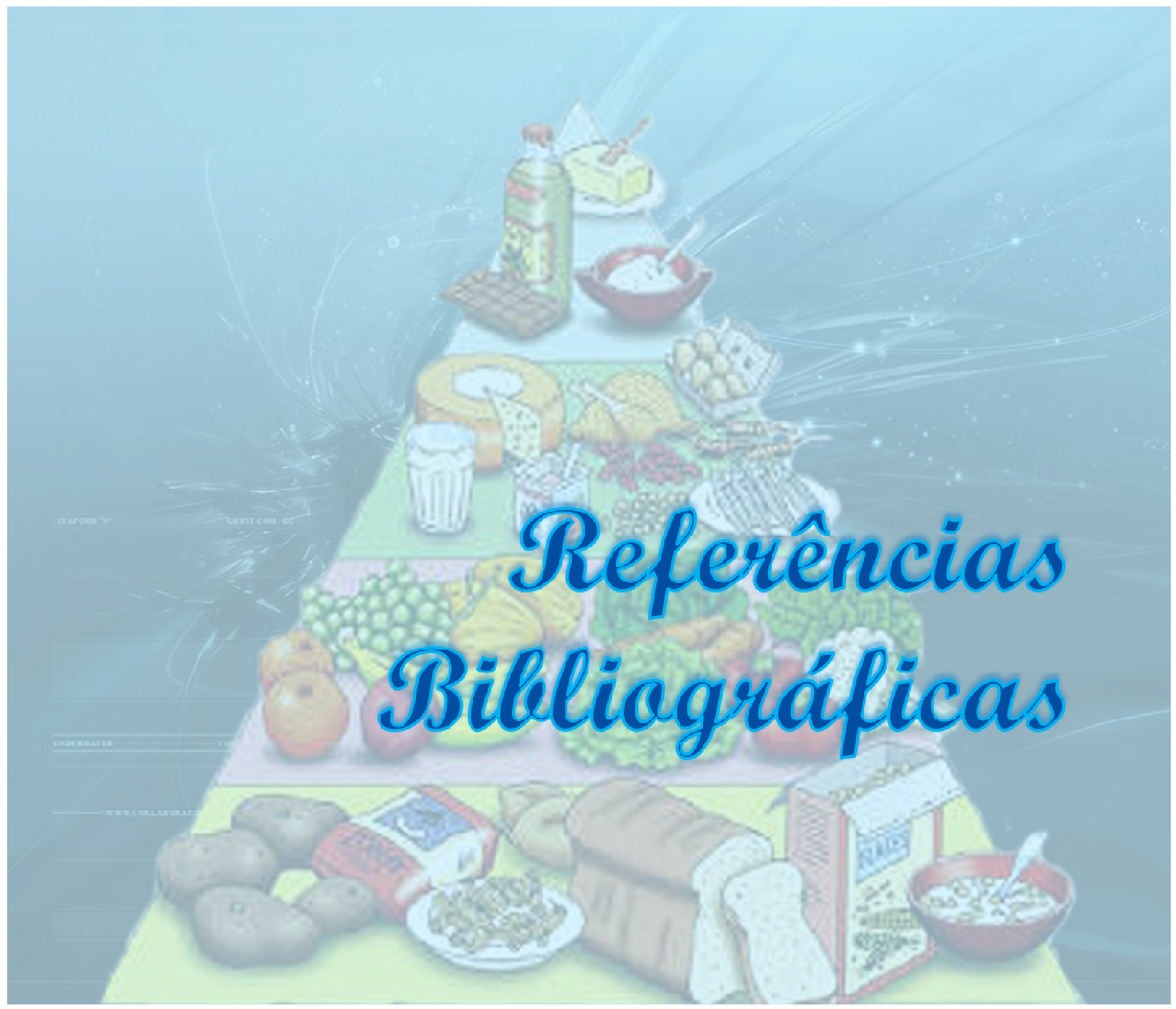




\section{Referências Bibliográficas}

1. ALLEN, C.D.; ASHLEY, F.D.; NAYLOR, M.N. Caries experience in 11- years-old schoolchildren between 1962 and 1981. Brit. dent. J., v.154, n.6, p.167-70, Mar. 1983.

2. ALMEIDA, B.S.; CARDOSO, V.E.S.; BUZALAF, M.A.R. Fluoride ingestion from toothpaste and diet in 1-3-year-old Brazilian children. Community Dent. oral Epidem., v.35, p.53-63, 2007.

3. ANDLAW, R.J.; BURCHELL, C.K.; TUCKER, G. Comparison of dental health in 11- years-old children in 1970 and 1979, and of 14- years-old children in 1973-1979, studies in Bristol, England. Caries Res., v.16, n.3, p.257-64, 1982.

4. AQUINO, R. C.; PHILIPPI, S. T. Consumo infantil de alimentos industrializados e renda familiar na cidade de São Paulo. Saúde Pública, v. 36, n.6, p. 655-660, 2002.

5. BARANOWSKI T, DOMEL,S.B. A cognitive model of children's reporting of food intake. Am J Clin Nutr., v.59, n.1(Suppl), p.212S-217S, 1994.

6. BASTOS, J.R. de M. et al. Concentração de flúor em água mineral engarrafada e de fontes naturais das cidades de Lindóia, Águas de Lindóia e Serra Negra, Brasil. Rev. Univ. Fed. Passo Fundo, v.6, n.1, p.15-19, jan./jun. 2001.

7. BIESWANGER, B.B.; STOOKEY, G.K. The comparative clinical cariostatic efficacy of sodium fluoride and sodium monofluoropfosphate dentifrice: a review of trials. ASDC J. dent Child, v.57, n.5, p.337-47, Sept./Oct. 1989.

8. BLEIL,S.I. O padrão alimentar ocidental: considerações sobre a mudança de hábitos no Brasil. Cadernos de debate -Unicamp/ Núcleo de estudos e Pesquisas em Alimentação: MS/INAN, v.6, p.1-25, 1998. 
9. BRASIL. Ministério da Saúde. Secretaria Nacional de Vigilância Sanitária. Lei no 6050, de 24 de maio de 1974. Disponível na Internet. www.saude.gov.br/sp./areastecnicas/bucal/dados/fluor/lei6050.htm

10. BRASIL. Ministério da saúde. Secretaria Nacional de Vigilância Sanitária. Portaria $\mathrm{n}^{\text {o. }} 22$ de 20 de dezembro de 1989. Disponível na Internet. www.saude.gov.br/sps/areastecnicas/bucal/dados/fluor/port22vig.htm.

11. BRASIL. Ministério da saúde. Secretaria Nacional de Vigilância Sanitária. Portaria $\mathrm{n}^{0} 518$ de 25 de março de 2004. Disponível na Internet. www.saude.gov.br/sas/portarias/Port 2004/GM518.htm.

12. BURT, B.A. The changing patterns of systemic fluoride intake. J. dent. Res., v.1, n. 5, p.1228-37, May 1992.

13. BURT, B.A. Prevention policies in the light of the changed distribution of dental caries. Acta odontol scand., v.56, p.179-86, 1998.

14. BURT BA, KEELS MA, HELLER KE. The effects of a break in water fluoridation on the development of dental caries and fluorosis. J dent Res., v.79, n.2, p.761-9, Feb 2000.

15. BURT, B.A., KEELS, M.A., HELLER, K.E. Fluorosis development in seven age cohorts after an 11-month break in water fluoridation. J dent Res., v.82, n.1, p.64-8, Jan 2003.

16. BUZALAF, M.A.R. et al. Fluoride content of infant formulas prepared whith deionized, bottled mineral and fluoridated drinking water. ASDC J. dent Child, v.68, n.1, p.37-41, Jan./Feb. 2001.

17. BUZALAF, M.A.R. et al. Fluoride content of infant foods in Brasil and risk of dental fluorosis. ASDC J. dent Child, v.69, n.2, p.196-200, May/Aug. 2002a. 
18. BUZALAF, M.A.R. et al. Association between the early use of toothpaste and other variables with dental fluorosis: a transversal retrospective study. Rev. FOB, v.10, n.3, p.196-200, jul./set. 2002.

19.BUZALAF, M.A.R. et al. Fluoride content of several brands of teas and juices found in Brasil and risk of dental fluorosis. Rev. FOB, v.10, n.4, p.263-7, out./dez. 2002.

20. BUZALAF, M.A.R. et al. Fluctuations in public water fluoride level in Bauru, Brazil. J. Publ. HIth. Dent., v.62, n.3, p.173-6, Summer 2002.

21. BUZALAF, M.A.R. et al. Fluoride content of several brands of chocolate bars and chocolate cookies found in Brazil. Pesq Odonto Bras, v.17, n.3, p.223-7, jul./set. 2003.

22. BUZALAF, M.A.R. Enamel fluorosis prevalence after a 7-year interruption in water fluoridation in Jaú, São Paulo, Brazil. J Public Health Dent., v. 64, n.4, p.2058, Fall 2004.

23. BUZALAF, M.A.R. et al. Fluoride content of UHT milks commercially available in Bauru, Brazil . Journal Of Applied Oral Science, v.14, n.1, p.38-42, 2006.

24. BUZALAF, M.A.R. et al. Availability of fluoride from meals given to kindergarten children in Brazil. Community Dent. oral Epidem., v.34, n.2, p.87-92, 2006.

25. BUZALAF; KOBAYASHI; PHILIPPI, 2008 - Fontes de ingestão de fluoretos. In: Buzalaf MAR (ed.) Fluoretos e Saúde Bucal. Santos, São Paulo, 2008 (in press).

26. CARDOSO, M. A. et al. Dietary patterns in Japanese migrants to southeastern Brazil and their descendants. J Epidemiol., v.7, n.4, p.198-204, Dec., 1997.

27. CARDOSO, M. A. et al. Reproducibility and validity of a food frequency questionnaire among women of japaneses ancestry living in Brazil. Nut Res, v.21, n.5, p. 725-733,may., 2001. 
28. CARDOSO, V. E. S. et al. Fluoride content of several breakfast cereals and snacks found in Brazil. J Appl Oral Sci, v.11, n.4, p.306-310, oct/dec., 2003.

29. CAPELLA et al. Ocorrência de fluorose dentária endêmica. Rev Gaúcha Odontol. ,v. 36, p.371-375, 1989.

30. CARMO, do M.D. et al. Localidades com diferentes concentrações de flúor nas águas de consumo e sua relação com a prevalência de fluorose. Odont. mod., v.22, n.4, p.18-21, out./dez. 1995.

31. CASARIN et al. Concentração de fluoreto em arroz, feijão e alimentos infantis industrializados. Rev. Saúde Pública, v.41, n.4, p.549-56, 2007.

32. CATANI D.B. et al. Relação entre níveis de fluoreto na água de abastecimento publico e fluorose dental. Rev.Saúde Pública, v. 41, n.5 , p. 732-39, 2007.

33. CHITTAISONG C.et al. Estimation of fluoride intake I relation to $\mathrm{F}, \mathrm{Ca}, \mathrm{Mg}$ and $\mathrm{P}$ contents in infants formulas. The Bulletin of Tokyo Dental College, v.36, n.1, p.19-26, feb.,1995.

34. CLARK, D.C. Trends in prevalence of dental fluorosis in North America. Community Dent. oral Epidem., v.22, p.148-52, 1994.

35. CLARKSON, J. J. International collaborative research on fluoride. J. dent. Res., v.79, n.4, p.893-904, Apr. 2000.

36. CLOVIS, J.; HARGREAVES, J.A. Fluoride intake from beverage comsumption. Community Dent. oral Epidem., v.16, n.1, p.11-5, Feb. 1988.

37.COCHRAN, J.A. et al. Development of a standardized method for comparing fluoride ingested from toothpaste by 1.5-3.5-year-old children in seven European countries. Part 2: ingestion results. Community Dent. oral Epidem., v.32, n.1, p.4753, 2004. 
38. COLUCCI A. C. A. Desenvolvimento de um questionário de freqüência alimentar para avaliação do consumo alimentar de crianças de 2 a 5 anos de idade. São Paulo; 2002. [Dissertação de Mestrado - Faculdade de Saúde Pública da USP].

39. COLUCCI, A. C. A.; PHILIPPI, S. T.; SLATER, B. Desenvolvimento de um questionário de freqüência alimentar para avaliação do consumo alimentar de crianças de 2 a 5 anos de idade. Bras Epidemiol., v.7, n.4, p393-401, 2004.

40. CULLEN, M.R.; REDLICH, C.A. Significance of individual sensitivity to chemicals: elucidation of host susceptibility by use of biomarkers in environmental health research. Clin. Chem., v.12, p.1809-13, Dec. 1995.

41. CURY, J.A. Concentração de fluoreto em chás brasileiros e seu significado na prevenção de cárie. Rev. gaúcha Odont., v.29, n.2, p.136-8, abr.jjun. 1981.

42. DEAN, H.T. Classification of mottled enamel diagnosis. Journal of the American Dental Association, v.21, p.1421-1426,1934.

43.DEAN, H.T.; ARNOLD, F.A.; ELVOVE, E. Domestic wáter and dental caries V. Additional studies of the relation of fluoride domestic waters to dental caries experience in 4,425 white children aged 12-14 years in 3 cities in 4 states. Public Health Reports, v.57, p.1155-1179, 1942.

44.DEAN, H.T. et al. Studies on mass control of dental caries though fluoridation of the public water supply. Publ. HIth Rep., v.65, p.1403-8, 1950.

45. DENBESTEN, P.K. Biological mechanisms of dental fluorosis relevant to the use of fluoride supplements. Community Dent Oral Epidemiol, v.27, n.1, p.41-7, 1999.

46. DWYER, J. T. Dietary assessment. In: SHILS, M. E.; OLSON, J. A; SHIKE, M. (Edit.). Modern nutrition in health disease. 8 ed. Philadelphia: Lea \& Febiger, 1999. p. 937-59. 
47. EAGER, J.M. Denti di Chiaie. Publ. HIth Rep., v.91, n.3, p.284-5, May /June, 1976.

48. EKSTRAND, J.; EHRNEBO, M. Absorption of fluoride from fluoride dentifrice. Caries Res., v.14, n.2, p.96-102, 1980.

49. EKSTRAND, J. et al. Pharmacokinetics of fluoride in man after single and multiple oral dosages. Eur. J. Clin. Pharmacol., v.12, p.311-7, 1977.

50. EMMONS, L; HAYES, M. Accuracy of 24-hour recalls of yong children. Journal of the American Diet Association, v.62, p.409-415, 1973.

51. ERICSSON, Y.; FORSMAN, B. Fluoride retained from mouthrinses and dentifrices in preschool children. Caries Res., v.3, n.3, p.290-9, 1969.

52. EVANS, R.W.; STAMM, J.W. Dental fluorosis following downward adjustment of fluoride in drinking water. J. Publ. HIth. Dent., v.51, n.2, p.91-8, Spring 1991.

53. FEJERSKOV, O.; THYLSTRUP, A.; LARSEN, M.J. Rational use of fluorides in caries prevention. Acta Odontol Scand, v. 39, p. 241-249, 1981.

54.FOMON, S.J.; EKSTRAND, J.; ZIEGLER, E.E. Fluoride intake and prevalence of dental fluorosis: trends in fluoride intake with special attention to infants. J. Publ. HIth. Dent., v. 60, n. 3, p. 131-9, 2000.

55. FORSMAN, B.; ERICSSON, Y. Fluoride absorption from swallowed fluoride toothpaste. Community Dent. oral Epidem., v.1, n.3, p.115-20, 1973.

56. FREIRE, M.C.M.; MACEDO, R.A.; SILVA, W.H. Conhecimentos, attitudes e práticas dos médicos pediatras em relação à saúde bucal. Pesq Odontol Bras, v.14, n.1,p.39-45, 2000. 
57. FROST ANDERSEN, L. et al. Evaluation of a quantitative food frequency questionnaire used in a group of Norwegian adolescents. European Journal of clinical Nutrition, v.49,p.543-54, 1995.

58.GREC, .H. da C. et al. Concentração de flúor em águas engarrafadas comercializadas no município de São Paulo. Rev. Saúde Pública, v.42, n.1, p.154-7, 2008.

59. GUHA-CHOWDHURY, N.; DRUMMOND, B. K.; SMILLIE, A.C. Total fluoride intake in children aged 3 to 4 years - a longitudinal study. J. dent. Res., v.75, n.7, p.1451-7, July 1996.

60. HARGREAVES, J.A.; INGRAM, G.S.; WAGG, B.J. A gravimetric study of the ingestion of toothpaste by children. Caries Res., v.6, n.3, p.237-43, 1972.

61. HEILMAN, J.R. et al. Fluoride concentration of infant foods. J. Amer. dent. Ass., v.128, n.7, p.857-63, July 1997.

62. HEILMAN, J.R. et al. Assessing fluoride levels of carbonated soft drinks. J. Amer. dent. Ass., v.130, n.11, p.1593-9, Nov. 1999.

63. HEINTZE, S.D.; BASTOS, J.R.de M. Avaliação do teor de flúor e pH em bebidas no mercado nacional. Rev. Ass. paul. cirurg. Dent., v.50, n.4, p.339-45, jul./ago. 1996.

64. HELER, K.E.; EKLUND, S.A.; BURT, B.A. Dental caries and dental fluorosis at varying water fluoride concentrations. J Public Health Dent,v. 57, n.3,p.136-43, 1997.

65. HOLT, R.D. et al. Enamel opacities and dental caries in children who used a low fluoride toothpaste between 2 and 5 years of age. Int. dent J., v. 44, n.4, p.331-41, Aug. 1994. 
66. INSTITUTO DE GEOGRAFIA E ESTATÍSTICA. Mapas, color. Tamanhos inderterminaveis. Disponível em: www.ibge.gov.br/cidadesat/default.php. Acesso em: jan. 2007.

67. IVACG - A report of the International Vitamin A Consulative Group. Guidelines for the development of a simplified dietary assessment to identify groups at risk for inadequate intake of vitamin A. Washington (DC); 1989.

68. JACKSON, R.D. et al. Dental fluorosis in children residing in communities with different water fluoride levels: 33-month follow-up. Pediat. Dent., v.21, n.4, p.248-54, July/Dec. 1999.

69. JACKSON, R. D. et al. The fluoride content of foods and beverages from negligibly and optimally fluoridated communities. Community Dent. oral Epidem. v.30, p.382-91, 2002.

70.JIMÉNEZ, L. G.; MARTÍN-MORENO, J. M. Cuestionario de frecuencia de consomo alimentario. In: SERRA MAJEM, L. Nutrición y Salud Pública: métodos, bases científicas y aplicaciones. España: Masson, 1995. p.90-106.

71. KHAN, A; MOOLA, M.H.; CLEATON-JONES, P. Global trends in dental fluorosis from 1980 to 2000: a systematic review. South Afr Dent J, v.60, p.418-421, 2005.

72. KIMURA T et al. Fluoride intake from food and drink in Japanese Children aged 16 years. Caries Research, v.35-31, n.1,p.47-49, jan/feb., 2001.

73. KUMAR, J.V. et al. Trends in dental fluorosis and dental caries prevalences in Newburg and Kingston, NY. Amer. J. Publ. Hlth, v. 79, n.5, p. 565-69, May 1989.

74. KUMAR, J.V.; SWANGO, P.A. Fluoride exposure and dental fluorosis in Newburgh and Kingston, New York: policy implications. Community Dent Oral Epidemiol, v.27, n.3, p.171-80, 1999. 
75. LALUMANDIER, J.A. The prevalence and risk factors of fluorosis among children in a padiatric practice in Asheville, North Carolina. J. Publ. HIth. Dent., v.52, n.3, p.188-9, 1992.

76. LALUMANDIER, J.A ROZIER. The prevalence and risk factors of fluorosis among patients in a pediatric dental practice. Pediatr Dent, v.17, n.1, p.19-25,1995.

77. LEAKE, J. et al. Has the level of dental fluorosis among Toronto children changed? J Canad. dent. Ass, v.68, n.1, p.21-5, Jan. 2002.

78. LEVERETT, D.H. Prevalence of dental fluorosis in fluoridated and in nonfluoridated communities-a preliminary investigation. J. Publ. Hlth. Dent., v.46, n.4, p.184-7, Fall 1986.

79. LEVY, S.M.; KIRITSY, M.C.; WARREN, J.J. Sources of fluoride intake in children. J. Publ. Hlth. Dent., v.55, n.1, p.39-52, Winter 1995.

80. LEVY, S.M. et al. Infants fluoride intake drinking water alone and from water added to formula,beverages, and food. J. dent. Res., v.74,n.7,p.1399-1407,1995.

81.LEVY, S.M. et al. Infants' fluoride ingestion from water, supplements and dentifrice. J Am Dent Assoc., v. 126, n.12, p.1625-32, 1995.

82.LEVY, F.M.; BASTOS, J.R.M; BUZALAF, M.A.R. Nails as biomarkers of fluoride in children of fluoridated communities. J. Dent. Child., v.71, n.2, p.121-5, May/Aug. 2004.

83.LIMA, Y.B.O.; CURY, J.A. Ingestão de flúor por crianças através da água e dentifrício. Rev. Saúde públ., v.35, n.6, p.576-81, dez. 2001.

84.LIU. K. Statistical issues related to semiquantitative food-frequency questionnaires. Am J Clin Nutr, v.59, n., p. 262S-265S, mês., 1994. 
85. LIVINGSTONE M. B.; ROBSON, P.J. Measurement of dietary intake in children. Proc Nutr Soc. , v.59, n.2, p. 279-93, May., 2000.

86. MAGUIRE A. et al. Bioavailability of fluoride in drinking water: a human experimental study. J. dent. Res., v.84, p.989-993, 2005.

87. MAINWARING, P.J.; NAYLOR, M.N. A four-year clinical study to determine the caries-inhibiting effect of calcium glycerophosphate and sodium fluoride in calcium carbonate base dentifrices containing sodium monofluorophosphate.Caries Res., v.17, n.3, p.267-76, 1983.

88. MALTZ, M.; FARIAS, C. Fluorose dentária em escolares de quarto cidades brasileiras com e sem água artificialmente fluoretada. Rev. Fac. Odont. Porto Alegre, v.39, n.2, p.18-21, dez. 1998.

89. MALTZ, M.; LACERDA, P. Conhecimento do pediatra na área de saúde bucal. Rev. ABO Nac., v.9, n.4, p. 210-6, 2001.

90. MANSBRIDGE, J.N.; BROWN, M.D. Changes in dental caries prevalence in Edinburgh children over three decades. Community dent. Hlth., v.2, n.1, p.3-13, Mar. 1985.

91. MARTÍN-MORENO, J. M. et al. Development and validation of a food frequency questionnaire in Spain. Int J Epidemiol, v.22, p.512-519, 1993.

92. MARTINS, C. C.; REIS, P. N.; MARTINS, P. S. Perfil de crianças portadoras de fluorose dentária quanto às diversas formas de acesso ao flúor. J Bras Odontopediatr Odontol, v.5, n.27, p.396-402, 2002.

93. MASCARENHAS, A.K.; BURT, B.A. Fluorosis risk from early exposure to fluoride toothpaste. Community Dent. oral Epidem., v.26, n.4, p.241-8, Aug. 1998.

94. MASCARENHAS, A.K. Risk factors for dental fluorosis: A review of the recent literature. Pediat. Dent., v.22, n.4, p.269-77, July/Aug. 2000. 
95. McCLURE, F.J. Water fluoridation. The search and the victory. Washington, DC, Us Government Printing Office, 1970.

96. McDOGNAGH, M. et al. Systematic review of water fluoridation. Brit. med. J., v.321, n.7265 p.855-9, Oct. 2000.

97. McKAY, F.S. Mottled enamel: The prevetion of its further production though a chance of water supply at Oakley, IDA. J. Amer. Dent. Ass., v.20, n.7, p.1137-49, July 1933.

98. McKNIGHT-HANES, M.C. et al. Fluoride content of infant formulas: soy-based formulas as potential factor in dental fluorosis. Pediatr Dent, 1988; v.10, n.3, p.18994, 1988.

99.MELLBERG, J.R.; RIPA, L.W. Self-applied topical fluoride Fluoride in preventive dentistry: theory and clinical implications. Chicago, Quintessence Publishing Co., p. 243-77, 1983.

100. MENEGHIM, $M$ de $C$ et al. Comparason of diagnostic methods for dental caries. J Dent Child., v.70, n.2, p.115-9, May-Aug 2003.

101. MIZIARA, A. P.B. Consumo alimentar de crianças de 2 a 6 anos de idade, com relação ao flúor, no município de Bauru - São Paulo. São Paulo, 2006. 219 p. Dissertação (Mestrado) - Faculdade de Ciências Farmacêuticas da USP. Faculdade de Economia, Administração e Contabilidade da USP. Faculdade de Saúde Pública da USP. Curso Interunidades em Nutrição Humana Aplicada.

102. MONTEIRO, C. A. et al. Da desnutrição para a obesidade: a transição nutricional no Brasil. In: . (Org.). Velhos e novos males da saúde no Brasil: a evolução do país e suas doenças. São Paulo: Hucitec, 1995. p.247-55.

103. MONTEIRO, C. A.; CONDE, W. L. A tendência secular da obesidade segundo estratos sociais: Nordeste e Sudeste do Brasil, 1975-1989-1997. Arq Bras Endocrinol Metabol, v.43, p.186-194, mês., 1999. 
104. MONTEIRO, C. A, CONDE, W. L. Tendência secular da desnutrição e da obesidade na infância na cidade de São Paulo (1974-1996). Rev. Saúde Pública, v.34, p.52-61, 2000. (6 Supl).

105. MUHLER, J.C. et al. The effect of a stannous fluoride-containing dentifrice on caries reduction in children. J. dent. Res., v.33, n.5, p.606-12, Oct. 1954.

106. NISHIJIMA, M.T. et al. A comparison of dietary fluoride intakes from food samples in Japan and Brazil. Bull Tokyo Dent Coll , v.34, n.2, p.43-50, 1993.

107. NOHNO, $\mathrm{K}$ et al. Fluoride intake from food and liquid in Japanese children living in two areas with different fluoride concentrations in the water supply. Caries Res., v.40, n.6, p.487-93, 2006.

108. NUZZO,L. Avaliação do estado nutricional de adolescentes de uma instituição particular de ensino. 1998.76p. Dissertação (Mestrado em Saúde Pública) - Faculdade de Saúde Pública, Universidade de são Paulo, São Paulo,1998.

109. OPHAUG et al. Estimated fluoride intake of 6-month-old infants in four dietary regions of the United States. American Journal of Clinical Nutrition, v.33, n.2,p.324-327, oct.,1980.

110. PANG, D.T.Y.; PHILIPPS, C.L.; BAWDEN, J.W. Fluride intake from beverage comsumption in a sample of North Carolina children. J. dent. Res., v.71, n.7, p.13828, July 1992.

111. PENDRYS, D.G.; KATZ, R.V. Risk of enamel fluorosis associated with fluoride supplementation, infant formula, and fluoride dentifrice use. Amer. J. Epidemiol., v.130, n.6, p.1199-208, Dec. 1989.

112. PENDRYS, D.G.; MORSE, D.E. Use of fluoride supplementation by children living in fluoridated communities. ASDC J. Dent. Child., v.57, n.5, p.343-7 Sept. / Oct. 1990. 
113. PENDRYS, D.G.; MORSE, D.E. Fluoride supplement use by children in fluoridated communities. J. Publ. Hlth. Dent., v.55, n.3, p.160-4, Summer 1995.

114. PENDRYS, D.G.; KATZ, R.V.; MORSE, D.E. Risk factors for enamel fluorosis in a nomfluoridated population. Amer. J. Epidemiol., v.143, n.8, p.808-15, Apr. 1996.

115. PENDRYS, D.G.; KATZ, R.V. Risk factors for enamel fluorosis in optimally fluoridated children born after the US manufacturer's decision to reduce the fluoride concentration of infant formula. Amer. J. Epidemiol., v.148, n.10, p.967-74, Nov. 1998.

116. PEREIRA, A.C. et al. Dental caries and fluorosis prevalence study in a nonfluoridated Brazilian community: trend analysis and toothpaste association. ASDC J. Dent. Child., v.67, n.2, p.132-5, Mar./Apr. 2000.

117. PERSSON, L. A.; CARLGREN, G. Measuring children's diet: evaluation of dietary assessment techniques in infancy and childhood. Int J Epidemiol., v.13, n.4, p506-517.,Dec., 1984.

118. PESSAN, J.P.; SILVA, S.M.B.; BUZALAF, M.A.R. Evaluation of the total fluoride intake of 4-7-years-old children from diet and dentifrice. J. Appl. Oral Sci., v.11, n.2, p.150-6, 2003.

119. PESSAN, J.P. et al. Analysis of fingernails and urine as biomarkers of fluoride exposure from dentifrice and varnish in 4- to 7- years-old children. Caries Res., v.39, n.5, p.363-70, Sept./Oct. 2005.

120. PHILIPPI, S. T. et al. Alimentação saudável na infância e adolescência. In: SILVA, M. V. (Org.). Curso de atualização em alimentação e nutrição para professores da rede pública de ensino. São Paulo: Universidade de São Paulo, Escola Superior de Agricultura Luiz de Queiroz, 2000. p. 46-60. 
121. PHILIPPI, S. T.; CRUZ, A. T. R.; COLUCCI, A. C. A. Pirâmide Alimentar para crianças de 2 a 3 anos. Rev Nutr, v.16, n.1, p.5-19, 2003.

122. [PNUD] PROGRAMA DAS NAÇÕES UNIDAS PARA O DESENVOLVIMENTO. Relatório do desenvolvimento humano, 2003.

123. RAMIRES, I. et al. Evaluation of the fluoride concentration and consumption of mineral water. Rev. Saúde públ., v.38, n.5, p.459-65, jun. 2004.

124. RAMIRES, I. et al. Fluoridation of the public water supply and prevalence of dental fluorosis in a peripheral district of the municipality of Bauru, SP. J. Appl. Oral Sci., v.14, n.2, p.136-141, 2006.

125. RAMIRES, I. et al. Heterocontrole da fluoretação da água de abastecimento público em Bauru, SP, Brasil. Rev. Saúde públ., v.40, n.5, p.883-889, 2006.

126. RICHARDS, A; BANTING, D.W. Fluoride toothpastes. In: Fejerskov, O.; Ekstrand, J.; Burt, B.A. Fluoride in dentistry. 2.ed. Copenhagen, Munksgaard, 1996, p. 328-46.

127. RIORDAN, P.J.; BANKS, J.A. Dental fluorosis and fluoride exposure in Western Australia. J. dent. Res., v.70, n.7, p.1022-8, July 1991.

128. ROCKETT, H.R.H.; COLDITZ, G. A. Assessing diets of children and adolescents. American Journal of clinical Nutrition, v.65 p.1116S-1122S,1997, (4 suppl).

129. RODRIGUES, M.H.C.; BASTOS, J.R.M.; BUZALAF, M.A.R. Fingernails and toenails of subcronic exposure fluoride from dentifrice in 2-to3 year old children. Caries Res., v.38, n.2, p.109-14, Mar/Apr. 2004. 
130. RODRIGUES, M.H.C. Concentração de flúor nas unhas e na urina: comparação entre crianças que receberam água natural ou artificialmente fluoretada, sal ou leite fluoretado. 2007. 186 p. Tese (Doutorado)- Faculdade de Odontologia de bauru. Universidade de São Paulo.

131. SANTIAGO, B.M. et al. Conhecimento dos médicos pediatras acerca da saúde bucal de bebês. Rev Bras Odontol, v.59, n.2, p.86-9, 2002.

132. SCHALKA, M.M.; RODRIGUES, C.R.M.D. A importância do médico pediatra na promoção de saúde bucal. Rev. Saúde Publ., v.30, n.2, p.179-86, 1996.

133. SICHIERI, R. Estudo de validação do questionário de freqüência de consumo de alimentos. Epidemiologia da obesidade. Rio de Janeiro: Eduerj, 1998. p.25-34.

134. SILVA M.; REYNOLDS, E.C. Fluoride content of infant formulae in Australia. Aus Dent J. , v.41,n.1,p.37-42, 1996.

135. SELWITZ, R.H. et al. Prevalence of dental caries and dental fluorosis in areas with optimal and above-optimal water fluoride concentrations: a 10-year follow-up survey. J Public Health Dent, v. 55, n.2, p.85-93, 1995.

136. SLATER, B. Desenvolvimento e validação de um questionário semiquantitativo de freqüência alimentar para adolescentes. 2001.Tese (Doutorado em Saúde Pública) - Faculdade de Saúde Pública, Universidade de São Paulo, 2001.

137. SLATER,B. et al. Validação de questionários de frequencia alimentar-QFA; considerações metodológicas. Revista Brasileira de Epidemiologia, v.6, n.3, p.200-208, 2003.

138. SMITH R. Doctors can reduce the harmful effects of poverty. Brit. med. J., v.314, p.698, 1997. 
139. SPAK, C.K.; EKSTRAND, J.; ZYLBERSTEIN, D. Bioavailability of fluoride added by baby formula and milk. Caries Res., v.16, n.3, p.249-56, 1982.

140. SPUZNAR, S.M.; BURT, B.A. Dental caries, dental fluorosis, and fluoride exposure in Michigan schoolchildren. J. dent. Res., v.67, n.5, p.802-6, May 1988.

141. TABARI, E.D. et al. Dental fluorosis in permanent incisor teeth in relation to water fluoridation, social deprivation and toothpaste use in infancy. Brit. dent. J., v.189, n.4, p.216-20, Aug. 2000.

142. TAVES, D.R. Separation of fluoride by rapid diffusion using hexamethyldisiloxane. Talanta, v.15, p.969-74, 1968.

143. TAVES, D.R. Dietary fluoride intake of fluoride ashed (total fluoride) unashed (inorganic fluoride) analysis of individual foods. Brit. dent. J., v.49, n.3, p.295-301, May 1983.

144. TEN CATE, J.M.; DUIJSTERS, P.P.E. Influence of fluoride in solution on tooth demineralization. I. Chemical data. Caries Res, v.17, p. 513-519, 1983.

145. TEN CATE, J.M.; FEATHERSTONE, J.D.B. Mechanistic aspects of the interactions between fluoride and dental enamel. Crit Rev Oral Biol Med, v.2, p.283296, 1991.

146. THOMPSON, F. E.; BYERS, T. Dietary assessment resource manual. J Nutr, v.124, p.2245S-2317S, 1994.

147. THYLSTRUP, A. FEJERSKOV, O .Clinical appearance of dental fluorosis in permanent teeth in relation to histologic changes. Community Dent Oral Epidemiol., v.6, n.6, p.315-28, Nov.,1978.

148. TOUMBA, K.J.; CORZON, M.E.J. The fluoride content of bottled drinking waters. Br Dent J, v.176, n.7, p.266-8, 1994. 
149. TRAUTNER, K.; SIEBERT, G. An experimental study of bioavailability of fluoride from dietary source in man. Arch. oral Biol., v.31, n.4, p.223-8, 1986.

150. TRAUTNER, K.; EINWAG, J. Influence of milk and food on fluoride bioavailability from $\mathrm{NaF}$ and $\mathrm{Na}_{2} \mathrm{FPO}_{3}$ in man. J. dent. Res., v.68, n.1, p.72-7, Jan. 1989.

151. TSUTSUI, A.; YAGI, M. HOROWITZ, A.M. The prevalence of dental caries and fluorosis in japanese communities with up to $1.4 \mathrm{ppm}$ of naturally occurring fluoride. J Public Health Dent, v.60, n.3, p.147-53, 2000.

152. VIEGAS, A.R. et al. Fluoretação da água de abastecimento público. Rev. Ass. paul. cirurg. Dent., v.41, n.4, p.202-4, jul./ago. 1987.

153. VILLENA, R.S.; BORGES, D.G.; CURY, J.A. Avaliação da concentração de flúor em águas minerais comercializadas no Brasil. . Rev. Saúde públ., v.30, n.6, p.512-8, dez. 1996.

154. WANG, N.J.; GROPEN, A.M.; OGAARD, B. Risk factors associated with fluorosis in a non-fluoridated population in Norway. Comm Dent Oral Epidemiol, v.25, n.6, p.396-401, 1997.

155. WARREN, J.J.; LEVY, S.M.A. A review of fluoride dentifrice related to fluorosis. Pediat. Dent., v.21, n.4, p.265-71, July /Aug. 1999.

156. WHITFORD, G.M. The physiological and toxicological characteristics of fluoride. J. dent. Res., v.69, p.539-49, Feb. 1990. Special issue.

157. WHITFORD, G.M. Intake and metabolism of fluoride. Advanc. dent. Res., v.8, n.1, p.5-14, June 1994.

158. WHITFORD, G. M. The metabolism and toxicity of fluoride. 2.ed. Basel, Karger, 1996. 
159. WHITFORD, G.M. et al. Fluoride pharmacokinetics following ingestion of water containing different fluoride compounds. Caries Res., v.40, n.4, p.308, 2006. /Abstract n. 14/.

160. WILLETT, W. C. et al. Reproducibility and validity of semiquantitative foodfrequency questionnaire. Am J Epidemiol, v.122, p.51-65, 1985.

161. WILLETT, W. C. Nutrition and epidemiology. In: Monographs in epidemiology and statistic. New York: Oxford University Press;,1990. p. 52-68.

162. WILLETT, W.C. The dietary pyramid: does the foundation need repair? Am J Clin Nutr., v.68, n.2, p.218-9, Aug, 1998.

163. WORLD HEALTH ORGANIZATION. Fluorides and oral health. Technical Report Series No. 846. Geneva: WHO; 1994.

164. ZACHERL, W.A.; LONG, D.M. Reduction in caries attack rate - nonfluoridated community. J. dent. Res., v. 58, p. 227, 1979. /Abstract n. 535/.

165. ZULKIFLI, S. N.; YU, S. M. The food frequency method for dietary assessment. J Am Diet Assoc, v.92, n., p.615-618, 1992.

166. ZIEGLER E. Kariesprophylaxe durch Fluoridierung der Milch. Schweiz Med Wochenschr, v.83, p.723-4, 1953. 


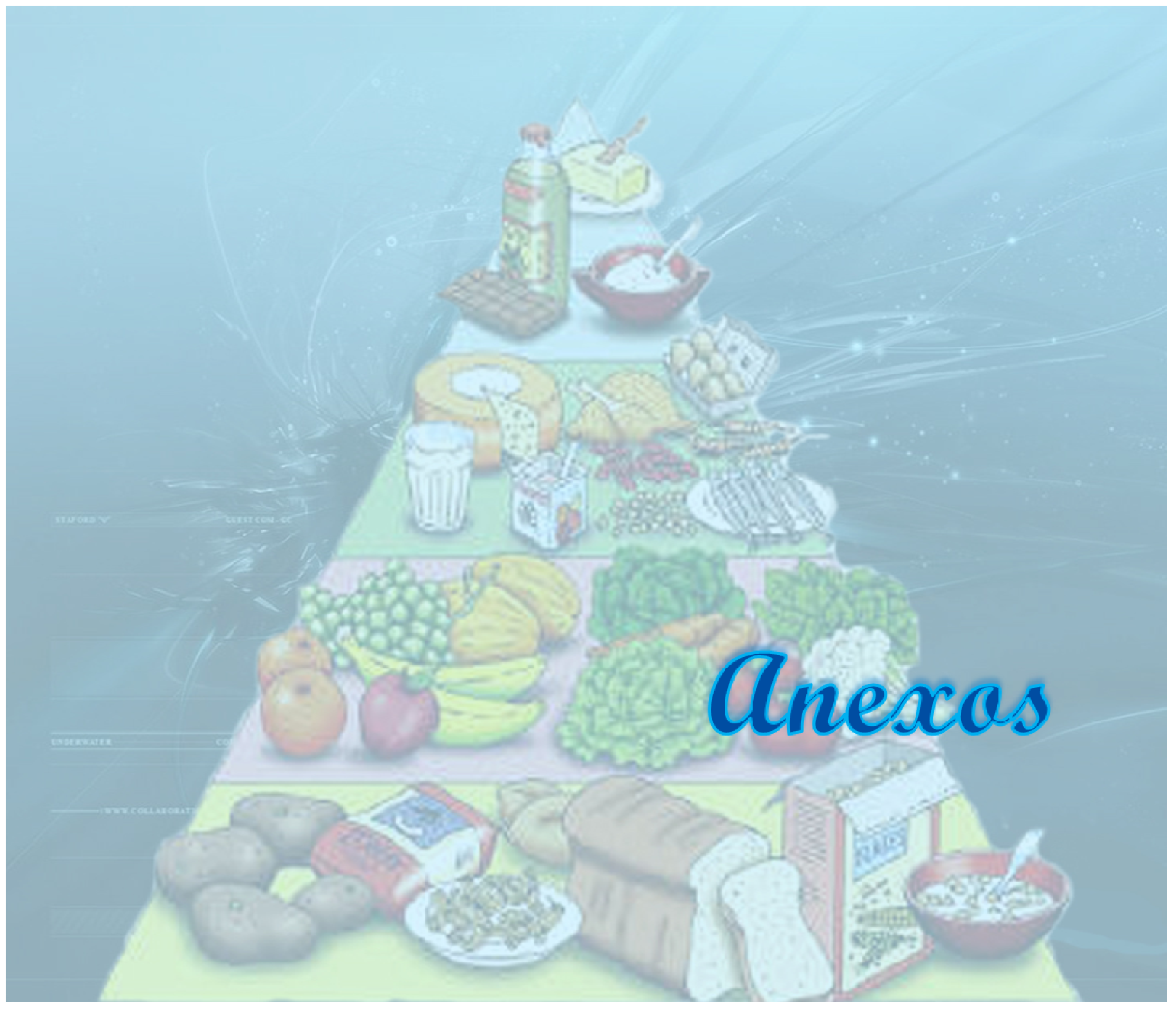


ANEXO 1

Aprovação do CEP

\author{
Universidade de São Paulo \\ Faculdade de Odontologia de Bauru \\ Al. Dr. Octávio Pinheiro Brisolla, 9-75 - Bauru-SP - CEP 17012-901 - C.P. 73 \\ PABX (0XX14)3235-8000-FAX (0XX14)3223-4679 \\ Comitê de Ética em Pesquisa
}

Processo n $n^{\circ} 68 / 2004$

Bauru, 01 de julho de 2004.

Senhora Professora,

O projeto de pesquisa encaminhado a este Comitê de Ética em Pesquisa em Seres Humanos, denominado "Avalią̧ãe da ingestão de flúor de crianças brasileiras de 2-6 anos de idade", de autoria de Flávia Mauad Levy, que será deseñvolvido sob sua orientação e colaboração do Prof. Dr. Fábio Correia Sampaio e da Prof $\mathrm{Dr}^{-2}$ Sônia Tucunduva Plilippi, foi enviado ao relator para avaliação.

Na reunião de 23 de junho de 2004 o parecer do relator, aprovando - projeto, foi aceito pelo Comitê, considerando que não existem infraçôes éticas pendentes.

Informamos que após o eivio do trabalho concluido, este Comitê enviará o parecer final, que será utilizado para publicação do trabalho.

Atenciosamente,

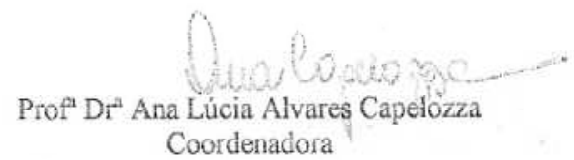

İ $\mathrm{m}^{\mathrm{a}} \mathrm{Sr}^{\mathrm{a}} \operatorname{Prof}^{\mathrm{a}} \mathrm{D} \mathrm{r}^{\mathrm{a}}$ Mirarilia Afonso Rabelo Buzalaf

DD. Docente do Departamento de Ciências Biológicas (Bioquímica) 


\title{
CARTA DE INFORMAÇÃO AO VOLUNTÁRIO E TERMO DE CONSENTIMENTO LIVRE E ESCLARECIDO
}

\author{
UNIVERSIDADE DE SÃO PAULO \\ FACULDADE DE ODONTOLOGIA DE BAURU \\ Departamento de Ciências Biológicas
}

\section{CARTA DE INFORMACÃO AO VOLUNTÁRIO}

A fluorose dentária pode ser vista na forma de manchas nos dentes, que vão desde esbranquiçadas, até amarronzadas. O número de casos vem aumentando em regiões que têm ou não flúor na água de abastecimento. A fluorose dentária é causada quando existe uma ingestão muito grande de flúor ingerido entre 2 e 6 anos de idade, que é a época em que os dentes estão se formando. Entre as fontes de flúor temos a água de beber e os alimentos. Por isto, é importante conhecer a quantidade de flúor presente nos alimentos infantis. Este trabalho tem por objetivo identificar os alimentos mais consumidos por crianças brasileiras de 2-6 anos, para que depois se possa medir a quantidade de flúor presente nos mesmos. Com estes dados, será possível ter uma idéia da quantidade de flúor que as crianças estão ingerindo a partir dos alimentos. Assim, para se identificar os alimentos mais consumidos pelas crianças, um questionário será respondido pelos pais ou responsáveis. Em uma segunda etapa, a ser realizada apenas com parte dos voluntários da região Sudeste, escolhidos através de sorteio entre os participantes da primeira etapa, será coletada toda a dieta das crianças durante 2 dias consecutivos. Para isto, tudo o que a criança comer ou beber num determinado dia, será coletado em um recipiente e fornecido para os pesquisadores. Nestes voluntários selecionados, também será avaliada a ingestão de dentifrício através da escovação. Para isto, estas crianças escovarão os dentes, do mesmo jeito que escovam normalmente, na presença dos pesquisadores e tudo o que a criança cuspir durante a realização da escovação será coletado pelos pesquisadores. Os pesquisadores estarão sempre à disposição para o esclarecimento de quaisquer dúvidas sobre o trabalho de pesquisa. Em caso de dúvida, entrar em contato com a pesquisadora Flávia Mauad Levy (3227-7166 ou 9717-3045) ou Profạ. Marília Buzalaf (3225-8346).

\section{TERMO DE CONSENTIMENTO LIVRE E ESCLARECIDO}

Pelo presente instrumento que atende às exigências legais, o Sr. (a) portador da cédula de identidade após leitura minuciosa da CARTA DE INFORMAÇÃO AO VOLUNTÁRIO, devidamente explicada pelos profissionais em seus mínimos detalhes, ciente dos serviços e procedimentos aos quais seu filho será submetido, não restando quaisquer dúvidas a respeito do lido e explicado, firma seu CONSENTIMENTO LIVRE E ESCLARECIDO concordando em permitir a participação de seu filho participar da pesquisa proposta.

Fica claro que o paciente ou seu representante legal podem, a qualquer momento, retirar seu CONSENTIMENTO LIVRE E ESCLARECIDO e deixar de participar desta pesquisa e ciente de que todas as informações prestadas tornaram-se confidenciais e guardadas por força de sigilo profissional (Art. $9^{\circ}$ do Código de Ética Odontológica).

Por estarem de acordo assinam o presente termo.

Pirajuí-SP, de de 
ANEXO 3

QFA

$N^{\circ}$ de identificação:

Data:

\section{Avaliação da ingestão de flúor de crianças brasileiras de 2 a 6 anos de idade}

\section{1 - Dados de identificação:}

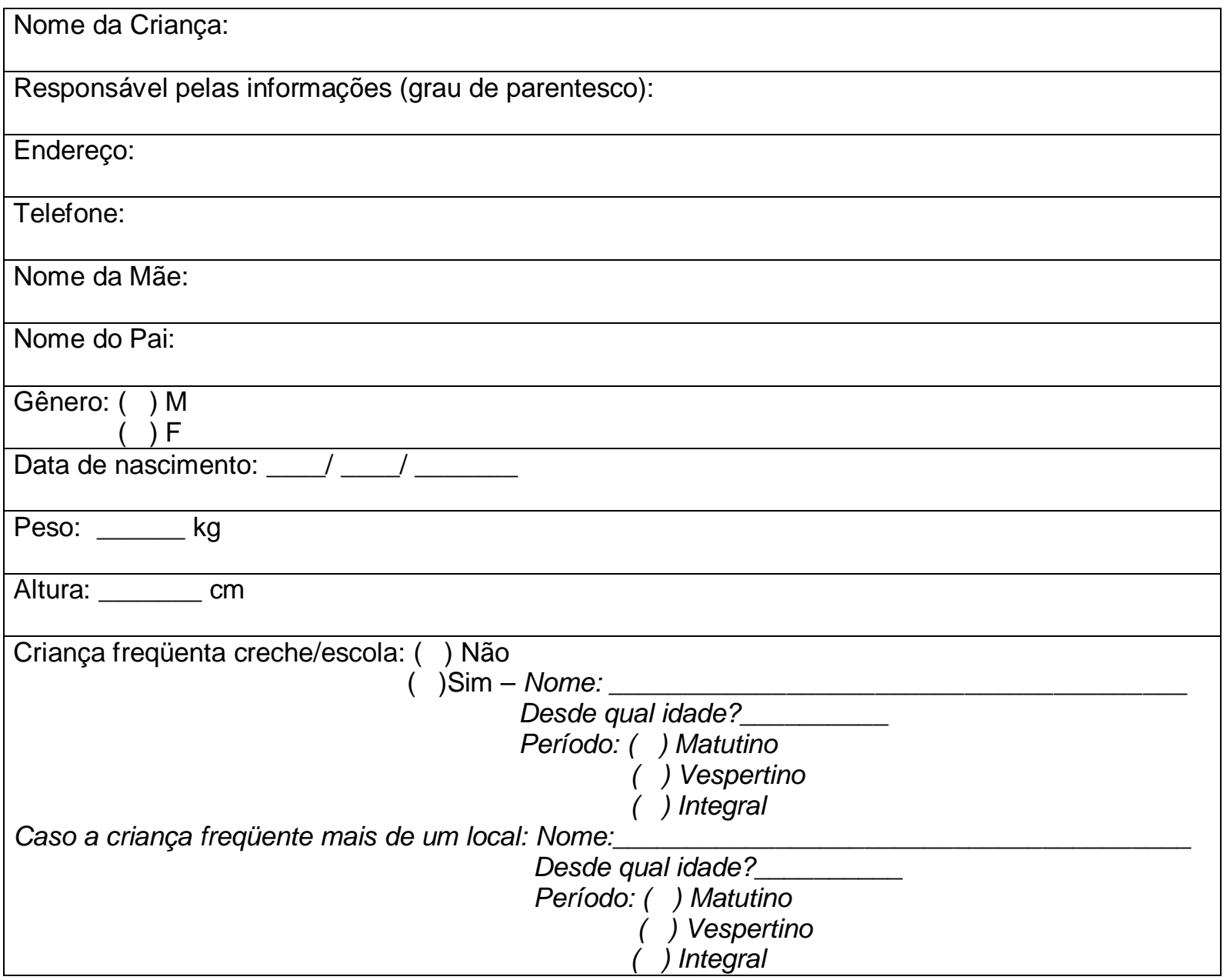




\section{QUESTIONÁRIO DE FREQÜÊNCIA ALIMENTAR SEMIQUANTITATIVO (QFAsq)}

Assinale com um $X$ a quantidade de cada alimento que a criança consumiu habitualmente durante os últimos 6 meses:

Arroz, Pão, Massa, Batata

\begin{tabular}{|c|c|c|c|}
\hline $\begin{array}{l}\text { (1) Nunca } \\
\text { (2) Menos de } 1 \text { vez por mês } \\
\text { (3) } 1 \text { a } 3 \text { vezes por mês } \\
\text { (4) } 1 \text { vez por semana } \\
\text { (5) } 2 \text { a } 4 \text { vezes por semana } \\
\text { (6) } 1 \text { vez por dia } \\
\text { (7) } 2 \text { ou mais vezes por dia }\end{array}$ & $\begin{array}{l}\text { (1) Nunca } \\
\text { (2) Menos de } 1 \text { vez por mês } \\
\text { (3) } 1 \text { a } 3 \text { vezes por mês } \\
\text { (4) } 1 \text { vez por semana } \\
\text { (5) } 2 \text { a } 4 \text { vezes por semana } \\
\text { (6) } 1 \text { vez por dia } \\
\text { (7) } 2 \text { ou mais vezes por dia }\end{array}$ & $\begin{array}{l}\text { (1) Nunca } \\
\text { (2) Menos de } 1 \text { vez por mês } \\
\text { (3) } 1 \text { a } 3 \text { vezes por mês } \\
\text { (4) } 1 \text { vez por semana } \\
\text { (5) } 2 \text { a } 4 \text { vezes por semana } \\
\text { (6) } 1 \text { vez por dia } \\
\text { (7) } 2 \text { ou mais vezes por dia }\end{array}$ & 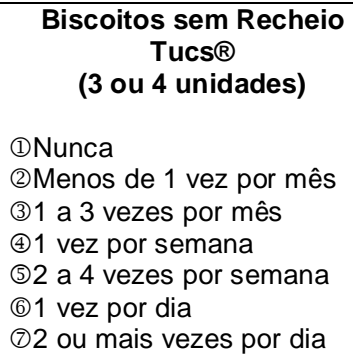 \\
\hline $\begin{array}{l}\begin{array}{r}\text { Biscoitos com Recheio } \\
\text { Chocolate, Wafer } \\
\text { (3 unidades) }\end{array} \\
\text { (1) Nunca } \\
\text { (2) Menos de } 1 \text { vez por mês } \\
\text { (3)1 a } 3 \text { vezes por mês } \\
\text { (4)1 vez por semana } \\
\text { (5) } 2 \text { a } 4 \text { vezes por semana } \\
\text { (6)1 vez por dia } \\
\text { (7) } 2 \text { ou mais vezes por dia }\end{array}$ & $\begin{array}{l}\begin{array}{c}\text { Cereal Matinal tipo } \\
\text { Snowflakes }{ }^{\circledR} \\
\text { (1 xícara) }\end{array} \\
\text { (1) Nunca } \\
\text { (2)Menos de } 1 \text { vez por mês } \\
\text { (3)1 a } 3 \text { vezes por mês } \\
\text { (4)1 vez por semana } \\
\text { (5)2 a } 4 \text { vezes por semana } \\
\text { (6)1 vez por dia } \\
\text { (7)2 ou mais vezes por dia }\end{array}$ & $\begin{array}{l}\text { (1) Nunca } \\
\text { (2) Menos de } 1 \text { vez por mês } \\
\text { (3) } 1 \text { a } 3 \text { vezes por mês } \\
\text { (4) } 1 \text { vez por semana } \\
\text { (5) } 2 \text { a } 4 \text { vezes por semana } \\
\text { (6) } 1 \text { vez por dia } \\
\text { (7) } 2 \text { ou mais vezes por dia }\end{array}$ & $\begin{array}{l}\text { Macarrão Nissin Miojo® } \\
\text { (1/3 do pacote) }\end{array}$ \\
\hline & $\begin{array}{l}\text { Pão Francês } \\
\text { (1/2 unidade) }\end{array}$ & $\begin{array}{l}\text { Espessantes - Maizena®, } \\
\text { Farinha Láctea }{ }^{\circledR} \text {, } \\
\text { Mucilon } \AA^{*} \text {, Cremogema } \\
\text { (1 ou } 2 \text { colheres de sopa) } \\
\text { (1) Nunca } \\
\text { (2) Menos de } 1 \text { vez por mês } \\
\text { (3)1 a } 3 \text { vezes por mês } \\
\text { (4)1 vez por semana } \\
\text { (5) } 2 \text { a } 4 \text { vezes por semana } \\
\text { (6) } 1 \text { vez por dia } \\
\text { (7) } 2 \text { ou mais vezes por dia }\end{array}$ & \\
\hline
\end{tabular}

Feijão

Feijão

( $1 / 2$ concha)

(1)Nunca

(2) Menos de 1 vez por mês

(3)1 a 3 vezes por mês

(4)1 vez por semana

(5) 2 a 4 vezes por semana

(6) 1 vez por dia

(7) 2 ou mais vezes por dia 


\section{Verduras e legumes}

Obs.: As sopas com os legumes deverão ser informados no grupo dos salgados e preparações (a seguir). Neste momento, assinale apenas quando o alimento for consumido cozido, refogado ou em salada.

\begin{tabular}{|c|c|c|c|}
\hline $\begin{array}{l}\text { Abóbora } \\
\text { (2 colheres de sopa) } \\
\text { (1) Nunca } \\
\text { (2)Menos de } 1 \text { vez por mês } \\
\text { (3)1 a } 3 \text { vezes por mês } \\
\text { (4)1 vez por semana } \\
\text { (5)2 a } 4 \text { vezes por semana } \\
\text { (6)1 vez por dia } \\
\text { (7) ou mais vezes por dia }\end{array}$ & $\begin{array}{l}\text { Alface } \\
\text { (2 folhas) }\end{array}$ & $\begin{array}{l}\text { Repolho } \\
\text { ( } 1 \text { colher de sopa) } \\
\text { (1) Nunca } \\
\text { (2)Menos de } 1 \text { vez por mês } \\
\text { (3)1 a } 3 \text { vezes por mês } \\
\text { (4)1 vez por semana } \\
\text { (5) a } 4 \text { vezes por semana } \\
\text { (6)1 vez por dia } \\
\text { (7)2 ou mais vezes por dia }\end{array}$ & $\begin{array}{l}\text { Tomate } \\
\text { (3 fatias) }\end{array}$ \\
\hline $\begin{array}{l}\text { Molho de Tomate } \\
\text { (1 colher de sopa) }\end{array}$ & $\begin{array}{l}\text { Cenoura } \\
\text { (1/2 colher de servir) } \\
\text { (1) Nunca } \\
\text { (2)Menos de } 1 \text { vez por mês } \\
\text { (3)1 a } 3 \text { vezes por mês } \\
\text { (4)1 vez por semana } \\
\text { (5) a } 4 \text { vezes por semana } \\
\text { (6) } 1 \text { vez por dia } \\
\text { (7)2 ou mais vezes por dia }\end{array}$ & $\begin{array}{l}\text { Chuchu } \\
\text { (1 colher de sopa) } \\
\text { (1) Nunca } \\
\text { (2) Menos de 1 vez por mês } \\
\text { (3)1 a } 3 \text { vezes por mês } \\
\text { (4)1 vez por semana } \\
\text { (5)2 a } 4 \text { vezes por semana } \\
\text { (6)1 vez por dia } \\
\text { (7)2 ou mais vezes por dia }\end{array}$ & $\begin{array}{l}\text { Mandioquinha } \\
\text { (1/2 colher de sopa) } \\
\text { (1) Nunca } \\
\text { (2) Menos de 1 vez por mês } \\
\text { (3)1 a } 3 \text { vezes por mês } \\
\text { (4)1 vez por semana } \\
\text { (5) 2 a } 4 \text { vezes por semana } \\
\text { (6)1 vez por dia } \\
\text { (7) ou mais vezes por dia }\end{array}$ \\
\hline
\end{tabular}

\section{Frutas}

\begin{tabular}{|c|c|c|c|c|c|c|}
\hline $\begin{array}{l}\text { Banana } \\
\text { (1 unidade) }\end{array}$ & \multicolumn{2}{|c|}{$\begin{array}{l}\text { (1) Nunca } \\
\text { (2) Menos de } 1 \text { vez por mês } \\
\text { (3) } 1 \text { a } 3 \text { vezes por mês } \\
\text { (4) } 1 \text { vez por semana } \\
\text { (5) } 2 \text { a } 4 \text { vezes por semana } \\
\text { (6) } 1 \text { vez por dia } \\
\text { (7) } 2 \text { ou mais vezes por dia }\end{array}$} & \multicolumn{2}{|c|}{$\begin{array}{l}\text { (1) Nunca } \\
\text { (2) Menos de } 1 \text { vez por mês } \\
\text { (3) } 1 \text { a } 3 \text { vezes por mês } \\
\text { (4) } 1 \text { vez por semana } \\
\text { (5) } 2 \text { a } 4 \text { vezes por semana } \\
\text { (6) } 1 \text { vez por dia } \\
\text { (7) } 2 \text { ou mais vezes por dia }\end{array}$} & \multicolumn{2}{|c|}{$\begin{array}{l}\text { (1) Nunca } \\
\text { (2) Menos de } 1 \text { vez por mês } \\
\text { (3) } 1 \text { a } 3 \text { vezes por mês } \\
\text { (4) } 1 \text { vez por semana } \\
\text { (5) } 2 \text { a } 4 \text { vezes por semana } \\
\text { (6) } 1 \text { vez por dia } \\
\text { (7) } 2 \text { ou mais vezes por dia }\end{array}$} \\
\hline \multicolumn{2}{|c|}{$\begin{array}{l}\text { (1) Nunca } \\
\text { (2) Menos de } 1 \text { vez por mês } \\
\text { (3) } 1 \text { a } 3 \text { vezes por mês } \\
\text { (4) } 1 \text { vez por semana } \\
\text { (5) } 2 \text { a } 4 \text { vezes por semana } \\
\text { (6) } 1 \text { vez por dia } \\
\text { (7) } 2 \text { ou mais vezes por dia }\end{array}$} & \multicolumn{2}{|c|}{$\begin{array}{l}\text { (1) Nunca } \\
\text { (2) Menos de } 1 \text { vez por mês } \\
\text { (3) } 1 \text { a } 3 \text { vezes por mês } \\
\text { (4) } 1 \text { vez por semana } \\
\text { (5) } 2 \text { a } 4 \text { vezes por semana } \\
\text { (6) } 1 \text { vez por dia } \\
\text { (7) } 2 \text { ou mais vezes por dia }\end{array}$} & \multicolumn{2}{|c|}{$\begin{array}{l}\text { (1) Nunca } \\
\text { (2) Menos de } 1 \text { vez por mês } \\
\text { (3) } 1 \text { a } 3 \text { vezes por mês } \\
\text { (4) } 1 \text { vez por semana } \\
\text { (5) } 2 \text { a } 4 \text { vezes por semana } \\
\text { (6) } 1 \text { vez por dia } \\
\text { (7) } 2 \text { ou mais vezes por dia }\end{array}$} & \\
\hline
\end{tabular}


Carnes e Ovos

\begin{tabular}{|c|c|c|c|}
\hline $\begin{array}{c}\text { Bife } \\
\text { (1 unidade) }\end{array}$ & $\begin{array}{c}\text { Carne Cozida } \\
\text { (panela/moída) } \\
(1 / 2 \text { fatia/3 colheres de } \\
\text { sopa) }\end{array}$ & $\begin{array}{l}\text { Lingüiça Perdigão® } \\
(1 / 2 \text { gomo })\end{array}$ & $\begin{array}{c}\text { Presunto Sadia } \AA \\
\text { (1 fatia) }\end{array}$ \\
\hline $\begin{array}{l}\text { (1) Nunca } \\
\text { (2) Menos de } 1 \text { vez por mês } \\
\text { (3) } 1 \text { a } 3 \text { vezes por mês } \\
\text { (4) } 1 \text { vez por semana } \\
\text { (5) a } 4 \text { vezes por semana } \\
\text { (6) } 1 \text { vez por dia } \\
\text { (7) } 2 \text { ou mais vezes por dia }\end{array}$ & $\begin{array}{l}\text { (1) Nunca } \\
\text { (2) Menos de } 1 \text { vez por mês } \\
\text { (3) } 1 \text { a } 3 \text { vezes por mês } \\
\text { (4) } 1 \text { vez por semana } \\
\text { (5) a } 4 \text { vezes por semana } \\
\text { (6) } 1 \text { vez por dia } \\
\text { (7) } 2 \text { ou mais vezes por dia }\end{array}$ & $\begin{array}{l}\text { (1) Nunca } \\
\text { (2)Menos de } 1 \text { vez por mês } \\
\text { (3) } 1 \text { a } 3 \text { vezes por mês } \\
\text { (4) } 1 \text { vez por semana } \\
\text { (5) a } 4 \text { vezes por semana } \\
\text { (6) } 1 \text { vez por dia } \\
\text { (7) } 2 \text { ou mais vezes por dia }\end{array}$ & $\begin{array}{l}\text { (1) Nunca } \\
\text { (2) Menos de } 1 \text { vez por mês } \\
\text { (3) } 1 \text { a } 3 \text { vezes por mês } \\
\text { (4) } 1 \text { vez por semana } \\
\text { (5) a } 4 \text { vezes por semana } \\
\text { (6) } 1 \text { vez por dia } \\
\text { (7) } 2 \text { ou mais vezes por dia }\end{array}$ \\
\hline $\begin{array}{c}\text { Bife de Fígado de Boi } \\
\text { (1 unidade) }\end{array}$ & $\begin{array}{l}\text { Frango (Cozido, Frito, } \\
\text { Grelhado, Assado) } \\
\text { (1 pedaço / } 1 \text { unidade) }\end{array}$ & $\begin{array}{l}\text { Peixe (Cozido, Frito) } \\
\text { (1/2 filé / 1/2 pedaço) }\end{array}$ & $\begin{array}{c}\text { Ovo (Frito, Cozido) } \\
\text { (1 unidade) }\end{array}$ \\
\hline $\begin{array}{l}\text { (1) Nunca } \\
\text { (2) Menos de } 1 \text { vez por mês } \\
\text { (3) } 1 \text { a } 3 \text { vezes por mês } \\
\text { (4) } 1 \text { vez por semana } \\
\text { (5) } 2 \text { a } 4 \text { vezes por semana } \\
\text { (6) } 1 \text { vez por dia } \\
\text { (7) } 2 \text { ou mais vezes por dia }\end{array}$ & $\begin{array}{l}\text { (1) Nunca } \\
\text { (2) Menos de } 1 \text { vez por mês } \\
\text { (3) } 1 \text { a } 3 \text { vezes por mês } \\
\text { (4) } 1 \text { vez por semana } \\
\text { (5) a } 4 \text { vezes por semana } \\
\text { (6) } 1 \text { vez por dia } \\
\text { (7) } 2 \text { ou mais vezes por dia }\end{array}$ & $\begin{array}{l}\text { (1) Nunca } \\
\text { (2) Menos de } 1 \text { vez por mês } \\
\text { (3) } 1 \text { a } 3 \text { vezes por mês } \\
\text { (4) } 1 \text { vez por semana } \\
\text { (5) } 2 \text { a } 4 \text { vezes por semana } \\
\text { (6) } 1 \text { vez por dia } \\
\text { (7) } 2 \text { ou mais vezes por dia }\end{array}$ & $\begin{array}{l}\text { (1) Nunca } \\
\text { (2)Menos de } 1 \text { vez por mês } \\
\text { (3) } 1 \text { a } 3 \text { vezes por mês } \\
\text { (4) } 1 \text { vez por semana } \\
\text { (5) } 2 \text { a } 4 \text { vezes por semana } \\
\text { (6) } 1 \text { vez por dia } \\
\text { (7) } 2 \text { ou mais vezes por dia }\end{array}$ \\
\hline
\end{tabular}

\section{Leite, Queijo, logurte}

\begin{tabular}{|c|c|c|c|}
\hline $\begin{array}{l}\text { Leite fluido integral } \\
\text { (1 xícara) }\end{array}$ & $\begin{array}{c}\text { Leite em Pó Integral diluído } \\
\text { com água de } \\
\text { abastecimento público } \\
\text { (1 xícara) }\end{array}$ & $\begin{array}{l}\text { Leite em Pó Integral diluído } \\
\text { com água mineral } \\
\text { (1 xícara) }\end{array}$ & $\begin{array}{l}\text { logurte de Frutas } \\
\text { (1 pote) }\end{array}$ \\
\hline $\begin{array}{l}\text { (1) Nunca } \\
\text { (2) Menos de } 1 \text { vez por mês } \\
\text { (3) } 1 \text { a } 3 \text { vezes por mês } \\
\text { (4) } 1 \text { vez por semana } \\
\text { (5) } 2 \text { a } 4 \text { vezes por semana } \\
\text { (6) } 1 \text { vez por dia } \\
\text { (7) } 2 \text { ou mais vezes por dia }\end{array}$ & $\begin{array}{l}\text { (1) Nunca } \\
\text { (2) Menos de } 1 \text { vez por mês } \\
\text { (3) } 1 \text { a } 3 \text { vezes por mês } \\
\text { (4) } 1 \text { vez por semana } \\
\text { (5) } 2 \text { a } 4 \text { vezes por semana } \\
\text { (6) } 1 \text { vez por dia } \\
\text { (7) } 2 \text { ou mais vezes por dia }\end{array}$ & $\begin{array}{l}\text { (1) Nunca } \\
\text { (2) Menos de } 1 \text { vez por mês } \\
\text { (3) } 1 \text { a } 3 \text { vezes por mês } \\
\text { (4) } 1 \text { vez por semana } \\
\text { (5) } 2 \text { a } 4 \text { vezes por semana } \\
\text { (6) } 1 \text { vez por dia } \\
\text { (7) } 2 \text { ou mais vezes por dia }\end{array}$ & $\begin{array}{l}\text { (1) Nunca } \\
\text { (2) Menos de } 1 \text { vez por mês } \\
\text { (3) } 1 \text { a } 3 \text { vezes por mês } \\
\text { (4) } 1 \text { vez por semana } \\
\text { (5) } 2 \text { a } 4 \text { vezes por semana } \\
\text { (6) } 1 \text { vez por dia } \\
\text { (7) } 2 \text { ou mais vezes por dia }\end{array}$ \\
\hline $\begin{array}{c}\text { Danoninho } \AA / \text { Chambinho } \AA \\
\text { (1 pote) }\end{array}$ & $\begin{array}{l}\left.\text { Leite Fermentado (Yakult }{ }^{\circledR}\right) \\
\text { (1 pote) }\end{array}$ & $\begin{array}{l}\text { Margarina / Manteiga } \\
\text { (1 colher de chá) }\end{array}$ & $\begin{array}{c}\text { Queijo Mussarela Tirolez }{ }^{\circledR} \\
\text { (1 fatia) }\end{array}$ \\
\hline $\begin{array}{l}\text { (1) Nunca } \\
\text { (2) Menos de } 1 \text { vez por mês } \\
\text { (3) } 1 \text { a } 3 \text { vezes por mês } \\
\text { (4) } 1 \text { vez por semana } \\
\text { (5) } 2 \text { a } 4 \text { vezes por semana } \\
\text { (6) } 1 \text { vez por dia } \\
\text { (7) } 2 \text { ou mais vezes por dia }\end{array}$ & $\begin{array}{l}\text { (1) Nunca } \\
\text { (2) Menos de } 1 \text { vez por mês } \\
\text { (3) } 1 \text { a } 3 \text { vezes por mês } \\
\text { (4) } 1 \text { vez por semana } \\
\text { (5) } 2 \text { a } 4 \text { vezes por semana } \\
\text { (6) } 1 \text { vez por dia } \\
\text { (7) } 2 \text { ou mais vezes por dia }\end{array}$ & $\begin{array}{l}\text { (1) Nunca } \\
\text { (2) Menos de } 1 \text { vez por mês } \\
\text { (3) } 1 \text { a } 3 \text { vezes por mês } \\
\text { (4) } 1 \text { vez por semana } \\
\text { (5) } 2 \text { a } 4 \text { vezes por semana } \\
\text { (6) } 1 \text { vez por dia } \\
\text { (7) } 2 \text { ou mais vezes por dia }\end{array}$ & $\begin{array}{l}\text { (1) Nunca } \\
\text { (2) Menos de } 1 \text { vez por mês } \\
\text { (3) } 1 \text { a } 3 \text { vezes por mês } \\
\text { (4) } 1 \text { vez por semana } \\
\text { (5) } 2 \text { a } 4 \text { vezes por semana } \\
\text { (6) } 1 \text { vez por dia } \\
\text { (7) } 2 \text { ou mais vezes por dia }\end{array}$ \\
\hline
\end{tabular}

\section{Requeijão}

(1 colher de sobremesa)

(1) Nunca

(2)Menos de 1 vez por mês

(3) 1 a 3 vezes por mês

(4)1 vez por semana

(5) 2 a 4 vezes por semana

(6) 1 vez por dia

(7) 2 ou mais vezes por dia 
Açúcar, Doces e Salgadinhos

\begin{tabular}{|c|c|c|c|}
\hline $\begin{array}{c}\text { Açúcar } \\
\text { (1 1/2 colher de sobremesa) }\end{array}$ & $\begin{array}{c}\text { Achocolatado em Pó } \\
\text { (Nescauß, Toddy } \AA \text { ) } \\
\text { (1 1/2 colher de sobremesa) }\end{array}$ & $\begin{array}{l}\text { Bolo Comum / Chocolate } \\
\text { (1 fatia) }\end{array}$ & $\begin{array}{c}\text { Chocolate / Bombom } \\
\text { (1 unidade) }\end{array}$ \\
\hline $\begin{array}{l}\text { (1) Nunca } \\
\text { (2) Menos de } 1 \text { vez por mês } \\
\text { (3) } 1 \text { a } 3 \text { vezes por mês } \\
\text { (4) } 1 \text { vez por semana } \\
\text { (5) } 2 \text { a } 4 \text { vezes por semana } \\
\text { (6) } 1 \text { vez por dia } \\
\text { (7) } 2 \text { ou mais vezes por dia }\end{array}$ & $\begin{array}{l}\text { (1) Nunca } \\
\text { (2) Menos de } 1 \text { vez por mês } \\
\text { (3) } 1 \text { a } 3 \text { vezes por mês } \\
\text { (4) } 1 \text { vez por semana } \\
\text { (5) } 2 \text { a } 4 \text { vezes por semana } \\
\text { (6) } 1 \text { vez por dia } \\
\text { (7) } 2 \text { ou mais vezes por dia }\end{array}$ & $\begin{array}{l}\text { (1) Nunca } \\
\text { (2) Menos de } 1 \text { vez por mês } \\
\text { (3) } 1 \text { a } 3 \text { vezes por mês } \\
\text { (4) } 1 \text { vez por semana } \\
\text { (5) } 2 \text { a } 4 \text { vezes por semana } \\
\text { (6) } 1 \text { vez por dia } \\
\text { (7) } 2 \text { ou mais vezes por dia }\end{array}$ & $\begin{array}{l}\text { (1) Nunca } \\
\text { (2)Menos de } 1 \text { vez por mês } \\
\text { (3) } 1 \text { a } 3 \text { vezes por mês } \\
\text { (4) } 1 \text { vez por semana } \\
\text { (5) } 2 \text { a } 4 \text { vezes por semana } \\
\text { (6) } 1 \text { vez por dia } \\
\text { (7) } 2 \text { ou mais vezes por dia }\end{array}$ \\
\hline
\end{tabular}

Salgadinho / Batata Chips ${ }^{\circledR}$

(1 pacote pequeno)

(1)Nunca

(2)Menos de 1 vez por mês

(3) 1 a 3 vezes por mês

(4) 1 vez por semana

(5) 2 a 4 vezes por semana

(6) 1 vez por dia

(7) ou mais vezes por dia

Salgados e Preparações

\begin{tabular}{|c|c|c|c|}
\hline $\begin{array}{l}\text { Polenta } \\
\text { (1 colher de servir / } 1 \text { fatia) } \\
\text { (1) Nunca } \\
\text { (2) Menos de } 1 \text { vez por mês } \\
\text { (3) } 1 \text { a } 3 \text { vezes por mês } \\
\text { (4) } 1 \text { vez por semana } \\
\text { (5) } 2 \text { a } 4 \text { vezes por semana } \\
\text { (6) } 1 \text { vez por dia } \\
\text { (7) } 2 \text { ou mais vezes por dia }\end{array}$ & $\begin{array}{l}\text { Sopa com Carne (legumes, } \\
\text { feijão, macarrão) } \\
\text { (1/2 prato) } \\
\text { (1) Nunca } \\
\text { (2) Menos de } 1 \text { vez por mês } \\
\text { (3)1 a } 3 \text { vezes por mês } \\
\text { (4) } 1 \text { vez por semana } \\
\text { (5)2 a } 4 \text { vezes por semana } \\
\text { (6)1 vez por dia } \\
\text { (7) ou mais vezes por dia }\end{array}$ & $\begin{array}{l}\text { Sopa sem Carne (legumes, } \\
\text { feijão, macarrão) } \\
\text { (1/2 prato) }\end{array}$ & $\begin{array}{l}\text { Pão de Queijo } \\
\text { (1 unidade pequena) } \\
\text { (1)Nunca } \\
\text { (2)Menos de 1 vez por mês } \\
\text { (3)1 a } 3 \text { vezes por mês } \\
\text { (4)1 vez por semana } \\
\text { (5)2 a } 4 \text { vezes por semana } \\
\text { (6)1 vez por dia } \\
\text { (7) ou mais vezes por dia }\end{array}$ \\
\hline & $\begin{array}{l}\begin{array}{l}\text { Pizza Mussarela Perdigãoß } \\
\text { (1/2 fatia) }\end{array} \\
\text { (1) Nunca } \\
\text { (2) Menos de } 1 \text { vez por mês } \\
\text { (3)1 a } 3 \text { vezes por mês } \\
\text { (4) } 1 \text { vez por semana } \\
\text { (5) } 2 \text { a } 4 \text { vezes por semana } \\
\text { (6) } 1 \text { vez por dia } \\
\text { (7) } 2 \text { ou mais vezes por dia }\end{array}$ & $\begin{array}{l}\text { Sanduíche (Misto, } \\
\text { Hambúrguer, Simples) } \\
\text { (1/2 unidade) }\end{array}$ & \\
\hline
\end{tabular}


Bebidas

\begin{tabular}{|c|c|c|c|}
\hline $\begin{array}{l}\text { Café com Açúcar } \\
\text { ((1 xícara de Café) } \\
\text { (1) Nunca } \\
\text { (2) Menos de } 1 \text { vez por mês } \\
\text { (3) } 1 \text { a } 3 \text { vezes por mês } \\
\text { (4) } 1 \text { vez por semana } \\
\text { (5) } 2 \text { a } 4 \text { vezes por semana } \\
\text { (6) } 1 \text { vez por dia } \\
\text { (7) } 2 \text { ou mais vezes por dia }\end{array}$ & $\begin{array}{l}\text { Refrigerante Coca-Cola }{ }^{\circledR} \\
\text { (1/2 copo) } \\
\text { (1) Nunca } \\
\text { (2)Menos de } 1 \text { vez por mês } \\
\text { (3)1 a } 3 \text { vezes por mês } \\
\text { (4) } 1 \text { vez por semana } \\
\text { (5) a } 4 \text { vezes por semana } \\
\text { (6) } 1 \text { vez por dia } \\
\text { (7)2 ou mais vezes por dia }\end{array}$ & 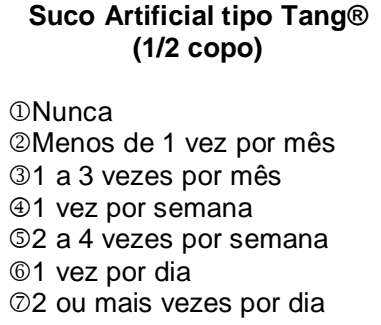 & $\begin{array}{l}\text { Chá Industrializado } \\
\text { (1/2 copo) }\end{array}$ \\
\hline & $\begin{array}{l}\text { Água } \\
\qquad(\mathbf{1 / 2} \text { copo) }\end{array}$ & $\begin{array}{l}\begin{array}{l}\text { Chá Preto (Apichá) } \\
\text { (1/2 copo) }\end{array} \\
\text { (1) Nunca } \\
\text { (2) Menos de } 1 \text { vez por mês } \\
\text { (3)1 a } 3 \text { vezes por mês } \\
\text { (4)1 vez por semana } \\
\text { (5) } 2 \text { a } 4 \text { vezes por semana } \\
\text { (6)1 vez por dia } \\
\text { (7)2 ou mais vezes por dia }\end{array}$ & \\
\hline
\end{tabular}

\section{Outros}

\begin{tabular}{|c|c|c|c|}
\hline $\begin{array}{l}\text { Leite em Pó à base de soja } \\
\text { diluído com água de } \\
\text { abastecimento público } \\
\text { (1 xícara) } \\
\text { (1) Nunca } \\
\text { (2) Menos de } 1 \text { vez por mês } \\
\text { (3)1 a } 3 \text { vezes por mês } \\
\text { (4)1 vez por semana } \\
\text { (5) 2 a } 4 \text { vezes por semana } \\
\text { (6) 1 vez por dia } \\
\text { (7) } 2 \text { ou mais vezes por dia }\end{array}$ & $\begin{array}{l}\text { Leite em Pó à base de soja } \\
\text { diluído com água mineral } \\
\text { (1 xícara) } \\
\text { (1) Nunca } \\
\text { (2) Menos de } 1 \text { vez por mês } \\
\text { (3)1 a } 3 \text { vezes por mês } \\
\text { (4)1 vez por semana } \\
\text { (5) 2 a } 4 \text { vezes por semana } \\
\text { (6)1 vez por dia } \\
\text { (7) } 2 \text { ou mais vezes por dia }\end{array}$ & $\begin{array}{l}\text { Achocolatado Toddynho® } \\
\text { (1 unidade) }\end{array}$ & $\begin{array}{l}\text { Bebida Isotônica Gatorade }{ }^{\circledR} \\
\text { (1/2 garrafa) } \\
\text { (1)Nunca } \\
\text { (2) Menos de } 1 \text { vez por mês } \\
\text { (3)1 a } 3 \text { vezes por mês } \\
\text { (4)1 vez por semana } \\
\text { (5)2 a } 4 \text { vezes por semana } \\
\text { (6)1 vez por dia } \\
\text { (7) } 2 \text { ou mais vezes por dia }\end{array}$ \\
\hline $\begin{array}{l}\text { (1) Nunca } \\
\text { (2) Menos de } 1 \text { vez por mês } \\
\text { (3) } 1 \text { a } 3 \text { vezes por mês } \\
\text { (4) } 1 \text { vez por semana } \\
\text { (5) } 2 \text { a } 4 \text { vezes por semana } \\
\text { (6) } 1 \text { vez por dia } \\
\text { (7) } 2 \text { ou mais vezes por dia }\end{array}$ & $\begin{array}{l}\text { Biscoito Danyt's } \\
\text { (3 unidades) } \\
\text { (1) Nunca } \\
\text { (2)Menos de 1 vez por mês } \\
\text { (3)1 a } 3 \text { vezes por mês } \\
\text { (4)1 vez por semana } \\
\text { (5)2 a } 4 \text { vezes por semana } \\
\text { (6)1 vez por dia } \\
\text { (7)2 ou mais vezes por dia }\end{array}$ & $\begin{array}{l}\text { CHOCOLATE EM } \\
\text { BARRA } \\
\text { (1/2 barra pequena) } \\
\text { (1) Nunca } \\
\text { (2) Menos de } 1 \text { vez por mês } \\
\text { (3)1 a } 3 \text { vezes por mês } \\
\text { (4)1 vez por semana } \\
\text { (5)2 a } 4 \text { vezes por semana } \\
\text { (6)1 vez por dia } \\
\text { (7)2 ou mais vezes por dia }\end{array}$ & $\begin{array}{l}\text { (1) Nunca } \\
\text { (2) Menos de } 1 \text { vez por mês } \\
\text { (3) } 1 \text { a } 3 \text { vezes por mês } \\
\text { (4) } 1 \text { vez por semana } \\
\text { (5) } 2 \text { a } 4 \text { vezes por semana } \\
\text { (6) } 1 \text { vez por dia } \\
\text { (7) } 2 \text { ou mais vezes por dia }\end{array}$ \\
\hline
\end{tabular}


Questionário de ingestão de dentifrício

$N^{\circ}$ de identificação:

Data:

Dados de ingestão de dentifrício:

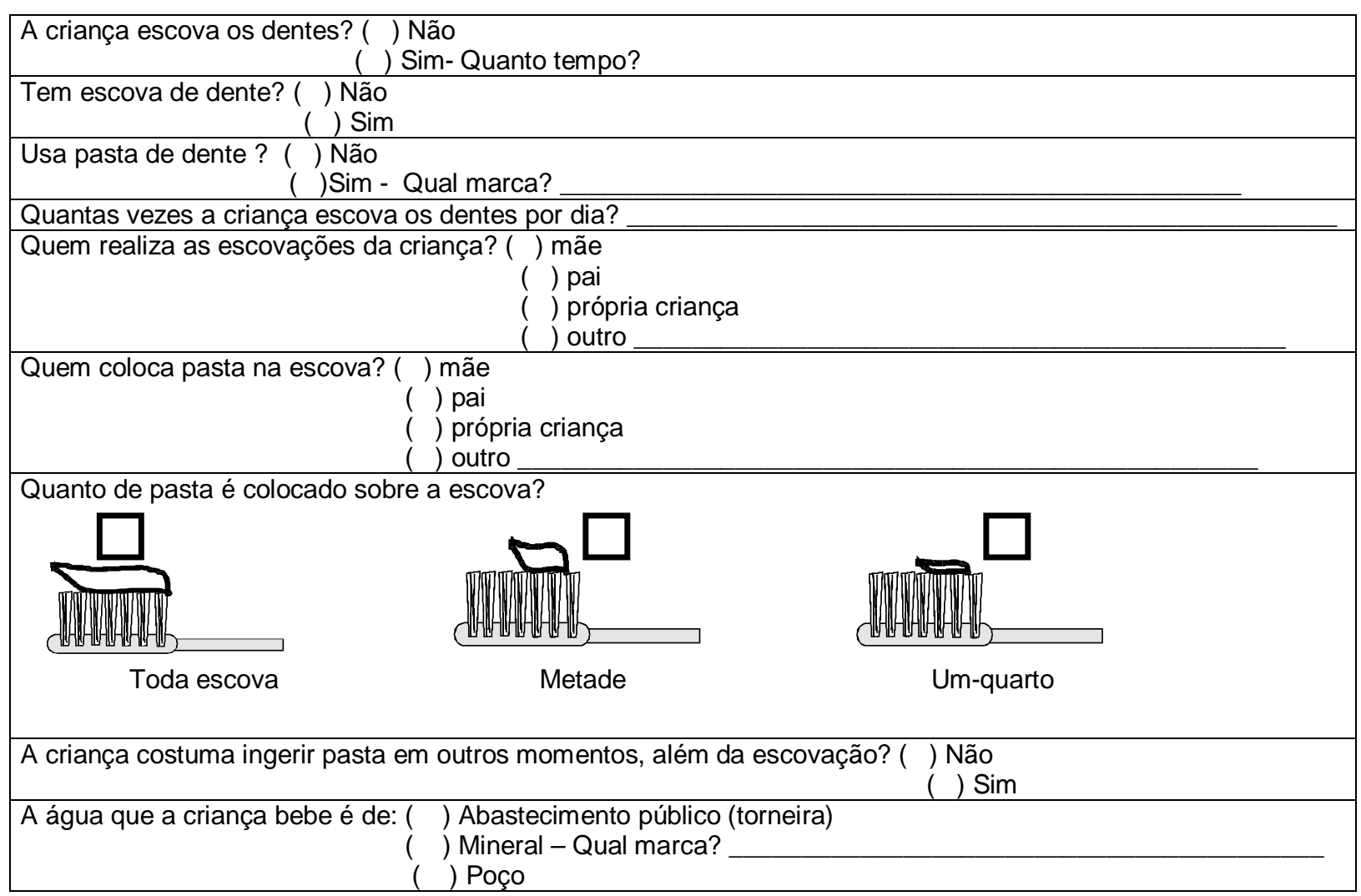


ANEXO 5

Itens alimentares, porções do QFAsq e peso médio (g)

\begin{tabular}{|c|c|c|c|}
\hline $\mathbf{n}$ & Alimento & Medida Caseira & $\begin{array}{c}\text { Peso médio } \\
\text { (g) }\end{array}$ \\
\hline 1 & arroz cozido & 3 colheres de sopa & 82,0 \\
\hline 2 & batata cozida & 1 colher de servir & 51,0 \\
\hline 3 & batata frita & 1 escumadeira & 103,0 \\
\hline 4 & biscoito sem recheio Tucs $\AA$ & 3 ou 4 unidades & 19,5 \\
\hline 5 & biscoito com recheio & 3 unidades & 39,0 \\
\hline 6 & cereal Snowflakes® & 1 xícara & 39,0 \\
\hline 7 & macarrão cozido & 1 escumadeira & 72,0 \\
\hline 8 & macarrão Miojo® & $1 / 3$ do pacote & 25,0 \\
\hline 9 & pão francês & $1 / 2$ unidade & 25,0 \\
\hline 10 & espessantes & 1 ou 2 colheres de sopa & 19,0 \\
\hline 11 & feijão & $1 / 2$ concha & 52,0 \\
\hline 12 & abóbora & 2 colheres de sopa & 70,0 \\
\hline 13 & alface & 2 folhas & 15,5 \\
\hline 14 & repolho & 1 colher de sopa & 15,5 \\
\hline 15 & tomate & 3 fatias & 50,0 \\
\hline 16 & molho de tomate & 1 colher de sopa & 19,0 \\
\hline 17 & cenoura & $1 / 2$ colher de servir & 15,0 \\
\hline 18 & chuchu & 1 colher de sopa & 23,0 \\
\hline 19 & mandioquinha & $1 / 2$ colher de sopa & 18,0 \\
\hline 20 & banana & 1 unidade & 86,0 \\
\hline 21 & maçã/pêra & 1 unidade & 93,0 \\
\hline 22 & laranja & 1 unidade & 128,0 \\
\hline 23 & suco de laranja & $1 / 2$ copo & 128,0 \\
\hline 24 & suco de outras frutas (maracujá, abacaxi) & $1 / 2$ copo & 116,0 \\
\hline 25 & mamão & 1 fatia & 90,0 \\
\hline 26 & goiaba & $1 / 2$ unidade & 51,0 \\
\hline 27 & bife & 1 unidade & 76,0 \\
\hline 28 & carne cozida & $1 / 2$ fatia, 3 colheres de sopa & 54,0 \\
\hline 29 & lingüiça Perdigão® & $1 / 2$ gomo, 1 unidade & 31,0 \\
\hline 30 & presunto Sadia® & 1 fatia & 31,0 \\
\hline 31 & fígado & 1 unidade & 100,0 \\
\hline 32 & frango & 1 pedaço, 1 unidade & 62,0 \\
\hline 33 & peixe & $1 / 2$ filé, $1 / 2$ pedaço & 56,0 \\
\hline 34 & ovo & 1 unidade & 41,0 \\
\hline 35 & leite & 1 xícara & 184,0 \\
\hline 36 & leite pó integral diluído com AAP & 1 xícara & 184,0 \\
\hline 37 & leite pó integral diluído com AM & 1 xícara & 184,0 \\
\hline 38 & iogurte de frutas & 1 pote & 138,0 \\
\hline 39 & iogurte Danoninho®/Chambinho $\AA$ & 1 pote & 51,0 \\
\hline 40 & leite fermentado Yakult@ & 1 pote & 96,0 \\
\hline 41 & margarina/manteiga & 1 colher de chá & 7,0 \\
\hline 42 & queijo mussarela Tirolez $\AA$ & 1 fatia & 14,0 \\
\hline 43 & requeijão & 1 colher de sobremesa & 19,0 \\
\hline 44 & açúcar & $11 / 2$ colher de sobremesa & 21,0 \\
\hline 45 & achocolatado pó Nescauß, Toddy® & $11 / 2$ colher de sobremesa & 13,0 \\
\hline 46 & bolo Dona Benta® & 1 fatia & 83,0 \\
\hline 47 & bombom & 1 unidade & 29,0 \\
\hline 48 & salgadinho Chips® & 1 pacote pequeno & 55,0 \\
\hline 49 & polenta & 1 colher de servir, 1 fatia & 84,0 \\
\hline 50 & sopa com carne & $1 / 2$ prato & $120,0^{*}$ \\
\hline 51 & sopa sem carne & $1 / 2$ prato & 95,0 \\
\hline 52 & pão de queijo & 1 unidade pequena & 58,0 \\
\hline 53 & pizza mussarela Perdigão® & $1 / 2$ fatia & 54,0 \\
\hline 54 & sanduíche & $1 / 2$ unidade & 101,0 \\
\hline 55 & café com açúcar & 1 xícara de café & 40,0 \\
\hline 56 & refrigerante Coca-Cola $\AA$ & $1 / 2$ copo & 170,0 \\
\hline 57 & suco artificial tipo Tang® & $1 / 2$ copo & 164,0 \\
\hline 58 & chá industrializado & $1 / 2$ copo & 221,0 \\
\hline 59 & água abastecimento público & $1 / 2$ copo & 150,0 \\
\hline 60 & água mineral & $1 / 2$ copo & 150,0 \\
\hline 61 & água poço & $1 / 2$ copo & 150,0 \\
\hline 62 & chá preto & $1 / 2$ copo & 221,0 \\
\hline
\end{tabular}




\begin{tabular}{|l|l|l|l|}
\hline 63 & leite pó soja diluído com AAP & 1 xícara & 184,0 \\
\hline 64 & leite pó soja diluído com AM & 1 xícara & 184,0 \\
\hline 65 & achocolatado Toddynho $\AA$ & 1 unidade & 200,0 \\
\hline 66 & bebida isotônica Gatorade $\AA$ & $1 / 2$ garrafa & 237,0 \\
\hline 67 & cereal Neston $\AA$ & 6 colheres de sopa & 42,0 \\
\hline 68 & biscoito Danyt's $\AA$ & 3 unidades & 39,0 \\
\hline & & & \\
\hline
\end{tabular}


ANEXO 6

Divisão dos itens alimentares em alimentos sólidos, água e outros líquidos

\begin{tabular}{|c|c|c|}
\hline Sólidos ( $n=52)$ & Água $(n=3)$ & Outros líquidos $(n=15)$ \\
\hline abóbora & água abastecimento público & achocolatado Toddynho® \\
\hline achocolatado pó Nescau®, Toddy® & água mineral & bebida isotônica Gatorade® \\
\hline açúcar & água poço & café com açúcar \\
\hline alface & & chá industrializado \\
\hline arroz cozido & & chá preto \\
\hline banana & & leite \\
\hline batata cozida & & leite fermentado Yakult@ \\
\hline batata frita & & leite pó integral diluído com AAP \\
\hline bife & & leite pó integral diluído com AM \\
\hline biscoito com recheio & & leite pó soja diluído com AAP \\
\hline biscoito Danyt's® & & leite pó soja diluído com AM \\
\hline biscoito sem recheio Tucs $\AA$ & & refrigerante Coca-Cola ${ }^{\circledR}$ \\
\hline bolo Dona Benta® & & suco artificial tang® \\
\hline bombom & & suco de laranja \\
\hline carne cozida & & suco de outras frutas \\
\hline \multicolumn{3}{|l|}{ cenoura } \\
\hline \multicolumn{3}{|l|}{ cereal Neston® } \\
\hline \multicolumn{3}{|l|}{ cereal nowflakes® } \\
\hline \multicolumn{3}{|l|}{ chocolate em barra } \\
\hline \multicolumn{3}{|l|}{ chocolate $\mathrm{M} \& \mathrm{Ms} \AA$} \\
\hline \multicolumn{3}{|l|}{ chuchu } \\
\hline \multicolumn{3}{|l|}{ espessantes } \\
\hline \multicolumn{3}{|l|}{ feijão } \\
\hline \multicolumn{3}{|l|}{ fígado } \\
\hline \multicolumn{3}{|l|}{ frango } \\
\hline \multicolumn{3}{|l|}{ goiaba } \\
\hline \multirow{2}{*}{\multicolumn{3}{|c|}{$\begin{array}{l}\text { iogurte Danoninho®, Chambinho® } \\
\text { iogurte de frutas }\end{array}$}} \\
\hline & & \\
\hline \multicolumn{3}{|l|}{ Iaranja } \\
\hline \multicolumn{3}{|l|}{ lingüiça } \\
\hline \multicolumn{3}{|l|}{ maçã/pêra } \\
\hline \multicolumn{3}{|l|}{ macarrão cozido } \\
\hline \multicolumn{3}{|l|}{ macarrão Miojo® } \\
\hline \multicolumn{3}{|l|}{ mamão } \\
\hline \multicolumn{3}{|l|}{ mandioquinha } \\
\hline \multicolumn{3}{|l|}{ margarina/manteiga } \\
\hline \multicolumn{3}{|l|}{ molho de tomate } \\
\hline ovo & & \\
\hline pão de queijo & & \\
\hline pão francês & & \\
\hline peixe & & \\
\hline pizza mussarela Perdigão® & & \\
\hline polenta & & \\
\hline presunto & & \\
\hline queijo mussarela Tirolez® & & \\
\hline repolho & & \\
\hline requeijão & & \\
\hline salgadinho Chips® & & \\
\hline sanduíche & & \\
\hline sopa com carne & & \\
\hline sopa sem carne & & \\
\hline tomate & & \\
\hline
\end{tabular}




\section{Instruções para a coleta da dieta}

\section{Instruções aos pais}

- O método utilizado será o da dieta duplicada (Guha-Chowdhurry et al. 1996).

- A coleta da dieta será realizada durante dois dias consecutivos (dias 1 e 2 , ver figura).

- Serão oferecidos aos voluntários 3 potes (1L) para cada dia, que deverão ser devidamente etiquetados com: nome do voluntário, tipo de amostra: dieta sólida, água e outros líquidos (sucos, chás, refrigerantes, leite etc... ), data da coleta e local da coleta (Bauru, Pirajuí).

Lembre-se: as dietas não deverão ser misturadas, ou seja, para cada dia teremos um pote para coleta dos alimentos sólidos, um para a água e um terceiro para outros líquidos, caso seja necessário, poderemos oferecer mais potes.

- Os responsáveis pelos voluntários receberão instruções sobre a coleta por escrito. No entanto, é muito importante que façamos as orientações de forma falada para que haja um maior esclarecimento e seja possível tirar dúvidas.

- Como as crianças estarão freqüentando a escola, não nos esqueçamos que teremos que coletar amostras dos alimentos e bebidas que elas consumirem na escola. Para isso, será melhor esta coleta ser feita por uma pessoa devidamente orientada na escola também.

- Este método é realizado por observação visual. A quantidade de alimento e bebidas consumidos deverão ser estimados usando medidas caseiras (colher de chá, colher de sopa, xícara de chá, mamadeira etc...).

- Nas refeições, os pais deverão ser orientados a servirem dois pratos separados (um que para o que a criança vai comer e o outro para a coleta). Quando a criança terminar, o equivalente ao que ela comeu deverá ser retirado do prato e colocado no pote. Caso a criança repita o prato ou algum alimento, o mesmo deve ser feito.

- Os pais deverão ser orientados para conservar os potes em geladeira (se houver), e entregar na escola no dia seguinte da coleta. Se a criança não freqüenta a escola, o pesquisador deverá recolher os potes na casa da criança no dia seguinte à coleta, pela manhã.

- As amostras de dieta sólida deverão ser homogeneizadas pelo pesquisador. Colocar a amostra num liquidificador juntamente com um volume conhecido $(25 \mathrm{ml}, 50 \mathrm{ml}, 75 \mathrm{ml}, 100 \mathrm{ml})$ de água deionizada, a fim de obtermos uma mistura homogênea. Deverá ficar na consistência de mingau. Anotar o volume usado de água deionizada na ficha número Se não for possível homogeneizar no mesmo dia, as amostras deverão ser congeladas para posterior homogeinização. 
- Zerar a balança com o pote vazio. Transferir a amostra homogeneizada do liquidificador para o pote, tendo o cuidado de não deixar nada no liquidificador. Pesar as amostras sólidas homogeneizadas em gramas e com 2 casas após a vírgula. Anotar o peso nas fichas número $1 a$ (coleta do $1^{\circ}$ dia) e $1 b$ (coleta do $2^{\circ}$ dia).

- As amostras de água e outros líquidos deverão ser medidas pelo volume. Para isso, deveremos utilizar uma proveta graduada de vidro e anotar o volume (em $\mathrm{mL}$ ) nas fichas número 1a (coleta do 1익 e 1b (coleta do 20 dia). A proveta deverá ser lavada com água de torneira e por último com água deionizada, antes de se medir o volume da próxima amostra. Obs. Cada risco da proveta equivale a $5 \mathrm{~mL}$.

- Armazenar uma alíquota de $\pm 15 \mathrm{~mL}$ nos tubos de ensaio apropriados e congelar imediatamente, para que elas possam ser enviadas para a análise de flúor. Lembre-se: não nos esqueçamos de etiquetar estes potes com: nome do voluntário, tipo de amostra e data da coleta. Assim, teremos três tubos de alíquotas de $15 \mathrm{~mL}$, um para dieta sólida, outro para água e um terceiro para outros líquidos, para cada dia de coleta. No total, portanto, haverá 6 tubos para cada criança.

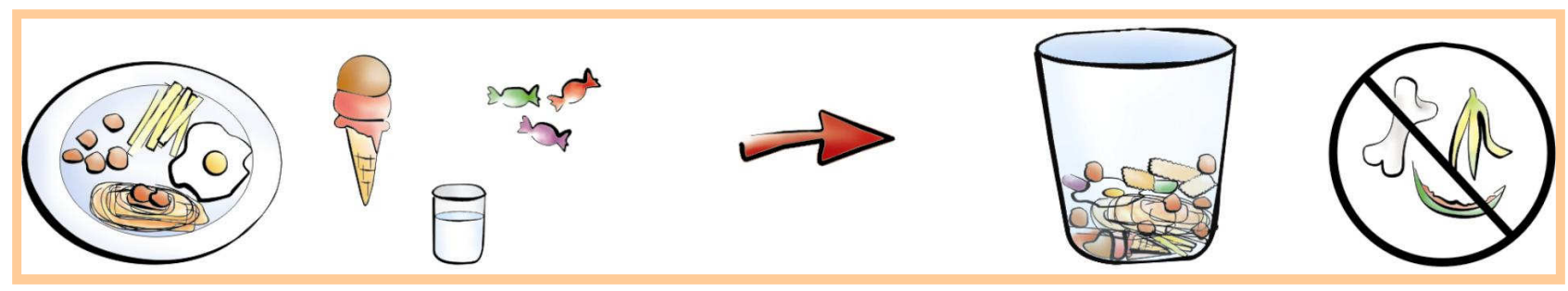


Ficha número 1a: Anotar o peso $(\mathrm{g})$ da dieta sólida depois de homogeneizada e o volume $(\mathrm{mL})$ da água e de outros líquidos do primeiro dia de coleta.

\begin{tabular}{|c|c|c|c|c|}
\hline \multirow[t]{2}{*}{ Criança } & \multicolumn{2}{|c|}{$\begin{array}{c}\text { Peso dieta sólida }(\mathrm{g}) \mathrm{e} \\
\text { volume de água usado } \\
\text { na homogeinização }\end{array}$} & \multirow[t]{2}{*}{$\begin{array}{l}\text { Volume } \\
\text { água } \\
(\mathrm{mL})\end{array}$} & \multirow{2}{*}{$\begin{array}{l}\text { Volume } \\
\text { outros } \\
\text { líquidos } \\
\text { (mL) }\end{array}$} \\
\hline & $\begin{array}{l}\text { Peso }(\mathrm{g}) \\
(\mathrm{mL})\end{array}$ & água & & \\
\hline \multicolumn{5}{|l|}{ 1) } \\
\hline \multicolumn{5}{|l|}{ 2) } \\
\hline \multicolumn{5}{|l|}{ 3) } \\
\hline \multicolumn{5}{|l|}{ 4) } \\
\hline \multicolumn{5}{|l|}{ 5) } \\
\hline \multicolumn{5}{|l|}{ 6) } \\
\hline \multicolumn{5}{|l|}{ 7) } \\
\hline \multicolumn{5}{|l|}{ 8) } \\
\hline \multicolumn{5}{|l|}{ 9) } \\
\hline \multicolumn{5}{|l|}{ 10) } \\
\hline \multicolumn{5}{|l|}{ 11) } \\
\hline \multicolumn{5}{|l|}{ 12) } \\
\hline \multicolumn{5}{|l|}{ 13) } \\
\hline \multicolumn{5}{|l|}{ 14) } \\
\hline \multicolumn{5}{|l|}{ 15) } \\
\hline \multicolumn{5}{|l|}{ 16) } \\
\hline \multicolumn{5}{|l|}{ 17) } \\
\hline \multicolumn{5}{|l|}{ 18) } \\
\hline \multicolumn{5}{|l|}{ 19) } \\
\hline \multicolumn{5}{|l|}{ 20) } \\
\hline \multicolumn{5}{|l|}{ 21) } \\
\hline \multicolumn{5}{|l|}{ 22) } \\
\hline \multicolumn{5}{|l|}{ 23) } \\
\hline \multicolumn{5}{|l|}{ 24) } \\
\hline 25) & & & & \\
\hline
\end{tabular}


Ficha número 1b: Anotar o peso $(\mathrm{g})$ da dieta sólida depois de homogeneizada e o volume $(\mathrm{mL})$ da água e de outros líquidos do segundo dia de coleta.

\begin{tabular}{|c|c|c|c|c|}
\hline \multirow[t]{2}{*}{ Criança } & \multicolumn{2}{|c|}{$\begin{array}{l}\text { Peso dieta sólida }(\mathrm{g}) \text { e } \\
\text { volume de água usado } \\
\text { na homogeinização }\end{array}$} & \multirow[t]{2}{*}{$\begin{array}{l}\text { Volume } \\
\text { água } \\
(\mathrm{mL})\end{array}$} & \multirow{2}{*}{$\begin{array}{l}\text { Volume } \\
\text { outros } \\
\text { líquidos } \\
(\mathrm{mL})\end{array}$} \\
\hline & $\begin{array}{l}\text { Peso }(\mathrm{g}) \\
(\mathrm{mL})\end{array}$ & água & & \\
\hline \multicolumn{5}{|l|}{ 1) } \\
\hline \multicolumn{5}{|l|}{ 2) } \\
\hline \multicolumn{5}{|l|}{ 3) } \\
\hline \multicolumn{5}{|l|}{ 4) } \\
\hline \multicolumn{5}{|l|}{ 5) } \\
\hline \multicolumn{5}{|l|}{ 6) } \\
\hline \multicolumn{5}{|l|}{ 7) } \\
\hline \multicolumn{5}{|l|}{ 8) } \\
\hline \multicolumn{5}{|l|}{ 9) } \\
\hline \multicolumn{5}{|l|}{ 10) } \\
\hline \multicolumn{5}{|l|}{ 11) } \\
\hline \multicolumn{5}{|l|}{ 12) } \\
\hline \multicolumn{5}{|l|}{ 13) } \\
\hline \multicolumn{5}{|l|}{ 14) } \\
\hline \multicolumn{5}{|l|}{ 15) } \\
\hline \multicolumn{5}{|l|}{ 16) } \\
\hline \multicolumn{5}{|l|}{ 17) } \\
\hline \multicolumn{5}{|l|}{ 18) } \\
\hline \multicolumn{5}{|l|}{ 19) } \\
\hline \multicolumn{5}{|l|}{ 20) } \\
\hline \multicolumn{5}{|l|}{ 21) } \\
\hline \multicolumn{5}{|l|}{ 22) } \\
\hline \multicolumn{5}{|l|}{ 23) } \\
\hline \multicolumn{5}{|l|}{ 24) } \\
\hline 25) & & & & \\
\hline
\end{tabular}


Instruções aos pais

Instruções para coleta da água da torneira (casa e escola)

- Deveremos coletar amostra da água da torneira, tanto da casa das crianças quanto da escola, durante os dois dias de coleta.

- Para esta coleta serão enviados tubos apropriados. Para cada criança serão fornecidos dois tubos para coletar a água nos dois dias de coleta (dias 1 e 2, ver figura) e o pesquisador coletará a água da torneira da escola também nos dois dias. Para coletar a água da torneira, deixar escorrer por $1 \mathrm{~min}$, lavar o tubo com a água e então fazer a coleta de aproximadamente $15 \mathrm{~mL}$.

- Identificar corretamente os tubos e armazená-los em freezer (congelar) até serem analizados. 


\section{ANEXO 9 \\ Instruções aos pais}

\section{Instruções para realização da estimativa de ingestão de flúor pelo dentifrício}

- Será realizada conforme Guha-Chowdhurry et al (1996) no primeiro e segundo dias do experimento, juntamente com a coleta da dieta. Se a criança escova os dentes em casa e também na escola teremos que fazer duas simulações em cada dia, uma na presença da pessoa que escova os dentes da criança em casa, e outra simulando a escovação que é feita na escola. No dia da coleta, a criança não deverá escovar os dentes em casa pela manhã, pois esta escovação será feita na escola, na presença dos pesquisadores. A escovação da escola, se for o caso, será feita na presença do pesquisador.

- Será realizado um questionário (ficha do voluntário) com os pais das crianças antes de iniciarmos o experimento.

- O questionário (será enviado junto com o material da pesquisa na quantidade necessária) nos fornecerá informações sobre os hábitos de escovação da criança necessárias para esta etapa, como freqüência de escovação e tipo de dentifrício utilizado.

- Para realizar a simulação da escovação, os pais deverão ser avisados anteriormente que neste dia eles deverão levar para a escola a pasta e a escova de dente que a criança usa em casa.

- No dia da simulação quem coloca a pasta na escova da criança em casa deverá comparecer à escola e levar a pasta de dentes que a criança usa em casa e os pesquisadores devem armazenar em um pote devidamente rotulado com o nome da criança uma quantidade pequena de pasta (em torno de $2 \mathrm{~g}$, ou seja, equivalente a encher 2 vezes a escova no sentido longitudinal). Se for necessário fazer a simulação na escola, quem auxilia a criança na escovação deverá participar desta fase do experimento. Se a 
criança escova os dentes sozinha, a estimativa deve ser feita com ela própria colocando a pasta na escova. Lembre-se: o importante é que a escovação seja feita exatamente como é feita rotineiramente.

- O pote $(500 \mathrm{~mL}$ ) que utilizaremos nesta etapa deverá ser pesado (em gramas, com 2 casas decimais) antes de iniciarmos a simulação e seu peso deverá ser anotado na ficha número $3^{\mathrm{a}}$ - primeiro dia ou na ficha $3 \mathbf{b}$ para 0 segundo dia (pesar sem a tampa e já com a etiqueta).

- Antes de pesar a escova esta deverá ser lavada com água deionizada. Colocar cerca de $30 \mathrm{~mL}$ de água deionizada num copinho plástico e limpar a escova, fazendo movimentos circulares. Remover o excesso de água deionizada da escova.

- Em seguida, pesar na balança eletrônica. Pesar em gramas com 2 casas decimais. Não esquecer de anotar este valor na ficha número 3a para o primeiro dia e a ficha $3 b$ para o segundo dia.

- Colocar o dentifrício na escova (dentifrício que a mãe levou, ou seja, a pasta que a criança usa em casa). Lembre-se: como é uma simulação tudo deverá transcorrer da maneira que a criança está acostumada, por exemplo, se em casa a mãe coloca a pasta na escova, nesta simulação a mãe deverá colocar a pasta. Se a própria criança coloca a pasta ela mesma que terá que colocar.

- Pesar agora a escova com a pasta (em gramas com duas casas decimais). Anotar o valor na ficha número 3a para o primeiro dia e a ficha $3 \mathrm{~b}$ para 0 segundo dia.

- A criança iniciará a escovação.

- Toda a saliva que a criança expectorar deverá ser coletada no pote de $500 \mathrm{~g}$ devidamente etiquetado com o nome da criança, data da coleta, tipo de amostra e cidade em que foi coletada a amostra. Se a criança enxaguar a 
boca este enxágüe deverá ser realizado com água deionizada e também expectorado no pote.

- A escova será lavada com $50 \mathrm{~mL}$ de água deionizada que será armazenado no mesmo pote que a criança expectorou a saliva.

- Para lavar a escova deveremos utilizar um copo plástico descartável com \pm $30 \mathrm{~mL}$ da água deionizada, assim iremos lavar a escova realizando movimentos circulares (veja figura abaixo). Despejar esta água no pote que a criança expectorou a pasta e com os $20 \mathrm{~mL}$ restantes lavar o copo plástico e também despejar no pote. Lembre-se de dar algumas "batidas" com a escova o pote para que todo o excesso de água e pasta sejam removidos.

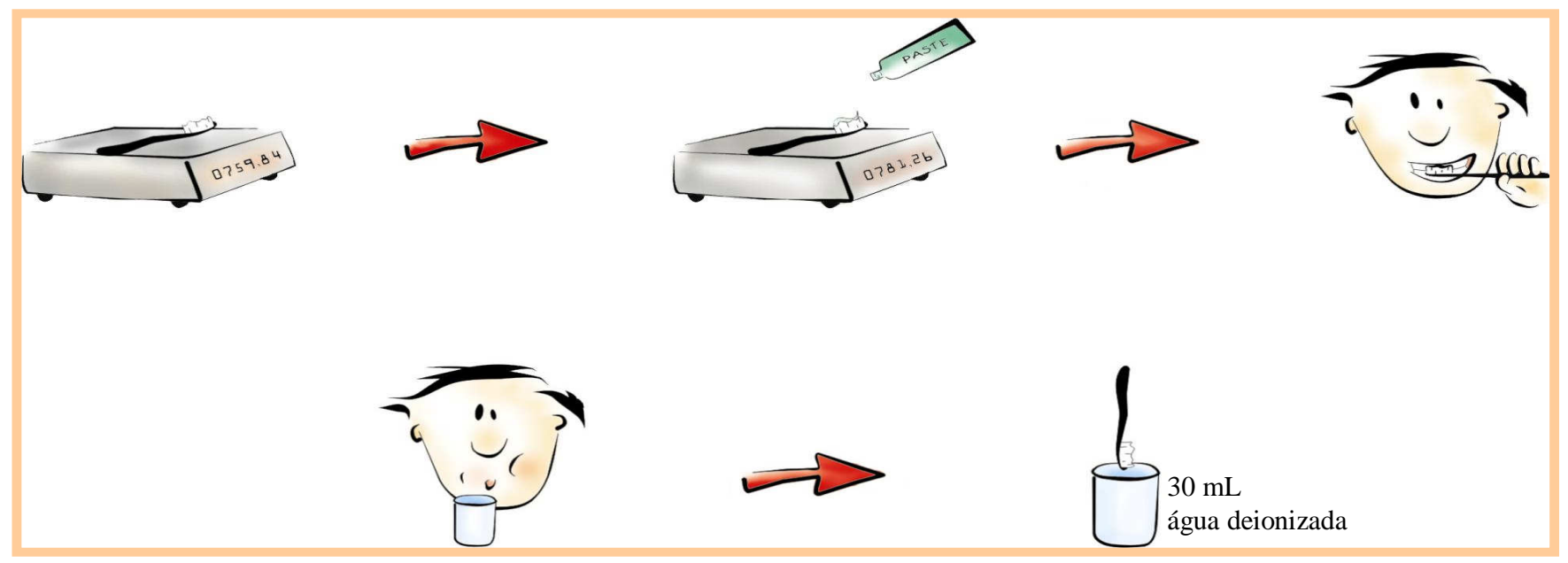

Despejar a água que a escova foi lavada no pote da criança, utilizar os $20 \mathrm{~mL}$ restantes para dar uma lavada no copo e despejar esta água no pote da criança. Lembre-se que os copos são descartáveis, então, cada criança deverá usar um e depois ser jogado fora

- Terminado o enxágüe, o pote deverá ser homogeneizado. Para isto, agitar manualmente o pote fechado por umas 10 vezes. Pesar (em g, 2 casas decimais) e anotar o valor na ficha número $3^{a}$ para o primeiro dia e $3 b$ para o segundo dia. 
- Coletar uma alíquota de $10 \mathrm{~mL}$ no tubo apropriado e congelar as amostras para serem enviadas para a análise.

- A ficha 3c só será utilizada se a criança tiver o hábito de realizar a escovação na escola. Caso contrário anule esta ficha. 